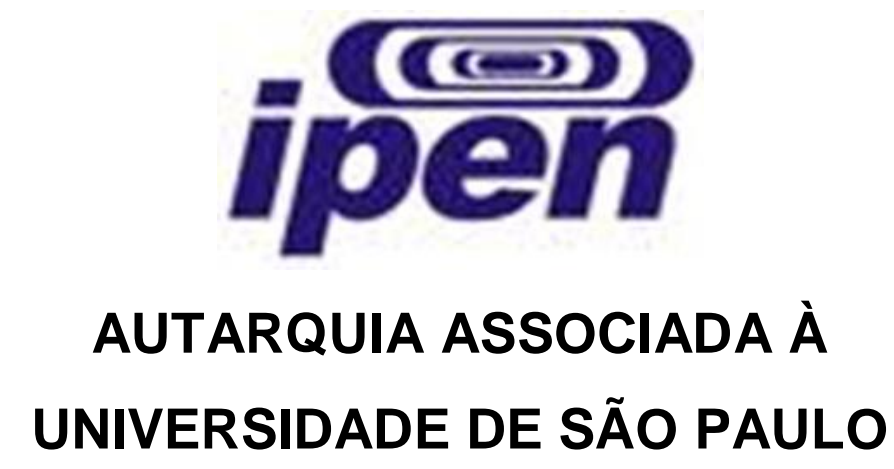

\title{
DESENVOLVIMENTO DE MÉTODOS RADIOMÉTRICOS PARA A CARACTERIZAÇÃO DE REJEITOS RADIOATIVOS
}

\section{ANA PAULA GIMENES TESSARO}

Dissertação apresentada como parte dos requisitos para obtenção do Grau de Mestre em Ciências na Área de Tecnologia Nuclear - Aplicações.

Orientador (a):

Dr. Roberto Vicente

\section{SÃO PAULO}

2015 
Dedico este trabalho a minha família, pelo apoio dado até aqui. Sei que posso contar com vocês. Saibam que a recíproca é verdadeira. 


\section{AGRADECIMENTOS}

Ao queridíssimo Orientador, Prof. Dr. Roberto Vicente. Este que me trouxe inúmeros aprendizados acadêmicos e para a vida. Muito obrigada por acreditar em mim, não poderia ter tido um Professor melhor.

Aos Professores do Instituto de Pesquisas Energéticas e Nucleares, com os quais tomei aulas durante a execução do trabalho e que me mostraram um mundo repleto de possibilidades.

Aos Professores que fizeram parte da minha graduação e que me mostraram que seria possível que eu seguisse em frente.

Como não falar dos amigos que conquistei para a vida tomando como ponto de partida esta etapa?! Para vocês espero que seja para sempre. É difícil encontrar pessoas tão boas assim, repentinamente. Que o sucesso venha para todos nós. Cheers! E que tenhamos muitas parcerias no futuro.

A equipe técnica do laboratório de Gerência de Rejeitos Radioativos que sempre está disposta a nos ajudar.

Aos meus pais e meu irmão: gratidão sempre. Vocês são os melhores.

Agradeço também ao Jefferson, que compartilha comigo os desejos e realizações, que me apoia para que eu continue seguindo rumo ao meu melhor.

Obrigada. 
"Nature is the most thrifty thing in the world: she never wastes anything; she undergoes change, but there is no annihilation, the essence remains--matter is eternal".

"A natureza é a coisa mais econômica no mundo: ela nunca desperdiça nada; ela sofre mudanças, mas não há aniquilação, a essência permanece - a matéria é eterna". 


\title{
RESUMO
}

\section{DESENVOLVIMENTO DE MÉTODOS RADIOMÉTRICOS PARA A CARACTERIZAÇÃO DE REJEITOS RADIOATIVOS}

\author{
Ana Paula Gimenes Tessaro
}

A aceitação de rejeitos radioativos em um repositório final depende, entre outras coisas, do conhecimento do inventário radioisotópico presente neles. Para obter essa informação, é necessário fazer a caracterização primária dos rejeitos de modo que a composição seja conhecida e oriente os passos seguintes da gestão. Os filtros cartucho que são utilizados no sistema de retratamento de água do reator de pesquisa IEA-R1 é um desses rejeitos. O IEA-R1 é um reator de pesquisa do tipo piscina, operando entre 2 e $5 \mathrm{MW}$, que utiliza a água como líquido de arrefecimento, moderador e blindagem biológica Além do seu uso em pesquisa, também é utilizado para produzir radioisótopos e irradiar amostras. Ele está localizado no Instituto de Pesquisas Energéticas e Nuclear, no campus da Universidade de São Paulo. Os filtros cartucho são utilizados para reter o material particulado em suspensão presente na água. Quando os filtros ficam saturados e são incapazes de manter o fluxo dentro dos limites estabelecidos, eles são substituídos e descartados como rejeito radioativo. Após um período de espera para o decaimento da atividade, são enviados para Gerência de Rejeitos Radioativos (GRR). O objetivo deste trabalho é apresentar os estudos realizados para determinar a atividade dos emissores gama presentes nos filtros cartucho. As atividades foram calculadas utilizando as taxas de dose medidas com detectores portáteis, as relações entre as taxas de emissão de fótons avaliadas por espectrometria gama, e o método de Point Kernel, que correlaciona a atividade de uma fonte com as taxas de dose a várias distâncias. $O$ método descrito pode ser utilizado para determinar de modo rotineiro o inventário radioisotópico destes filtros, dispensando análises radioquímicas destrutivas, e a necessidade de calibração da geometria de medição. 


\section{ABSTRACT \\ DEVELOPMENT OF RADIOMETRIC METHODS FOR RADIOACTIVE WASTE CHARACTERIZATION}

Ana Paula Gimenes Tessaro

The admission of radioactive waste in a final repository depends among other things on the knowledge of the radioisotopic inventory of the waste. To obtain this information it is necessary make the primary characterization of the waste so that it is composition is known, to guide the next steps of radioactive waste management. Filter cartridges that are used in the water polishing system of IEA-R1 research reactor is one of these wastes. The IEA-R1 is a pool-type research reactor, operating between 2 and $5 \mathrm{MW}$ that uses water as coolant, moderator and biological shield. Besides research, it is used for production of radioisotopes and irradiation of samples with neutron and gamma beams. It is located in the Nuclear and Energy Research Institute at the University of Sao Paulo campus. The filter cartridges are used to retain particles that are suspended in the cooling water. When filters become saturated and are unable to maintain the flow within the established limits, they are replaced and disposed of as radioactive waste. After a period of decay, they are sent to the Radioactive Waste Management Department. The aim of this work is to present the studies to determine the activity of gamma emitters present in the cartridge filters. The activities were calculated using the dose rates measured with handheld detectors, after the ratios of the emission rates of photons were evaluated by gamma spectrometry, by the Point Kernel method, which correlates the activity of a source with dose rates at various distances. The method described can be used to determine routinely the radioactive inventory of these filters, avoiding the necessity of destructive radiochemical analysis, or the necessity of calibrating the geometry of measurement. 


\section{SUMÁRIO}

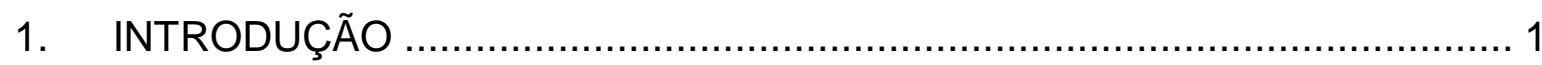

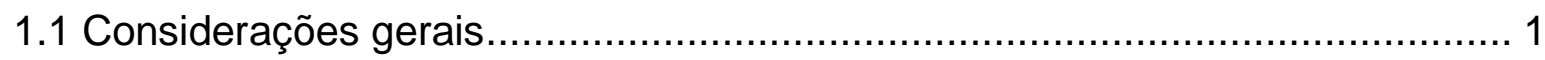

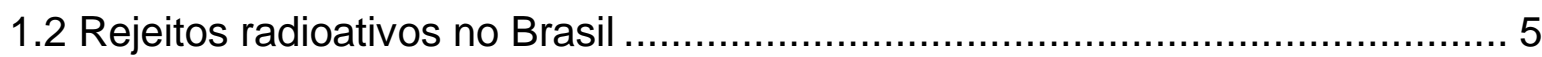

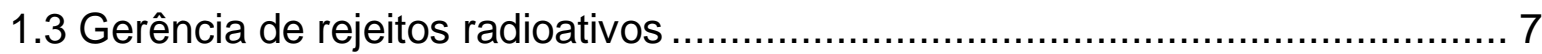

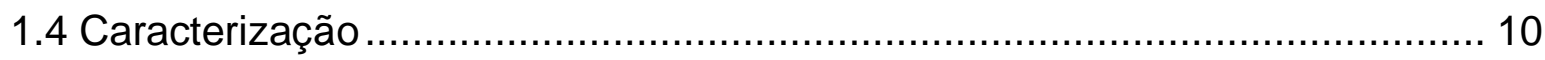

1.5 Métodos de Caracterização radioisotópica ............................................... 15

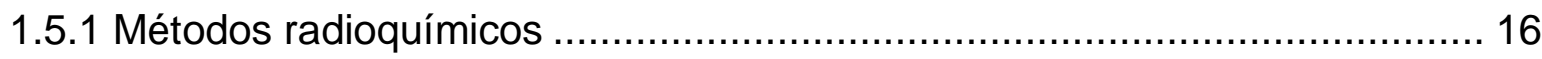

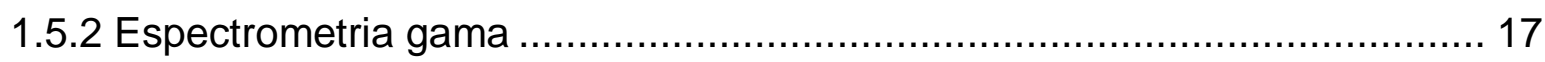

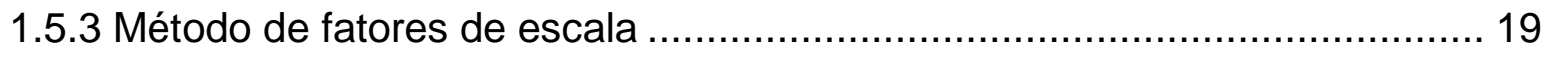

1.5.4 Caracterização por meio de medidas de taxa de dose ............................... 21

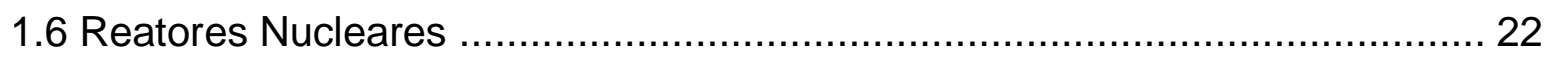

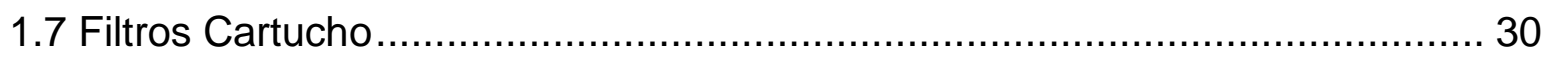

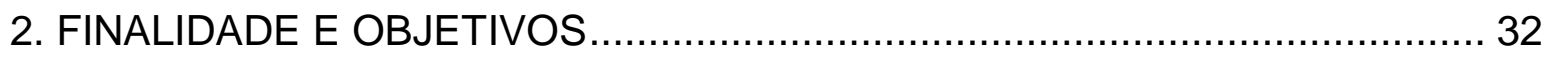

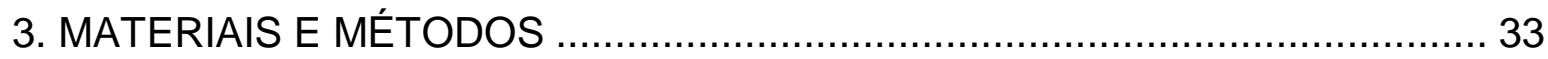

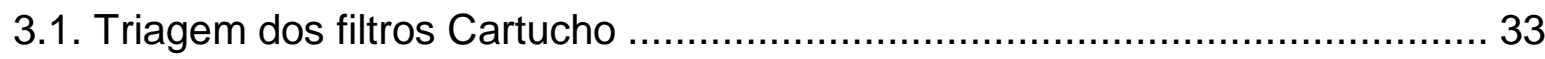

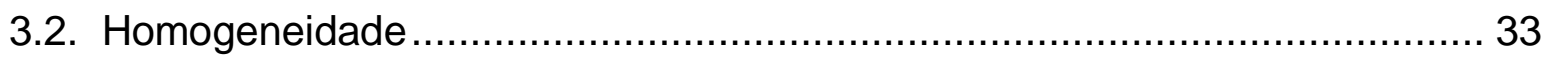

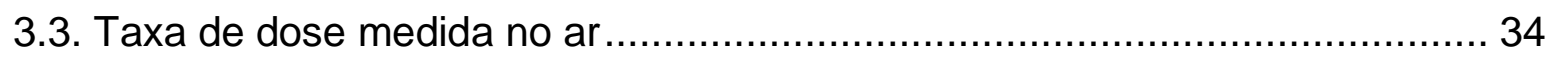

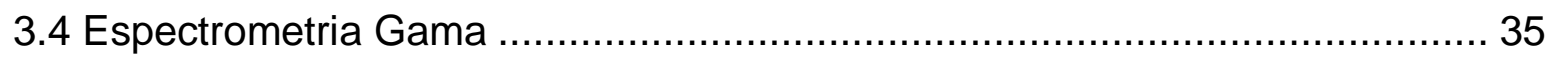

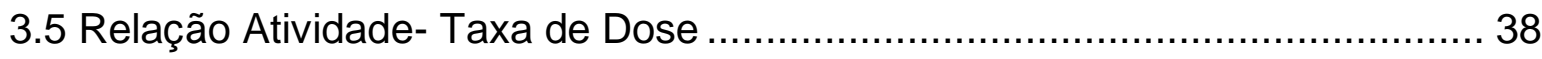

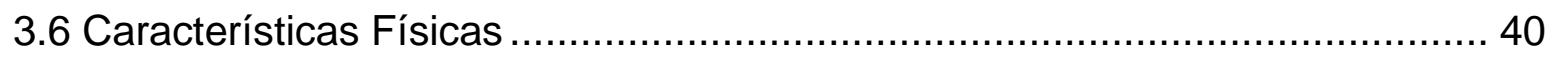

3.7 Taxas de dose calculadas com o MicroShield ${ }^{\circledR}$......................................... 41

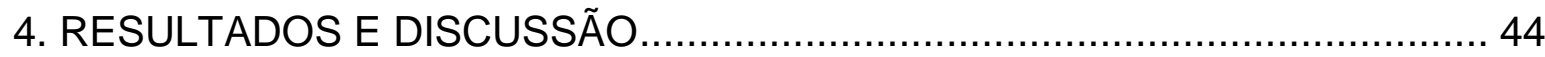

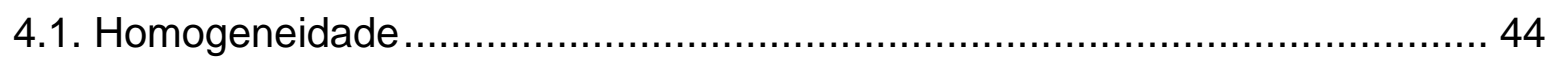

4.2. Radionuclídeos identificados nos filtros .................................................... 46

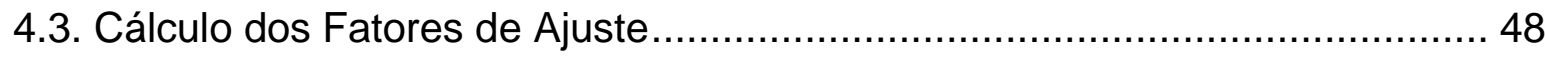

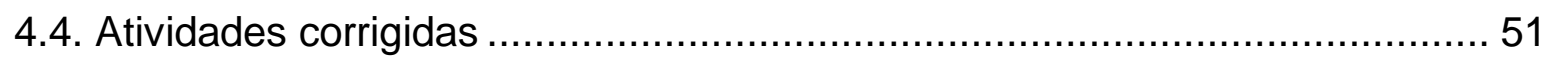

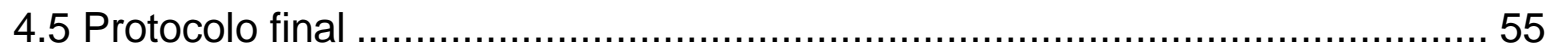

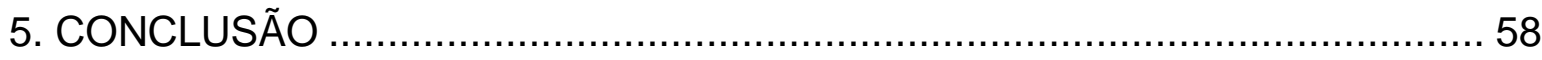


APÊNDICES: PLANILHA DE CÁLCULO DA ATIVIDADE CORRIGIDA FILTROS

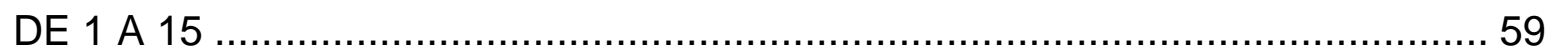

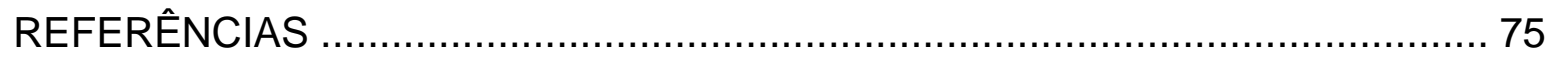




\section{LISTA DE FIGURAS}

FIGURA 1- organizações que recebem rejeitos radioativos no Brasil .................... 7

FIGURA 2- fluxograma das etapas de gerência de rejeitos radioativos .................. 9

FIGURA 3- métodos de imagem utilizados para avaliação de rejeitos radioativos 13

FIGURA 4- etapas para a análise radioquímica

FIGURA 5- Fluxograma para aplicação da metodologia de Fatores de Escala (TADDEI, 2013) 21

FIGURA 6- Distribuição dos reatores de potência em operação no mundo (PRIS, 2015). 23

FIGURA 7- vista da superfície da piscina do reator IEA-R1 .............................. 26

FIGURA 8- barras de controle do reator de pesquisa IEA-R1 vistas de cima ....... 27

FIGURA 9- Vista do núcleo do reator IEA-R1 (Marcelino e Neto, 2010) .............. 27

FIGURA 10- Fluxograma do sistema de tratamento e retratamento da água da piscina do reator nuclear IEA-R1 (Taddei, 2013)............................................ 29

FIGURA 11: filtro Cartucho utilizado no reator IEA-R1 .................................... 30

FIGURA 12- Arranjo experimental para teste de homogeneidade....................... 34

FIGURA 13- Arranjo experimental para a mediação de taxa de dose ................... 34

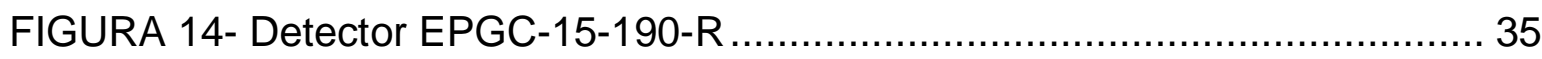

FIGURA 15- curva de eficiência do detector EPGC-15-190-R …....................... 36

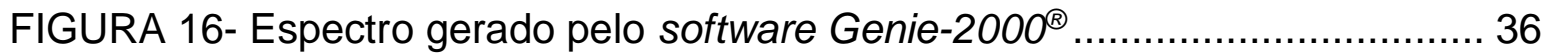

FIGURA 17- Arranjo experimental utilizado no HPGe ........................................ 37

FIGURA 18- Geometria da fonte e localização do detector para determinação do

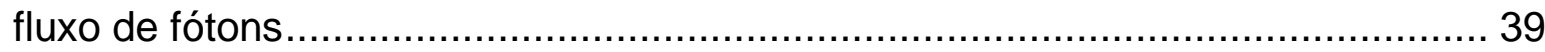

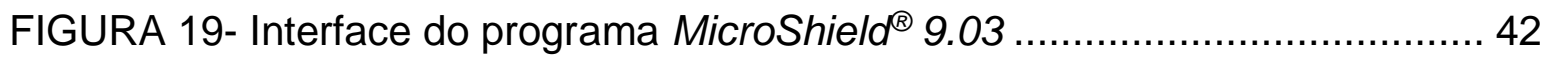

FIGURA 20: representação esquemática da metodologia utilizada na caracterização primária dos filtros ............................................................... 43

FIGURA 21- teste de homogeneidade amostra A ........................................... 44

FIGURA 22- teste de homogeneidade amostra $B$........................................... 45

FIGURA 23- teste de homogeneidade amostra C ............................................ 45 
FIGURA 24- teste de homogeneidade amostra D ............................................. 46

FIGURA 25: valores medidos e calculados utilizados para calcular o fator de correção, onde taxa de dose é dada em $\mu \mathrm{Sv} / \mathrm{h}$ para os filtros de $1-4 \ldots \ldots \ldots \ldots \ldots . . . .48$ FIGURA 26: valores medidos e calculados utilizados para calcular o fator de correção, onde taxa de dose é dada em $\mu \mathrm{Sv} / \mathrm{h}$ para os filtros de $5-12 \ldots \ldots \ldots \ldots \ldots . . . .49$ FIGURA 27- valores medidos e calculados utilizados para calcular o fator de correção, onde taxa de dose é dada em $\mu \mathrm{Sv} / \mathrm{h}$ para os filtros de 13-15.............. 50 FIGURA 28: Taxas de dose medidas e taxas de dose calculadas, em $\mu \mathrm{Sv} / \mathrm{h}$ utilizando a atividade dos radionuclídeos após aplicar o fator de correção para os filtros de 1-4. 52 FIGURA 29: Taxas de dose medidas e taxas de dose calculadas, em $\mu \mathrm{Sv} / \mathrm{h}$ utilizando a atividade dos radionuclídeos após aplicar o fator de correção para os filtros de 5-12 53

FIGURA 30: Taxas de dose medidas e taxas de dose calculadas, em $\mu \mathrm{Sv} / \mathrm{h}$ utilizando a atividade dos radionuclídeos após aplicar o fator de correção para os filtros de 13-15. 54 


\section{Lista de Tabelas}

Tabela 1: Distribuição de instalações radioativas por área.................................... 5

Tabela 2- Propriedades radiológicas dos rejeitos ............................................. 11

Tabela 3- Classificação dos rejeitos radioativos dadas pela facilidade de medição e capacidade de amostragem (IAEA, 2007) ................................................. 14

Tabela 4- Tipos de reatores e seus nomes descritivos...................................... 24

Tabela 5- reatores em funcionamento no Brasil ............................................ 25

Tabela 6- Radionuclídeos identificados nos filtros e suas características............. 47

Tabela 7- fatores de correção obtidos pela proporção entre os valores medidos e

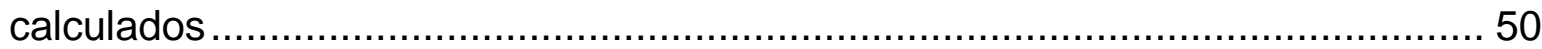

Tabela 8- Valores de atividade total dos filtros e a contribuição dos radionuclídeos

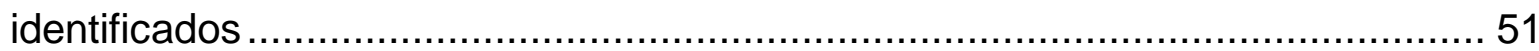




\section{INTRODUÇÃO}

\subsection{Considerações gerais}

As análises de segurança dos depósitos finais para rejeitos radioativos dependem, em primeiro lugar, do conhecimento do inventário radioisotópico dos rejeitos radioativos, essencial para garantir o nível adequado de segurança radiológica em longo prazo. Os padrões de segurança da Agência Internacional de Energia Atômica (IAEA) requerem que o conteúdo radioativo seja conhecido, possibilitando classificar os rejeitos, definir o tipo de coleta e transporte, tratamento, armazenamento, critérios de aceitação na deposição, estabelecimento dos planos de segurança para o manuseio dos rejeitos durante as fases operacionais e após o encerramento da atividade dos repositórios (PASCHOA e TRANJAN, 1995; IAEA, 2003; CNEN, 2014 a; CNEN,2014 b).

Rejeitos radioativos são definidos pela Agencia Internacional de Energia Atômica (IAEA) como sendo "qualquer material que contenha ou esteja contaminado com radionuclídeos em concentrações ou níveis de atividade maiores que os limites de isenção estabelecidos pela autoridade competente" (IAEA, 1988; IAEA, 2003). Os rejeitos radioativos são classificados em função de sua origem. Deste modo, os rejeitos podem ser:

a) Institucionais: são aqueles gerados no uso de radioisótopos em indústrias, clínicas médicas, hospitais e centro de pesquisas;

b) Ciclo do combustível: originados durante as etapas de fabricação e utilização do combustível nuclear;

c) Descomissionamento: materiais removidos de instalações radioativas descomissionadas. 
No Brasil, os rejeitos são classificados em quatro categorias, dependendo do nível de radioatividade que apresentam e de acordo com a meia-vida dos radionuclídeos presentes (CNEN, 2014 b). Desta forma, têm-se:

Classe 0: Rejeitos Isentos (RI): são os rejeitos contendo radionuclídeos com atividade ou concentração de atividade em massa ou volume, inferiores ou iguais aos respectivos níveis de dispensa estabelecidos pela autoridade regulatória;

Classe 1: Rejeitos de Meia-Vida Muito Curta (RVMC): rejeitos com meia-vida inferior a 100 dias, com níveis de atividade ou de concentração em atividade superiores aos respectivos níveis de dispensa;

Classe 2: Rejeitos de Baixo e Médio Níveis de Radiação (RBMN): rejeitos com meia vida superior a dos rejeitos da Classe 1, com níveis de atividade ou de concentração em atividade superiores aos níveis de dispensa e com potência térmica inferior a $2 \mathrm{~kW} \cdot \mathrm{m}^{-3}$;

Os rejeitos da Classe 2 são subdivididos em quatro categorias:

Classe 2.1: Meia-Vida Curta (RBMN-VC): rejeitos de baixo e médio níveis de radiação contendo emissores $\beta$ e $\gamma$, com meia-vida inferior a 30 anos e com concentração de radionuclídeos emissores $\alpha$ de meia-vida longa limitada em 3.700 kBq . $\mathrm{kg}^{-1} \mathrm{em}$ volumes individuais e com um valor médio de $370 \mathrm{kBq} \cdot \mathrm{kg}^{-1}$ para o conjunto de volumes;

Classe 2.2: Rejeitos Contendo Radionuclídeos Naturais (RBMN-RN): rejeitos provenientes da extração e exploração de petróleo, que contenham radionuclídeos das séries do urânio e tório em concentrações de atividade acima dos níveis de dispensa;

Classe 2.3: Rejeitos contendo Radionuclídeos Naturais (RBMN-RN): rejeitos contendo matérias primas minerais, naturais ou industrializadas, com radionuclídeos das séries do urânio e do tório em concentrações de atividade acima dos níveis de dispensa;

Classe 2.4: Rejeitos de Meia-Vida Longa (RBMN-VL): rejeitos não enquadrados nas Classes 2.2 e 2.3, com concentrações de radionuclídeos de meia-vida longa que excedem as limitações para classificação como rejeitos de meia-vida curta; 
Classe 3: Rejeitos de Alto Nível de Radiação (RAN): rejeitos com potência térmica maior que $2 \mathrm{~kW} \cdot \mathrm{m}^{-3}$ e com concentrações de radionuclídeos de meia-vida longa que excedam as limitações para classificação como rejeitos de meia-vida curta.

Rejeitos radioativos, se dispensados ou armazenados de forma incorreta, podem causar dano à saúde humana e ao meio ambiente, visto que existem diversos radionuclídeos que possuem meia vida longa e alta toxicidade. Deste modo, é necessário que os rejeitos radioativos sejam gerenciados corretamente, seguindo diretrizes de segurança definidas pelos órgãos responsáveis (RAJ, PRASAD, BANSAL, 2006; SARTORI, 2013).

A Gerência de Rejeitos Radioativos (GRR) tem como objetivo controlar os rejeitos de maneira a proteger a saúde humana e o meio ambiente, agora e no futuro, sem deixar encargos indevidos às futuras gerações, mantendo baixos os custos e as doses operacionais durante as etapas de manuseio destes rejeitos. Cabe à gerência zelar por esses rejeitos enquanto constituírem fonte potencial de perigo (CUMO, 2010; OKOSHI et al., 2001; PASCHOA e TRANJAN, 1995).

Uma das etapas mais importantes do programa de gerenciamento de rejeitos radioativos é a caracterização, o conjunto de análises para se determinar as propriedades físicas, químicas e radiológicas do rejeito.

A caracterização consiste em duas fases, chamadas de caracterização primária e caracterização do produto final. Na caracterização primária o objetivo é avaliar 0 rejeito "in natura" e então obter o conjunto de características necessárias para estabelecer o inventário radioisotópico e qual o melhor método de tratamento para 0 rejeito radioativo. Após o tratamento e imobilização deste material, seguindo os requisitos dos órgãos reguladores e seus padrões de boas práticas, é realizada a caracterização final para que então o material possa ser aceito no repositório (CNEN, 2002).

Diferentes métodos podem ser utilizados para a determinação radioisotópica de rejeitos radioativos. Análises radioquímicas, por exemplo, podem fornecer resultados exatos e precisos, entretanto são complexas e de alto custo. Cálculos baseados em modelos semi-empíricos, teóricos e fatores de escala também podem ser empregados e fornecem resultados de exatidão aceitável e de baixo custo (BICKEL et al., 2000; TOMA 
et al., 2007). Outra alternativa é utilizar estimativas que são baseadas em medidas da fluência dos fótons que são emitidos pelo material analisado. Esse método é aplicável quando os fatores de escala já são conhecidos. As estimativas não fornecem resultados exatos, entretanto, permitem analisar o rejeito de forma simples e rápida, podendo ser utilizadas na rotina do gerenciamento de rejeitos. Ao final, é possível afirmar que os três métodos podem e devem ser utilizados, pois se complementam (IAEA, 2009).

$O$ desenvolvimento de novos métodos de caracterização dos rejeitos tem sido necessário por causa da evolução das exigências dos órgãos reguladores, com base nas diretrizes da IAEA. Os requisitos estão mais severos sobre a qualidade das informações, declaradas em cada recipiente de rejeito e, sendo assim, exigem métodos mais exatos e mais confiáveis (IAEA, 2011).

É objetivo fundamental da GRR (IPEN), localizado no campus da Universidade de São Paulo (USP), desenvolver métodos que possibilitem caracterizar e guiar o melhor meio de tratamento dos rejeitos radioativos.

A GRR vem colaborando para tanto e desenvolve métodos para rejeitos produzidos internamente ao instituto e para aqueles que são recebidos de outras instituições. (Geraldo, 2012; Taddei, 2013) Alguns dos rejeitos gerenciados pela GRR são produzidos pela operação do reator de pesquisa IEA-R1, como por exemplo, os materiais provenientes do sistema de retratamento da água da piscina do reator. Os isótopos radioativos presentes na piscina do reator são produtos de ativação, produtos de fissão e elementos actinoides (TADDEl et al. 2011).

Dentre os rejeitos gerados pela operação do reator, os filtros cartucho de polipropileno, os leitos de resina de troca iônica e os leitos de carvão ativado, que fazem parte do sistema de retratamento da água da piscina do reator IEA-R1 são os mais ativos.

Os filtros de polipropileno retêm material particulado em suspensão na água e quando ficam incapazes de manter a vazão dentro dos limites estabelecidos, são substituídos, tornando-se rejeito radioativo. Estima-se que, quando o reator está em funcionamento, o tempo médio para a troca dos conjuntos de filtros é de aproximadamente três meses. Cada conjunto contém seis filtros. Ao serem substituídos, os filtros ficam armazenados em recipientes plásticos no interior da 
blindagem que abriga o sistema de retratamento antes de serem transferidos para a GRR, para que ocorra a secagem e o decaimento do material a um nível seguro para a sua manipulação e transporte.

Os filtros são do tipo cartucho cilíndrico tubular, fabricados com polipropileno termo-expandido. Esses filtros, ao serem encaminhados para o depósito da gerência de rejeitos radioativos, ficam armazenados em tambores de 200L. Apesar de serem conhecidos os elementos que estão presentes na água da piscina do reator, ainda não se sabe quais radionuclídeos ficam retidos nas unidades filtrantes

Não foram encontrados até o momento, na literatura, métodos de caracterização primária que indiquem métodos para se determinar o inventário radioisotópico de filtros de polipropileno que tenham sido utilizados em reatores. Logo, se faz necessário o desenvolvimento de um protocolo para a caracterização primária do material, de modo que se conheçam os radionuclídeos nele presentes e suas respectivas atividades.

\subsection{Rejeitos radioativos no Brasil}

No Brasil, a Comissão Nacional de Energia Nuclear (CNEN) é o órgão responsável pelo licenciamento e fiscalização de instalações nucleares e radioativas.

É estimado que atualmente existam 4.872 instalações radioativas licenciadas em atividade no país (TAB. 1) (NRB, 2014). Estima-se que aproximadamente 30\% dessas instalações gerem rejeitos radioativos regularmente.

Tabela 1: Distribuição de instalações radioativas por área

\begin{tabular}{|c|c|c|c|c|c|c|c|}
\hline Área & Medicina & Indústria & Pesquisa & Distribuição & Serviços & Produção & Total \\
\hline Número & 1705 & 1829 & 931 & 83 & 304 & 20 & 4872 \\
\hline
\end{tabular}

Todos os rejeitos gerados por essas instalações necessitam ser tratados e acondicionados da maneira correta em depósitos. 
Quanto aos depósitos para os rejeitos radioativos, estes devem ser construídos e licenciados de acordo com as normas estabelecidas pela CNEN, e podem ser classificados como:

- Depósito inicial: Depósito de rejeitos na própria instalação geradora. O rejeito radioativo e a responsabilidade civil por possíveis danos são encargos do titular da autorização para operação da instalação que gera os rejeitos;

- Depósito intermediário: Depósito situado, geralmente nos institutos da CNEN; nesse depósito os rejeitos radioativos são de responsabilidade da CNEN e ficam armazenados até a sua deposição final;

- Depósito final: o mesmo que repositório; é onde ocorre a deposição definitiva do rejeito radioativo e a CNEN se mantém responsável pelos rejeitos radioativos. (BRASIL, 2001).

Os rejeitos produzidos no país são temporariamente armazenados no IPEN (SP), IEN (RJ), CDTN (MG) e CRCN-NE (PE) que são institutos diretamente ligados a CNEN e possuem depósitos intermediários (FIG. 1).

O depósito final no município de Abadia (Go), que mantém os rejeitos gerados no acidente com Césio-137, ocorrido em 1987, ainda é o único depósito final do Brasil, mas foi construído única e exclusivamente para receber os rejeitos do acidente, não podendo receber outros rejeitos.

Sabe-se que usinas termonucleares não produzem gases que contribuem com o efeito estufa no processo de geração de energia, diferente de outras fontes de energia renováveis e não renováveis, tornando possível alavancar o desenvolvimento econômico e o aprimoramento tecnológico na área nuclear (BENTO e PEDROSO, 2010). Cientistas por todo o mundo defendem a expansão do uso da tecnologia nuclear não só para a geração de energia, mas também visando o aperfeiçoamento das suas aplicações de um modo geral. Entretanto, a falta de um depósito definitivo para os rejeitos radioativos é uma das questões mais relevantes dentre as que estão ligadas à expansão do uso dessa tecnologia no Brasil (BARROS, 2012). 


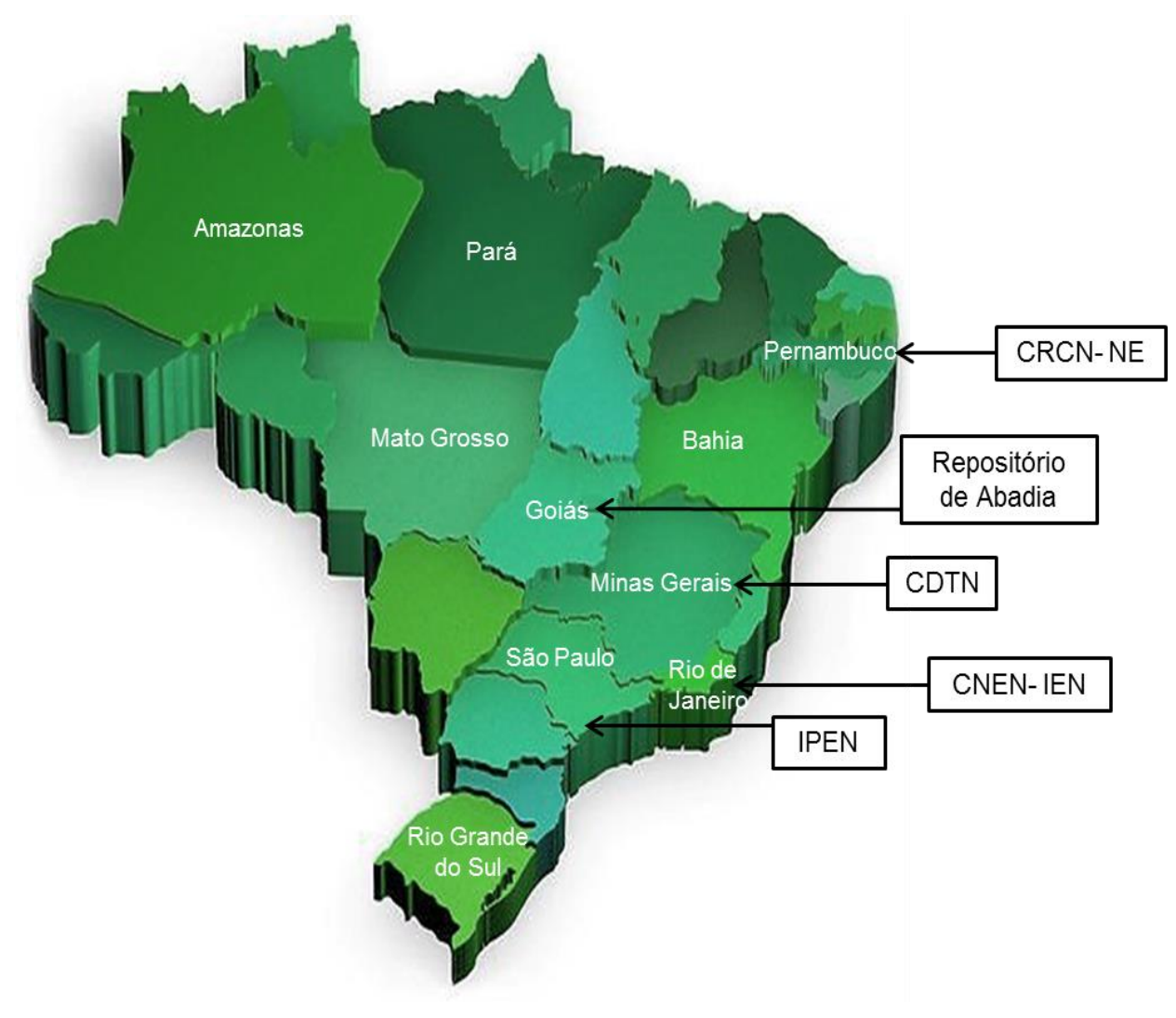

FIGURA 1- organizações que recebem rejeitos radioativos no Brasil

\subsection{Gerência de rejeitos radioativos}

Mesmo com os avanços nas tecnologias nucleares e o aumento da sua utilização na indústria, área médica e na geração de eletricidade, ainda se enfrenta um grande desafio diante da aceitação do seu uso: gerenciar os rejeitos originados durante os processos (RAMANA, 2013).

O gerenciamento de rejeitos radioativos atua com as premissas de proteção a saúde, proteção ambiental e a não geração de ônus ou encargos para as gerações futuras e abrange de forma conjunta processos técnicos e administrativos, que partem 
da geração do rejeito até a sua deposição final (IAEA, 1995; IAEA, 2006). De acordo com o regulamento CNEN-NN-8.01, o gerenciamento de rejeitos radioativos deve fazer parte do plano de proteção radiológica de instalações nucleares (CNEN, 2014 c).

Os métodos para gerenciar rejeitos radioativos podem sofrer adaptações, não seguindo qualquer tipo de modelo padrão, pois dependem de fatores tecnológicos, políticos, sociais, tipo de rejeito que está sendo gerado e quantidade (AMPHLETT, 1961; IAEA, 1983a; IAEA, 1983b; IAEA, 1984; IAEA, 1992; MARUMO, 2006). Mesmo porque, o gerenciamento de rejeitos radioativos não se restringe unicamente a programas nucleares realizados por órgãos governamentais ou indústria e a atividades de mineração (PASCHOA e TRANJAN, 1995; BEKEN et al., 2009).

O fluxograma (FIG. 2) apresenta as etapas do programa de gerenciamento de rejeitos radioativos e suas possíveis sequências, adotando o princípio ALARA (As Low As Reasonably Achievable ou "Tão baixo quanto razoavelmente alcançável") e levando em consideração as possibilidades de:

$>$ Diluir e dispensar (D\&D);

$>$ Reter e retardar a liberação $(R \& R)$;

$>$ Concentrar e confinar (C\&C).

Todas as etapas apresentadas no fluxograma se inter-relacionam. A exemplo disso: as características de um repositório final podem determinar os processos que melhor se adequam ao tratamento.

O gerenciamento de rejeitos deve ocorrer avaliando diferentes alternativas para cada etapa, possibilitando obter um sistema que cumpra com os princípios de proteção estabelecidos pelos órgãos reguladores. Entretanto, é necessário ressaltar que todos os modelos de entradas e saídas de um programa de gerenciamento de rejeitos radioativos são caracterizados pela alta complexidade (BEKEN et al., 2009). 


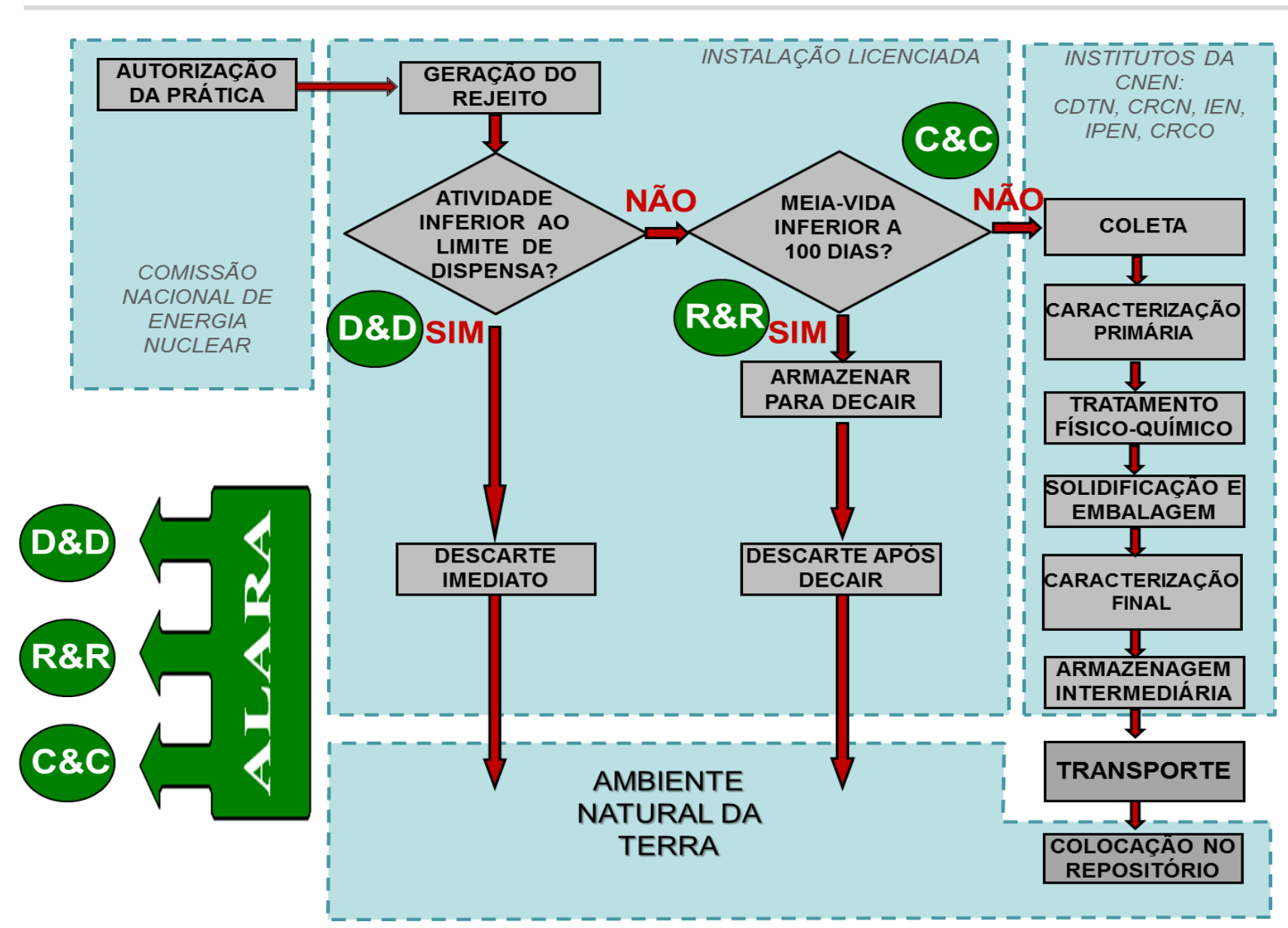

FIGURA 2- Fluxograma das etapas de gerência de rejeitos radioativos no Brasil, considerando as alternativas de D\&D - diluir e dispensar; $R \& R$ - reter e retardar a liberação; e C\&C - concentrar e confinar.

O gerenciamento de rejeitos radioativos deve visar principalmente à diminuição de custos e das doses operacionais (MARINGER et al. 2013). Além disso, é necessário ter em vista a redução na produção de resíduos radioativos durante a execução do gerenciamento. Apesar de ser tratada como uma tarefa complexa, a redução de resíduos pode ser alcançada seguindo alguns passos que incluem:

$>$ Planejamento prévio;

> Instalações e equipamentos de descontaminação adequados;

$>$ Formação dos profissionais que atuam na descontaminação sobre as operações e técnicas que podem ser utilizadas (PASCHOA e TRANJAN, 1995). 
A partir da geração do resíduo, inicia-se então o gerenciamento dos rejeitos radioativos, que consiste nas fases de:

Coleta e transporte: consiste em acondicionar os rejeitos segregados em embalagens adequadas e devidamente identificadas para então, serem transportados até o local de tratamento;

> Caracterização primária: qualifica e quantifica propriedades significativas para a escolha do processo de tratamento. Baseia-se na determinação de propriedades físicas, químicas e radiológicas dos rejeitos;

> Tratamento: visa reduzir o volume e condicionar física e quimicamente o rejeito, compatibilizando-o com as etapas seguintes;

> Imobilização: tem por objetivo fixar os radionuclídeos presentes no rejeito em uma matriz sólida (que mantenha integridade física e estabilidade mecânica e físico-química) evitando a dispersão dos mesmos para o meio ambiente;

> Caracterização do produto final: avalia se o produto final atende os critérios para a deposição final;

> Armazenamento: em um depósito intermediário, armazena de maneira não definitiva, os rejeitos radioativos já tratados e imobilizados;

Deposição final: é a ultima etapa do gerenciamento de rejeitos radioativos. Pode ser realizada por meio da eliminação ou do confinamento. A eliminação consiste na liberação do rejeito para o meio ambiente de forma gradativa e controlada de forma definitiva e irrecuperável. Já o confinamento preza zelar por esses rejeitos enquanto constituírem fonte potencial de perigo.

\subsection{Caracterização}

A caracterização de rejeitos radioativos incluí analisar os radionuclídeos presentes nos rejeitos e medir suas concentrações de atividades, além de identificar características físicas e químicas do rejeito. É um grande desafio para o programa de 
gerenciamento de rejeitos radioativos desenvolver e estabelecer técnicas viáveis para a caracterização. (MARINGER et al. 2013, KEKKI e TIITTA, 2000).

No Brasil, a CNEN é responsável por regulamentar o gerenciamento dos rejeitos radioativos. As normas 6.09 "Critérios de Aceitação para Deposição de Rejeitos Radioativos de Baixo e Médio Nível de Radiação" e 8.01 "Gerência de Rejeitos Radioativos de Baixo e Médio Níveis de Radiação" estabelecem os critérios de aceitação dos embalados para que estes possam ser, futuramente, enviados para o repositório final.

De acordo com a norma 6.09, "O tipo, composição e conteúdo de radionuclídeos do produto devem ser conhecidos e documentados com suficiente precisão para apresentar evidência de sua conformidade com os limites autorizados", tornando a caracterização uma atividade extremamente necessária dentro do programa de gerenciamento de rejeitos radioativos (CNEN, 2002; Taddei, 2013a). A tabela 2 apresenta as principais propriedades radiológicas que devem ser avaliadas nos rejeitos radioativos, segundo documento da IAEA de 1997.

Tabela 2- Propriedades radiológicas dos rejeitos:

\begin{tabular}{cl}
\hline Composição de radionuclídeos & $\begin{array}{l}\text { A composição isotópica dos radionuclídeos deve ser } \\
\text { determinada a fim de guiar as etapas do } \\
\text { gerenciamento }\end{array}$ \\
\hline Atividade total & $\begin{array}{l}\text { A atividade total de emissores alfa, beta e gama } \\
\text { presentes do rejeito }\end{array}$ \\
\hline $\begin{array}{c}\text { Massa físsil e segurança de } \\
\text { criticalidade }\end{array}$ & $\begin{array}{l}\text { Para evitar criticalidades não esperadas, é } \\
\text { necessário determinar a massa físsil presente no } \\
\text { rejeito }\end{array}$ \\
\hline Energia térmica & $\begin{array}{l}\text { A energia térmica deve ser quantificada garantindo } \\
\text { a integridade física do rejeito e do embalado }\end{array}$ \\
\hline Taxa de dose de superfície & $\begin{array}{l}\text { A fim de cumprir a regulamentação de transportes, } \\
\text { com base no principio ALARA }\end{array}$ \\
\hline
\end{tabular}

A caracterização inicial ou primária não é expressamente exigida pelas normas da CNEN, entretanto é de extrema importância, pois a partir dela é possível selecionar os métodos apropriados para o tratamento e imobilização dos rejeitos, além de tornar conhecida a atividade presente em cada embalado, garantindo a segurança 
ocupacional durante os processos de tratamento, armazenamento e transporte (ISO,2007; SINGLEDECKER et al., 2012).

Ainda quanto às características dos rejeitos, devem ser consideradas as propriedades físicas e químicas. As propriedades químicas do rejeito radioativo devem ser conhecidas, pois em grande maioria dos casos, os radionuclídeos são a menor parte do material, sendo que o restante é composto por outras substâncias que podem ser inofensivas ou ainda, em alguns casos, quimiotóxicas, como isótopos de metais pesados, solventes e cianetos. Quanto às propriedades físicas, é necessário avaliar a presença de líquidos livres, agentes quelantes e misturas complexas (KEKKI e TIITTA, 2000).

As principais propriedades químicas são:

> Composição química;

> Estabilidade química;

$>$ Reatividade;

$>$ Corrosividade;

> Compatibilidade química;

$>$ Toxicidade.

Entre as físicas, as mais relevantes são:

$>$ Estado físico;

$>$ Volume;

$>$ Densidade

$>$ Homogeneidade;

> Porosidade;

$>$ Permeabilidade.

Para a caracterização física dos embalados de rejeitos é possível utilizar técnicas não destrutivas. Alguns métodos de imagem tais como a radiografia em tempo real, tomografia, ressonância magnética (FIG.3 A) e neutrongrafia (FIG.3 B), podem ser empregados na inspeção de embalados, verificando a composição do rejeito, sua distribuição, resistência e a presença de fontes seladas. Essas técnicas são aplicadas 
com a intenção de minimizar exposições elevadas às quais os trabalhadores podem estar submetidos nos processos de amostragem e análise dos rejeitos radioativos (NRC, 2002).
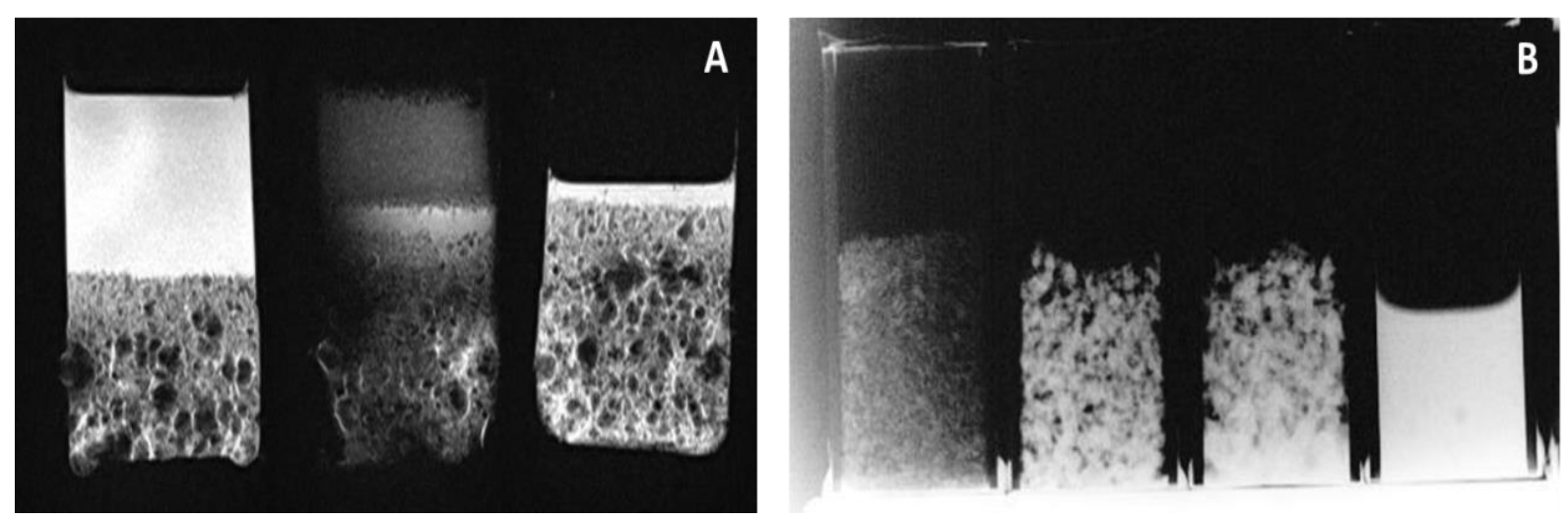

FIGURA 3- métodos de imagem utilizados para avaliação de rejeito radioativo proveniente do reator IEA-R1. Figura A: Ressonância magnética de carvão ativado acondicionado em embalagem plástica. Figura B: neutrongrafia com o carvão ativado acondicionado em embalagem de alumínio.

Rejeitos gerados em reatores podem conter produtos de fissão, ativação e elementos transurânicos. Alguns dos radionuclídeos são emissores de raios gama e podem ser detectados com facilidade devido à alta frequência de emissão que é dada para cada decaimento. Também podem ser encontrados alguns radionuclídeos de difícil detecção ou medição (RDM), de modo que estes podem ser partículas alfa ou beta ou até mesmo emissores gama de pouca energia ou pequena frequência. Deste modo, os RDM's podem ser caracterizados apenas por análises radioquímicas.

A IAEA, na tentativa de guiar os processos a serem seguidos, publicou documentos como o guia "Strategy and Methodology for Radioactive Waste Characterization" que sugere três formas básicas para caracterizar rejeitos radioativos de forma quantitativa e qualitativa: conhecimento do processo que gera o rejeito, ensaios não destrutivos ou análises destrutivas (IAEA, 2007), sendo que o principal objetivo desses métodos é possibilitar o conhecimento do inventário radioisotópico do rejeito radioativo. 
A caracterização pode ser classificada de duas formas distintas, sendo que uma depende da existência de informações sobre as propriedades dos rejeitos dadas pelo gerador e a outra que leva em consideração a heterogeneidade e possíveis modificações do rejeito como exemplificado na tabela 3.

$\mathrm{Na}$ primeira classificação, agrupa os rejeitos que possuem histórico conhecido e os que possuem histórico com informações incompletas. Os que possuem histórico, também podem ser chamados de "rejeitos novos" e necessitam da caracterização apenas para que sejam tratados corretamente. Já os que não possuem histórico são chamados de "rejeitos antigos" e podem estar parcialmente tratados ou não ou ainda foram tratados de forma incorreta, descumprindo os critérios de aceitação dos repositórios finais.

A segunda classificação é aplicada aos "rejeitos novos" e pode ser divida em: rejeitos simples-estáveis, simples-variáveis, complexo-estáveis e ainda complexosvariáveis (IAEA, 2007).

Tabela 3- Classificação dos rejeitos radioativos dadas pela facilidade de medição e capacidade de amostragem (IAEA, 2007)

\begin{tabular}{ccccc}
\hline Rejeitos Rastreáveis & $\begin{array}{c}\text { Simples } \\
\text { e estável }\end{array}$ & $\begin{array}{c}\text { Complexo } \\
\text { e estável }\end{array}$ & $\begin{array}{c}\text { Simples } \\
\text { e variado }\end{array}$ & $\begin{array}{c}\text { Complexo } \\
\text { e variado }\end{array}$ \\
Usinas Nucleares & $\checkmark$ & $\checkmark$ & & \\
$\quad$ Institucionais & $\checkmark$ & & & \\
Laboratórios de pesquisa & & & $\checkmark$ & \\
$\quad$ Reprocessamento & & $\checkmark$ & & $*$ \\
Enriquecimento e fabricação & & & & \\
$\quad$ de combustível & $\checkmark$ & & & \\
Descomissionamento & $*$ & $*$ & & \\
$\quad$ Fonte selada & $\checkmark$ & & & \\
Combustível Usado & $\checkmark$ & & & \\
$\quad$ Rejeito Final & & $\checkmark$ & & \\
Rejeitos Não Rastreáveis & & & & \\
$\quad$ Históricos & $* *$ & $* *$ & & \\
\hline Classificados sempre da mesma forma & & & \\
$*$ Dependente da instalação & & &
\end{tabular}


** Pode ou não incluir o subtipo

Os filtros cartucho, objetos estudados neste trabalho, podem ser classificados como rejeitos simples-estáveis, pois são homogêneos e gerados sempre com as mesmas características (IAEA, 2007).

\subsection{Métodos de Caracterização radioisotópica}

A caracterização radioisotópica de rejeitos baseia-se na determinação do inventário dos radionuclídeos presentes no rejeito radioativo, também conhecido como inventario radioisotópico. De modo geral, é possível encontrar nos rejeitos radioativos radionuclídeos de difícil e fácil medição e também radionuclídeos de medição impossível. O inventário radioisotópico pode ser obtido por várias técnicas, que dependem das características físicas e químicas dos rejeitos, dos radionuclídeos presentes e do nível de precisão requerida (KEKKI e TIITTA, 2000). Os radionuclídeos presentes nos rejeitos podem ser classificados como Radionuclídeos de difícil medição, radionuclídeos de fácil medição e radionuclídeos de medição impossível.

Radionuclídeos de difícil medição (RDM) são aqueles que emitem partículas alfa ou beta puros ou ainda que emitem radiação gama de pouca energia ou baixa frequência.

Os radionuclídeos de fácil medição podem ser medidos de forma direta e são conhecidos também como radionuclídeos-chave $(R C)$, justamente porque podem ser utilizados como referência no método de fatores de escala para a determinação de outros radionuclídeos.

Radionuclídeos de medição impossível são os que possuem características radiológicas que não permitem a sua detecção ou ainda que permitem, mas que proporcionam resultados extremamente imprecisos, que devem ser desconsiderados na determinação do inventário radioisotópico. 
Conhecendo as características dos radionuclídeos que podem ser encontrados nos rejeitos radioativos, sabe-se que para caracterizar RDM's é necessário aplicar técnicas destrutivas, como análises radioquímicas que dependem da retirada e processamento de amostras do rejeito para que só então, sejam realizadas as medidas. Já para os RC's é possível aplicar métodos não destrutivos, possibilitando realizar medidas diretas nos embalados dos rejeitos radioativos de maneira simples.

A radiação ionizante pode ser medida através das suas interações físicas e químicas com a matéria. Os métodos utilizados baseiam-se principalmente no uso de equipamentos que convertem a radiação em sinais elétricos. De um modo geral, utilizam-se câmaras de ionização, detectores Geiger- Muller, contadores de cintilação, detectores termoluminescentes e detectores de traços para monitorar e quantificar $\alpha, \beta$, $\gamma$ e nêutrons e deste modo, o tipo de radiação a ser medido determinará a escolha do detector e se deverão ser utilizadas amostras processadas ou não. (IAEA, 2003)

A seguir são apresentados alguns métodos que podem ser utilizados para caracterizar rejeitos radioativos.

\subsubsection{Métodos radioquímicos}

A caracterização de rejeitos radioativos deve ser precisa de modo que seja possível fazer uma projeção segura quanto à atividade e a dose presentes no material. Um dos grandes problemas enfrentados durante a caracterização de rejeitos radioativos é que alguns materiais possuem emissores alfa ou beta puros, o que torna impossível realizar medições diretas do embalado (KEKKI e TIITTA, 2000). Deste modo, para a obtenção do inventário radioisotópico é necessário utilizar métodos radioquímicos para a caracterização. Esses métodos consistem na retirada e processamento de amostras de rejeitos radioativos e aplicam técnicas que consistem, por exemplo, na precipitação, extração com solventes ou trocas iônicas que são utilizadas para a separação e quantificação diferentes radionuclídeos. 
Análises radioquímicas se baseiam em cinco etapas principais (GERALDO, 2012) que são apresentadas no fluxograma a seguir (FIG. 4):

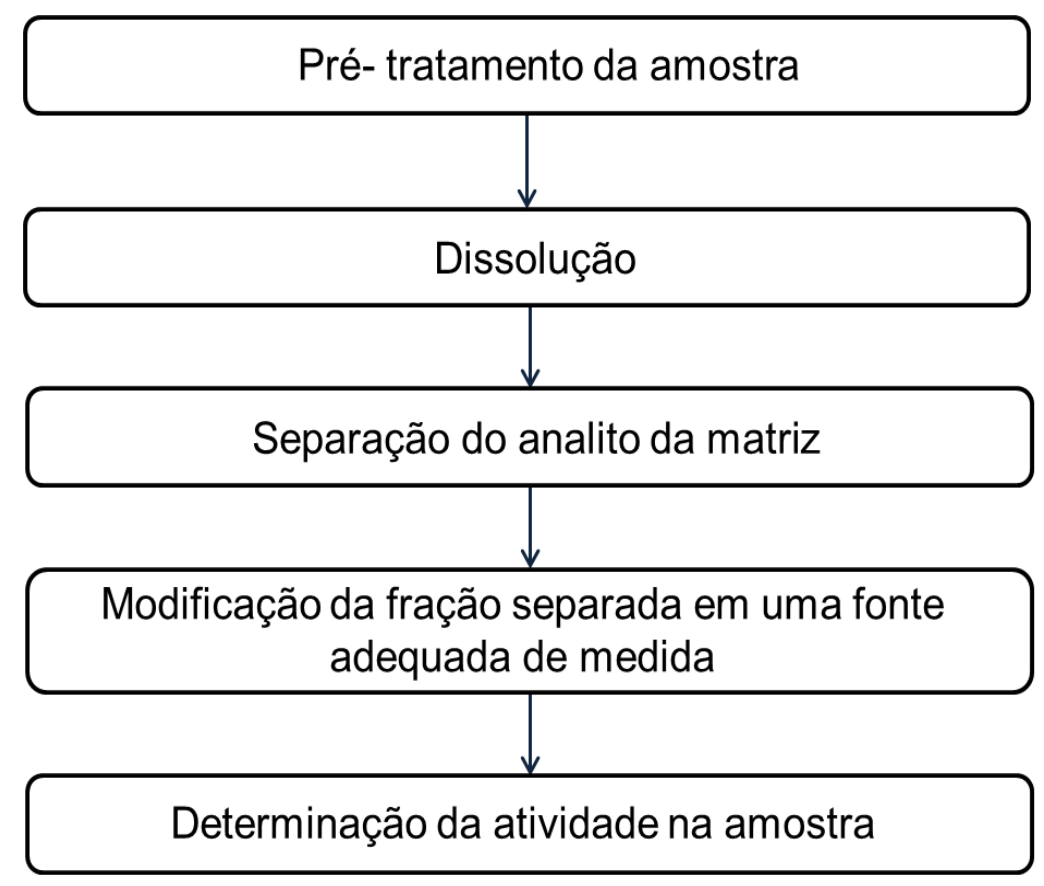

FIGURA 4- etapas para a análise radioquímica

Esses métodos, apesar de fornecerem resultados precisos, são de difícil implementação na rotina operacional do programa de gerenciamento de rejeitos radioativos pois, além de serem extremamente complexos e sofisticados e demandarem muito tempo para a realização, são de alto custo e geram grandes quantidades de rejeitos químicos.

\subsubsection{Espectrometria gama}

Raios gama podem ser identificados por meio do uso de espectrometria gama, que consiste em um método não destrutivo que utiliza detectores de germânio hiperpuro (HPGe) (VARGAS et al.,2002; TADDEl et al., 2013b ; TZIKA et al., 2010). Essa técnica vem sendo empregada para identificar e determinar a concentração da 
atividade de alguns radionuclídeos. Nela identifica-se cada fóton emissor de radiação $\gamma$ que possuí uma energia discreta, sendo que essa energia é característica do isótopo fonte (MONTANHEIRO et al., 1977).

Por se tratar de uma técnica não destrutiva, a espectrometria gama é frequentemente utilizada no gerenciamento de rejeitos radioativos com a finalidade de controlar e contabilizar materiais, principalmente determinando o conteúdo (radionuclídeos) presentes nos embalados.

A espectrometria gama é datada de 1970, onde detectores de germânio dopados com lítio-Ge ( $\mathrm{Li}$ )- foram amplamente utilizados em medições biológicas, ambientais e de resíduos. A partir de 1980, com aprimoramento do detector, passou-se a utilizar germânio hiperpuro, no qual as vantagens operacionais estão relacionadas à quantidade de informações obtidas por meio de uma única análise.

O recente desenvolvimento na espectrometria gama introduz a utilização de um volume maior de cristal $\mathrm{Ge}$, que acarreta no aumento da eficiência de contagem em 100-150\%, que ainda sim pode variar com a energia dos raios gama, distância fontedetector, e tamanho do cristal de Ge (CARNEIRO, 2011).

Normalmente, detectores HPGe são construídos de forma cilíndrica e coaxial, permitindo analisar volumes maiores de materiais (KNOLL, 1989).

De forma genérica, um sistema de espectrometria gama é composto por um detector gama, uma fonte de alta tensão, pré-amplificador, amplificador, conversor, um analisador multicanal e, por fim, um registrador (CRISTIANO, 2014). É necessário realizar a calibração em energia do detector que consiste na medida de dois conjuntos de parâmetros, sendo estes a energia do raio-gama em função do canal e a forma do pico em função da energia do raio-gama. A calibração pode ser feita com fontes padrões de energia que podem variar entre 50 e $1500 \mathrm{keV}$. Podem ser utilizadas fontes monoenergéticas ou multienergéticas. Fontes multienergéticas tais como o ${ }^{152} \mathrm{Eu}$ e $0{ }^{133} \mathrm{Ba}$ por exemplo, tendem a apresentar maior vantagem pois possuem um espectro de energia amplo e com meia-vida mais longa (AGARWAL, 2011; COSTA, 2014; TADDEI, 2013).

É possível obter os valores de atividade dos emissores gama de uma fonte radioativa com o uso da espectrometria gama, no entanto é necessário ter um 
conhecimento prévio quanto à calibração em eficiência do detector. A calibração em eficiência é feita utilizando fontes padrão que respeitam as mesmas características do material a ser avaliado, como geometria, densidade e composição química. Contudo, existem casos em que não é possível produzir uma fonte que contemple todas as características citadas, sendo necessário atrelar este método a outros para a obtenção de resultados.

A espectrometria gama, apesar de fornecer resultados mais inexatos do que os fornecidos por análises radioquímicas, pode ser empregada na rotina operacional do programa de gerenciamento de rejeitos radioativos pelo seu baixo custo, e por proporcionar maior segurança radiológica aos operadores.

\subsubsection{Método de fatores de escala}

$\mathrm{Na}$ identificação e determinação de RDM's é necessário utilizar métodos radioquímicos de alta complexidade. Em algumas situações, o grande número de embalados contendo rejeitos radioativos torna inviável a aplicação desse método já que a necessidade de coletar e analisar amostras poderiam expor os operadores a elevadas doses (TADDEI, 2013a).

No método de fatores de escala, as concentrações dos RDM's são avaliadas multiplicando as concentrações dos RC's pelos coeficientes calculados com base nos dados dos radionuclídeos obtidos por meio de amostragens e análises radioquímicas, ou seja, é estabelecida uma correlação entre as atividades dos RDM's e dos RC's (IAEA, 2009; TADDEl et al. 2013b).

Órgãos reguladores podem aceitar a determinação do inventário radioisotópico do rejeito através de fatores de escala por recomendação da Agencia Internacional de Energia Atômica, entretanto, esses fatores são específicos para cada instalação nuclear. Isso implica em levar em consideração cada rejeito de maneira individual, impossibilitando o uso de valores estabelecidos por outras instalações já que, mesmo que o rejeito radioativo fosse semelhante, o método seria insuficiente por utilizar valores 
genéricos. É aceitável utilizar fatores de escala obtidos por amostragem única, desde que essa represente todo o rejeito radioativo.

Ainda seguindo as recomendações, é dado que a dispersão entre as concentrações de atividade dos radionuclídeos de difícil medição (RDM's) pelos fatores de escala e os valores de amostragem podem variar em um fator menor ou igual a 10.

O método utilizado para a obtenção dos fatores de escala é complexo e extenso e está sendo empregado em alguns países desde a década de 80 para rejeitos de baixa e média atividades, produtos de reatores nucleares de potência (REMEIKES et al., 2009).

Alguns critérios devem ser levados em consideração para a escolha do radionuclídeo chave. O RC deve:

Estar presente em quantidades significativas no rejeito a ser estudado;

> Ter emissões gama suficientes para ser detectado na espectrometria gama;

> Ter meia vida de tempo suficiente que permita a caracterização.

De forma simplificada, o fluxograma apresentado na figura 5 aborda as etapas que devem ser seguidas para a aplicação do método de fatores de escala.

Atualmente, o maior desafio a ser enfrentado para a utilização desse método é a capacitação suficiente dos laboratórios para a realização das análises necessárias para determinar as atividades dos radionuclídeos de difícil medição. 


\section{Etapa 1}

- Estudo das características gerais da instalação nuclear

- Seleção dos radionuclídeos a serem determinados

- Elaboração do plano de amostragem dos rejeitos radioativos

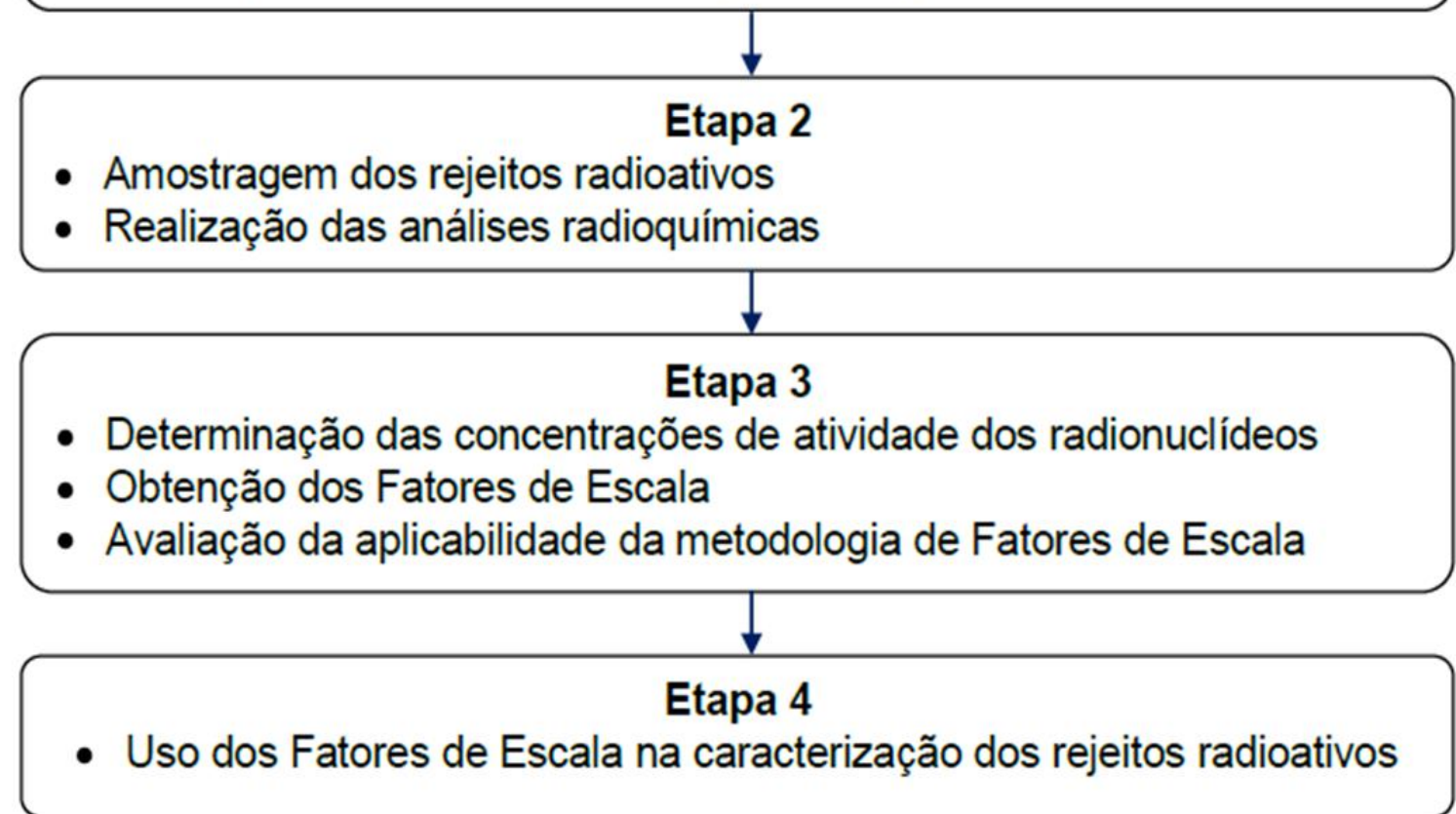

FIGURA 5- Fluxograma para aplicação da metodologia de Fatores de Escala (TADDEI, 2013)

\subsubsection{Caracterização por meio de medidas de taxa de dose}

Um dos resultados esperados ao final do processo de caracterização é o conhecimento quanto aos radionuclídeos que compõe o rejeito e a obtenção do valor de atividade contida no material. Muitos métodos desenvolvidos incluem a amostragem de certa quantidade do resíduo e a caracterização através de análises destrutivas (CUMO, 2010; GERALDO, 2012; GRATE, O'HARA e EGOROV, 2012 ; HORWLTZ, DIETZ e CHIARIZIA, 1992; LEOPOLD et al., 2007). Entretanto, é importante frisar que análises destrutivas são difíceis e necessitam de grande cautela visto que dependem da manipulação de amostras que podem sofrer dispersão, volatização e outros 
processos que podem acarretar custos a saúde do operador caso exista algum problema durante o procedimento.

Existem métodos alternativos que trazem como resposta final resultados de atividade com certa precisão e que consistem em ensaios não destrutivos (PROKHORETS et al. 2007; LIERSE et al. 1995). Dentre esses métodos, destaca-se a medida de taxa de kerma no rejeito vinculada ao método de Point-Kernel ou a modelagens de Monte Carlo. Esse método é frequentemente utilizado na rotina de gerenciamento de rejeitos radioativos, justificando sua aplicação pelo baixo custo e por proporcionar menor periculosidade para o operador, principalmente quando os rejeitos analisados são de médio ou alto níveis de radiação (ANTILLA, 1996; KLOOSTERMAN e HOOGENBOOM, 1988; KOCHER, 1986; POTIENS e HIROMOTO, 2002; SARTORI, 2013).

A técnica, chamada de dose-to-curie, consiste em correlacionar a taxa de dose (de radionuclídeos que podem ser medidos diretamente tais como o ${ }^{60} \mathrm{Co}$ ou ${ }^{137} \mathrm{Cs}$ ) obtida na superfície do rejeito com as distribuições isotópicas obtidas por fatores de conversão desenvolvidos empiricamente. É possível também estimar a atividade baseando-se na medida de atividade de um indicador, como $0^{60} \mathrm{Co}$, e correlacionar essa atividade com a de outros radionuclídeos (NRC, 2002).

A taxa de dose medida por um detector no entorno do embalado que contém o rejeito radioativo pode ser interpretada como sendo taxa de dose absorvida ou taxa de exposição. A grandeza a ser usada dever estar relacionada à calibração do detector de radiação utilizado nesse método e aos fatores de conversão de kerma no ar para a grandeza operacional de interesse. Estes valores estão definidos em publicação da ICPR (1997) (SOUZA, 2013).

\subsection{Reatores Nucleares}

Reatores são instalações que mantém reações de fissão em cadeia de forma controlada e são divididos entre reatores de potência e reatores de pesquisa. 
Reatores de potência têm como objetivo principal o aproveitamento do calor gerado pelo combustível para a geração de energia elétrica, processo de dessalinização e propulsão naval.

Reatores de pesquisa têm como objetivo o aproveitamento das partículas e das radiações geradas por meio do processo de fissão para a irradiação e teste de materiais, produção de radioisótopos, etc.

No mundo existem atualmente 437 reatores de potência (FIG. 6) e 248 reatores de pesquisa em operação (IAEA, 2015; PRIS, 2015).

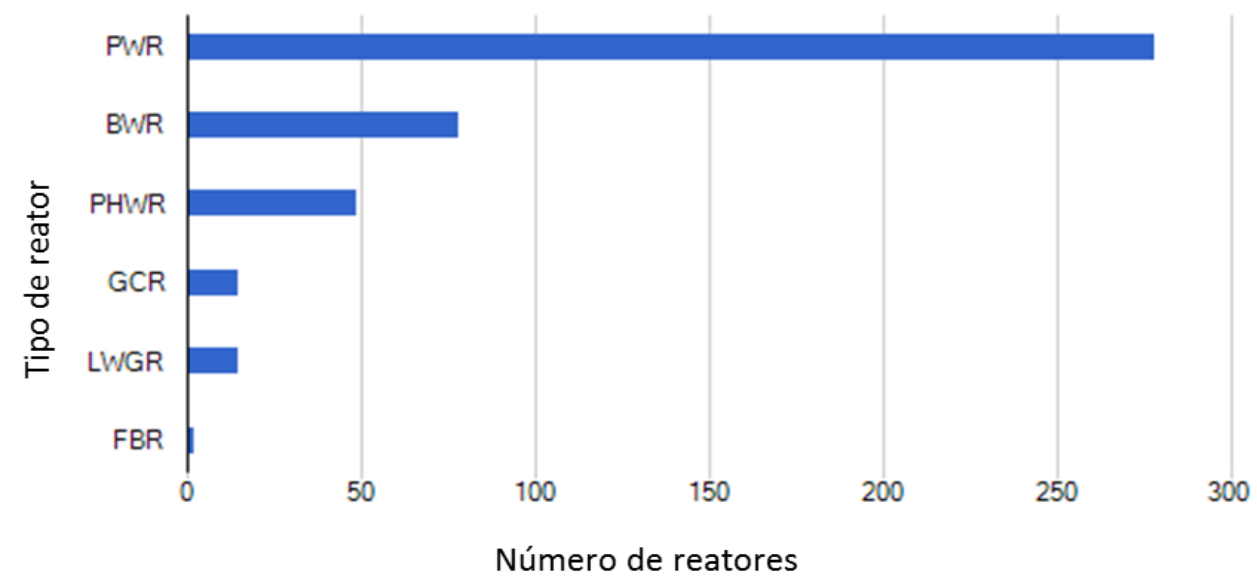
2015)

FIGURA 6- Distribuição dos reatores de potência em operação no mundo (PRIS,

De um modo geral, reatores nucleares são compostos por:

Combustível nuclear: contém os elementos físseis que irão produzir as fissões e reações em cadeia;

$>$ Estruturas: todo e qualquer material utilizado para estruturação e revestimento dos componentes do reator;

Moderadores: tem a função de moderar a energia proveniente dos nêutrons resultada do processo de fissão. É utilizado também como refletor periférico do núcleo, minimizando a fuga de nêutrons;

$>$ Absorvedores/ controladores: mantêm controlada a reação em cadeia que ocorre no núcleo; 
Refrigerantes: retira o calor gerado no núcleo proveniente das fissões;

Blindagem: serve como barreira para a radiação, reduzindo os efeitos da mesma no meio externo e nos componentes estruturais (PERROTA, 1999).

A composição química do combustível, o tipo de líquido de arrefecimento, e outros detalhes importantes para o funcionamento do reator dependem do seu design. Os tipos de reatores são apresentados na tabela 4 e podem ser:

Tabela 4- Tipos de reatores e seus nomes descritivos

\begin{tabular}{cc}
\hline SIGLA & REATOR \\
\hline BWR & Boiling Light-Water-Cooled and Moderated Reactor \\
PWR & Pressurized Light-Water-Moderated and Cooled Reactor \\
PHWR & Pressurized Heavy-Water-Moderated and Cooled Reactor \\
LWGR & Light-Water-Cooled, Graphite-Moderated Reactor \\
GCR & Gas-Cooled, Graphite-Moderated Reactor \\
FBR & Fast Breeder Reactor \\
MTR & Materials Testing Reactor \\
\hline
\end{tabular}

No Brasil as usinas Angra I e Angra II utilizam reator do tipo PWR. Angra I, que entrou em operação comercial em 1985, tem potência de 640 megawatts. A outra começou a operar em 2001 e sua potência é de 1.350 megawatts. Além das usinas, quatro reatores de pesquisa estão em atividade, sendo eles apresentados na tabela 5.

Em destaque, o reator IEA-R1, também chamado de MTR, foi o primeiro reator a operar no hemisfério sul e em 16 de setembro de 1957 teve sua primeira criticalidade (PERROTTA et al., 1998; MAIORINO, 1999). Localizado no IPEN, em local multidisciplinar, é utilizado para pesquisas de ciências nucleares e não há registros de qualquer incidente que tenha causado prejuízo à saúde de operadores e pesquisadores do reator, do público em geral ou ao meio ambiente (SAUER, 2000; MARCELLINO e MATTAR, 2010). 
Tabela 5- reatores em funcionamento no Brasil

\begin{tabular}{|c|c|c|c|c|}
\hline Reator & Local & Potência & Combustível & $\begin{array}{c}\text { Primeira } \\
\text { Criticalidade } \\
\end{array}$ \\
\hline IEA-R1 & $\begin{array}{c}\text { Instituto de } \\
\text { Pesquisas } \\
\text { Energéticas } \\
\text { Nucleares- IPEN } \\
\text { (São Paulo, SP) }\end{array}$ & $5 \mathrm{MW}$ & U (20\%) & $\begin{array}{l}16 \text { de setembro } \\
\text { de } 1957\end{array}$ \\
\hline IPEN/MB-01 & $\begin{array}{c}\text { Instituto de } \\
\text { Pesquisas } \\
\text { Energéticas } \\
\text { Nucleares- IPEN } \\
\text { (São Paulo, SP) }\end{array}$ & $100 \mathrm{~W}$ & U $(4,3 \%)$ & $\begin{array}{c}9 \text { de novembro } \\
\text { de } 1988\end{array}$ \\
\hline ARGONAUTA & $\begin{array}{c}\text { Instituto de } \\
\text { Engenharia Nuclear } \\
\text { - IEN (Rio de } \\
\text { Janeiro, RJ) }\end{array}$ & $\begin{array}{l}500 \mathrm{~W} \text { a } \\
5000 \mathrm{~W}\end{array}$ & U $(19,91 \%)$ & $\begin{array}{l}20 \text { de fevereiro } \\
\text { de } 1965\end{array}$ \\
\hline $\begin{array}{c}\text { TRIGA IPR- } \\
\text { R1 }\end{array}$ & $\begin{array}{c}\text { Centro de } \\
\text { Desenvolvimento da } \\
\text { Tecnologia Nuclear- } \\
\text { CDTN (Belo } \\
\text { Horizonte, MG) }\end{array}$ & $\begin{array}{c}100 \mathrm{~kW} \\
\mathrm{a} \\
250 \mathrm{~kW}\end{array}$ & U (20\%) & $\begin{array}{c}6 \text { de novembro } \\
\text { de } 1960\end{array}$ \\
\hline
\end{tabular}

O IEA-R1 (FIG. 7) é um reator nuclear de pesquisa do tipo piscina aberta, com potência de máxima de 5MW. Utiliza água leve como meio moderador, blindagem e fluído refrigerante.

O combustível nuclear utilizado atualmente tem em sua composição U3Si2, com dispersão em matriz de Al. No cerne do reator são encontrados refletores de grafite ou berílio, também revestidos por Al e as barras de controle (FIG. 8) são constituídas por uma liga de $\mathrm{Ag}$ - In - Cd, revestida de Ni (GERALDO 2012; TADDEI 2013). 


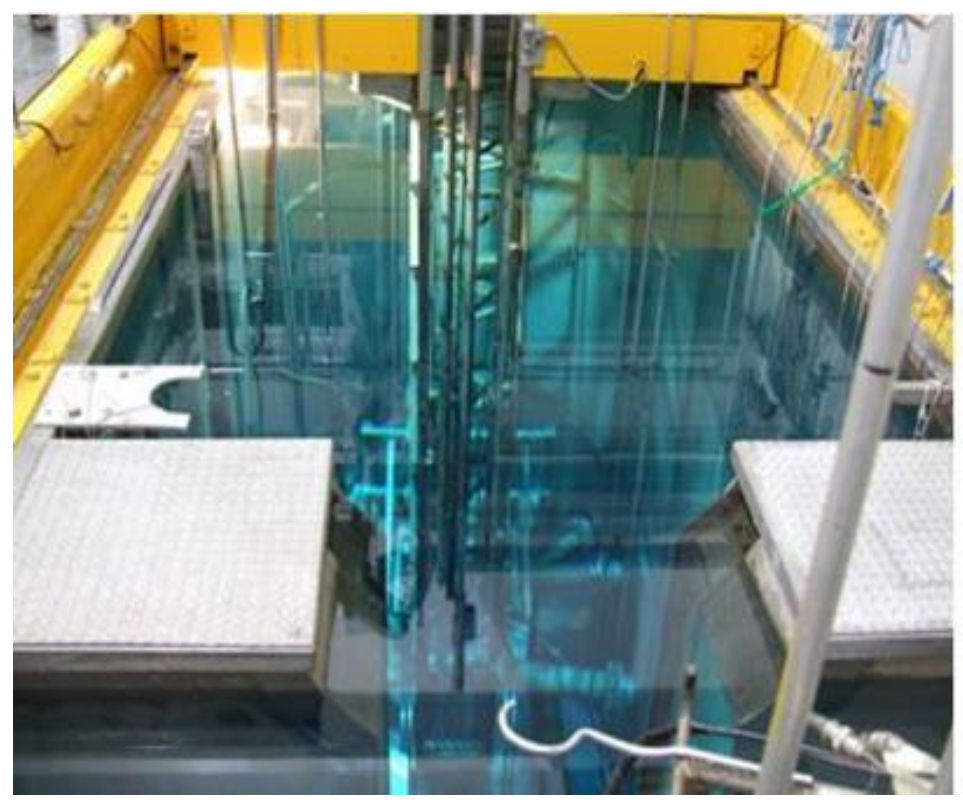

FIGURA 7- vista da superfície da piscina do reator IEA-R1

O sistema de tratamento da água que chega até a piscina do reator é divido em dois circuitos, sendo um desses um circuito não radioativo e outro radioativo.

O circuito não radioativo é composto por:

Dois conjuntos de seis filtros Cartucho cada, que desempenham a função e reter partículas em suspensão acima de $25 \mu$;

$>$ Um tanque com trocadores iônicos, chamado de amolecedor, que tem por função reter $\mathrm{Ca}^{+2}$ e $\mathrm{Mg}^{+2}$;

$>$ Um leito de carvão ativado, que retêm moléculas de substâncias orgânicas que possam estar presentes na água;

Dois leitos de resinas mistas sendo estas catiônicas e aniônicas, que tem como função retirar substâncias dissolvidas na água. Quando um dos leitos necessita de regeneração, o outro é utilizado.

A parte de retratamento da água radioativa é composta por dois circuitos idênticos. Cada um desses circuitos é composto por um conjunto de seis filtros cartucho, um leito de carvão ativado e um leito de resina de troca iônica mista. 


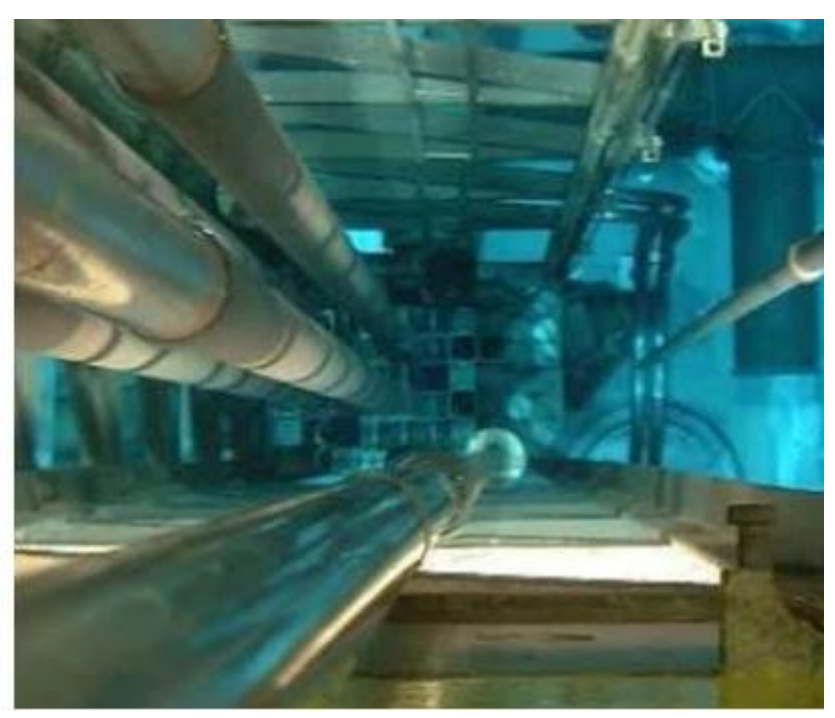

FIGURA 8- barras de controle do reator de pesquisa IEA-R1 vistas de cima

A água presente na piscina se torna ativa após passar pelo núcleo do reator (FIG. 9), por meio de sua própria ativação, da ativação de impurezas presentes na água que são produto da corrosão de estruturas, de reações nucleares dos materiais que se encontram no núcleo do reator para receberem algum fluxo de nêutrons, do desprendimento de radionuclídeos de materiais que compõem o núcleo e de produtos de fissão dos elementos combustíveis.

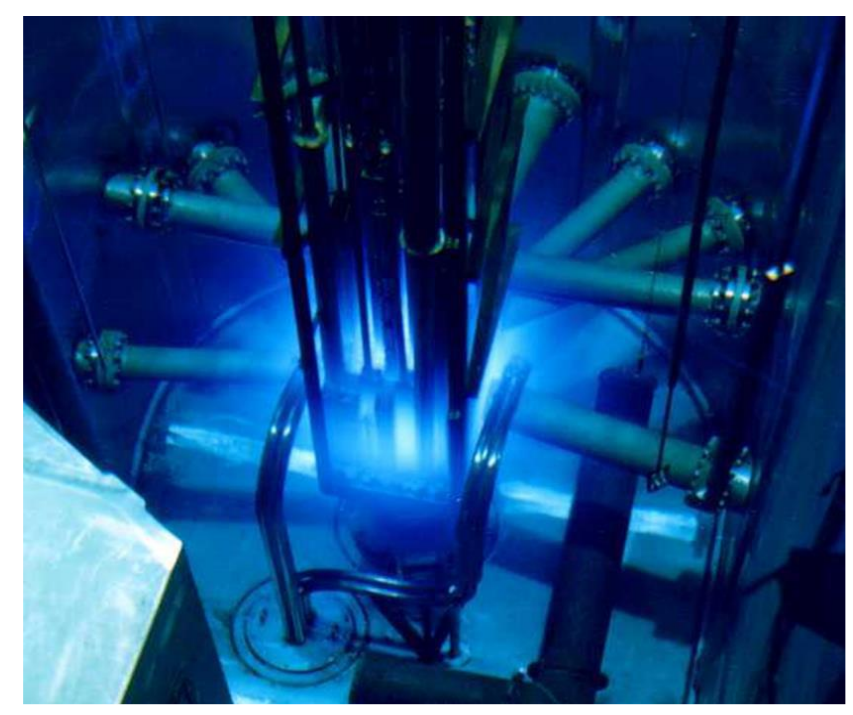

FIGURA 9- Vista do núcleo do reator IEA-R1 (Marcelino e Neto, 2010) 
O circuito radioativo desempenha a função de retratar a água presente na piscina de maneira contínua e manter sua qualidade. Esse sistema (FIG. 10) tem capacidade de tratar $75 \mathrm{~L} \mathrm{~min}^{-1}$ de água e preza manter o grau de impurezas da água em torno de 2 ppm de substâncias solúveis. Por ter dois circuitos idênticos é possível que o retratamento da água nunca seja interrompido, mesmo durante a manutenção do sistema.

Quando a condutividade da água utilizada na piscina deixa de atender os limites especificados é feita a regeneração das resinas e a retrolavagem do leito de carvão ativado. Quando a regeneração não é mais possível, tanto o leito de resina como o de carvão são substituídos. Os filtros cartucho utilizados no sistema são trocados frequentemente e o tempo para troca depende da operação do reator. Em média, os filtros do circuito radioativo são substituídos a cada três meses devido à saturação. Sendo assim, todos os materiais que deixam de atender as necessidades do sistema de retratamento, quando são substituídos, passam a ser considerados rejeitos radioativos. 


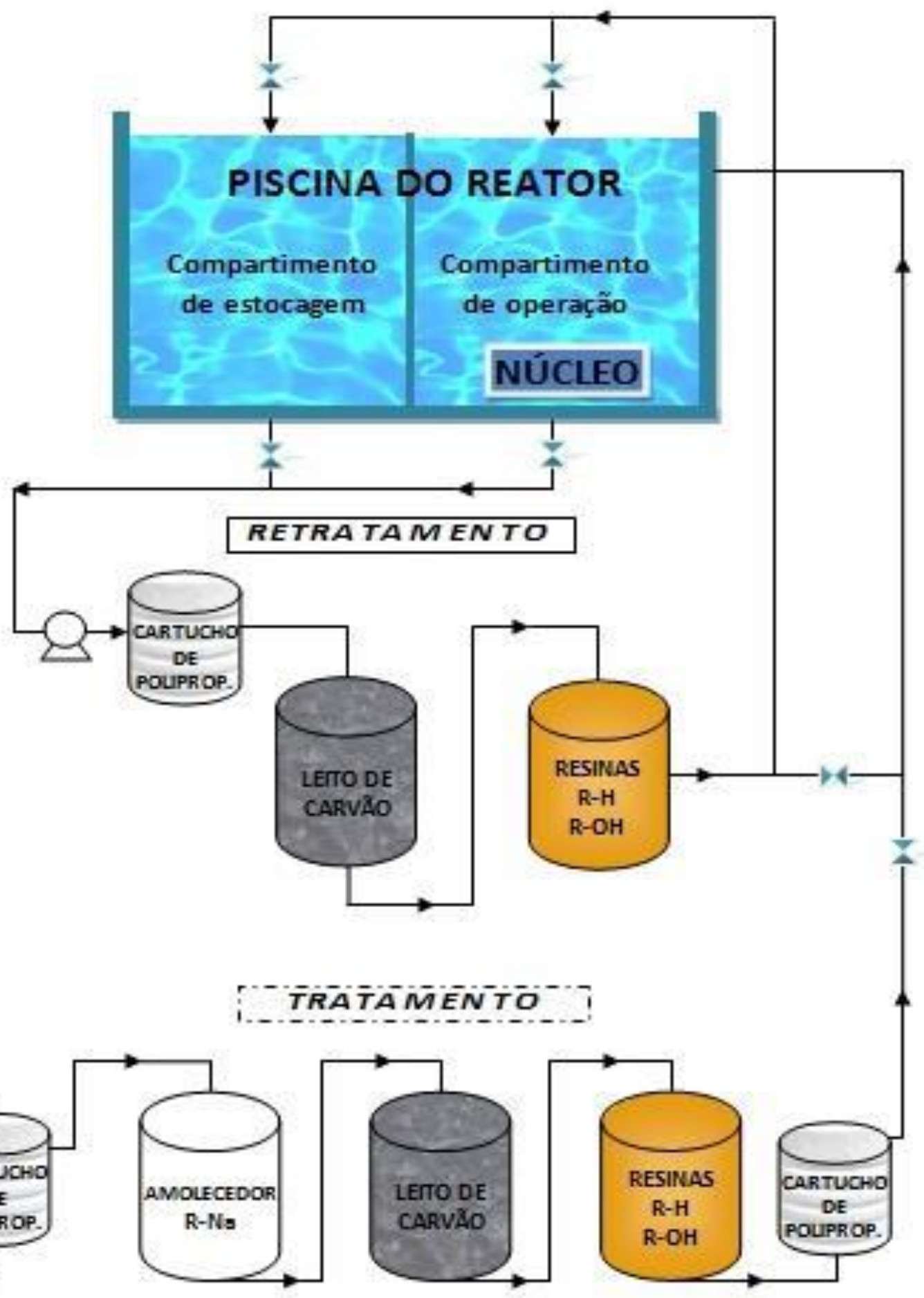

ALIMENTAÇĀO

FIGURA 10- Fluxograma do sistema de tratamento e retratamento da água da piscina do reator nuclear IEA-R1 (TADDEI, 2013) 


\subsection{Filtros Cartucho}

Os filtros (FIG. 11) são cartuchos tubulares, constituídos de polipropileno termoexpandido. Possuem baixa densidade e porosidade de $10 \mu \mathrm{m}$. Suas dimensões são de $508 \mathrm{~mm}$ de comprimento, $65 \mathrm{~mm}$ de diâmetro externo e $25 \mathrm{~mm}$ de diâmetro interno. $\mathrm{O}$ peso do material é de $350 \mathrm{~g}$.

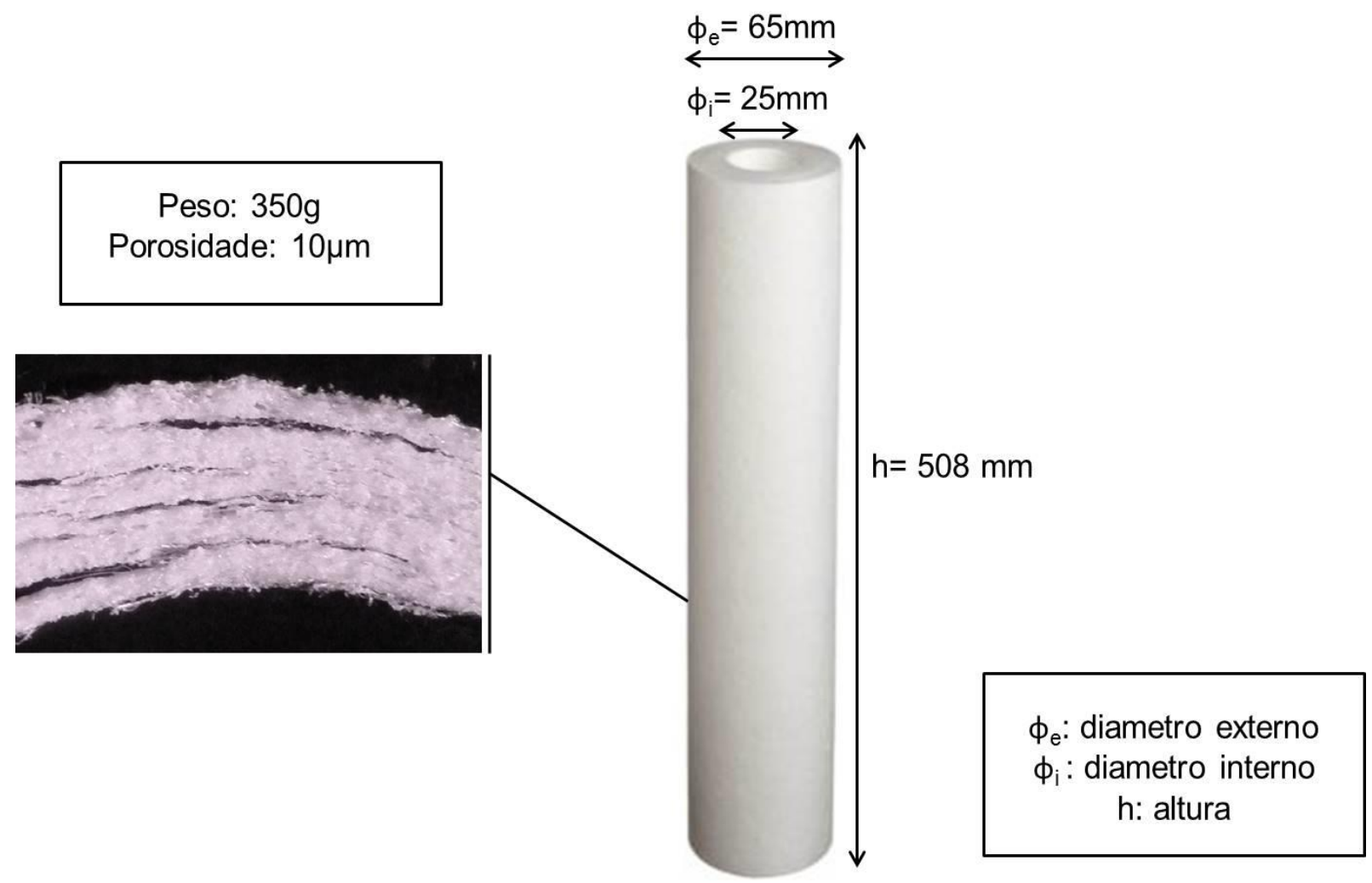

FIGURA 11: filtro Cartucho utilizado no reator IEA-R1

De acordo com Ahn et al.,2009 para a caracterização física dos filtros, recomendase a verificação do peso (densidade), porosidade e homogeneidade. E para a caracterização química, é possível utilizar o método de lixiviação, por exemplo. Para a 
caracterização final, recomenda-se o estudo da resistência à compressão e a integridade dos tambores nos quais os filtros ficarão armazenados.

A caracterização isotópica dos filtros envolve diferentes grupos de trabalho. Este trabalho traz informações sobre os radionuclídeos chave que são encontrados nas unidades filtrantes e juntamente a uma tese de doutorado que está em andamento, que tem como finalidade identificar os radionuclídeos de difícil medição (RDM), é pretendido criar o protocolo para caracterização primária desse rejeito.

Para que a aplicação do protocolo a ser desenvolvido seja aplicável a rotina não só da GRR, mas também de outros centros, busca-se desenvolver um método de caracterização através do uso de espectrometria gama. Entretanto, o uso de detectores HPGe normalmente requerem calibrações com a respectiva geometria da fonte, trazendo grande complexidade para que o método seja aplicado na rotina do setor.

$\mathrm{O}$ trabalho vem com o intuito de apresentar um método em que a proporção entre os valores de taxa de dose medidos com detectores Geiger-Müller e valores calculados de taxa de dose a partir do uso da espectrometria gama permite determinar um fator de correção para o número de fótons de cada energia e assim, determinar a atividade de cada radionuclídeo encontrado, sem que seja necessário realizar a calibração de geometria no equipamento (HPGe).

Com a verificação da homogeneidade da contaminação nas unidades filtrantes, que segundo a IAEA, pode ser dada pela avaliação de ${ }^{60} \mathrm{Co},{ }^{137} \mathrm{Cs}$ ou qualquer outro radionuclídeo em diferentes regiões do rejeito, variações de concentração dentro do intervalo de $\pm 30 \%$ em torno da média permitem classifica-lo como homogêneo, sendo possível desenvolver métodos de caracterização através de ensaios não destrutivos e garantindo maior segurança na manipulação do rejeito (IAEA, 2007). 


\section{FINALIDADE E OBJETIVOS}

A finalidade deste trabalho é criar um protocolo que possa ser aplicados na rotina da Gerência de Rejeitos Radioativos para a determinar a atividade dos filtros cartucho que são provenientes do sistema de retratamento do reator IEA-R1,

São objetivos:

- Medir a taxa de dose no ar e estimar a homogeneidade axial da contaminação no filtro;

- Medir a fluência de fótons com espectrometria gama;

- Correlacionar as proporções entre as atividades dos emissores gama presentes;

- Calcular as atividades dos filtros;

- Estabelecer os protocolos de medição, análise dos resultados e cálculo de atividade nos filtros que serão utilizados como ferramenta rotineira de avaliação;

- Verificar a possibilidade de inferir, com incerteza aceitável para os padrões internacionais estabelecidos na literatura, a atividade dos radioisótopos relevantes para a gestão dos filtros como rejeito radioativo. 


\section{MATERIAIS E MÉTODOS}

\subsection{Triagem dos filtros Cartucho}

Inicialmente, foram selecionados os filtros por meio da medição das taxas de dose com o detector 6150 AD Automess. Os filtros foram levados para uma região com baixo valor de background (BG) e foram medidos um a um, com a sonda do detector muito próxima a sua superfície. Quinze filtros com taxa de dose abaixo de $290 \mu \mathrm{Gy} / \mathrm{h}$ foram selecionados. Esse range de taxa de dose foi escolhido para otimizar a manipulação do rejeito, garantindo maior segurança seguindo o princípio ALARA (as low as reasonably achievable) durante as fases seguintes (IAEA,2006).

As unidades filtrantes selecionadas foram então acondicionadas individualmente em embalagem plástica e lacradas e identificadas por meio de números. Até a realização das etapas seguintes, os filtros ficaram acondicionados em tambores de $50 \mathrm{~L}$.

\subsection{Homogeneidade}

A homogeneidade ao longo dos filtros foi verificada para permitir modelar as unidades filtrantes como fontes cilíndricas homogêneas, excluindo a necessidade de utilizar métodos destrutivos e validando os métodos escolhidos. Para tanto, desenvolveu-se uma blindagem composta por blocos de chumbo. Um furo foi feito no bloco central da blindagem, possibilitando o encaixe do detector (FIG. 12). Foram feitas leituras a cada $3 \mathrm{~cm}$ do filtro e 3 medidas para cada fatia, totalizando dezessete fatias e 51 medidas para cada unidade filtrante. 


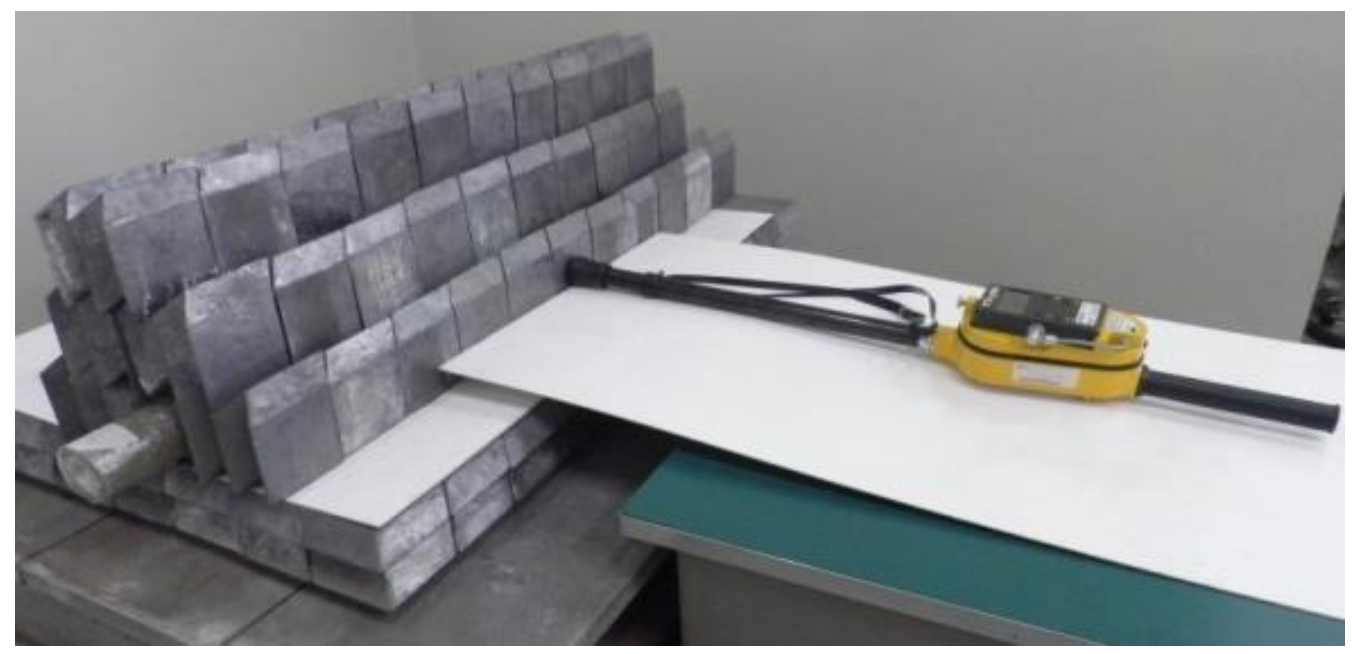

FIGURA 12- Arranjo experimental para teste de homogeneidade com detector AD 6150 Automess

\subsection{Taxa de dose medida no ar}

Utilizando o detector Radiagem 2000 e o detector 6150 AD Automess, as taxas de dose dos 15 filtros foram medidas em distâncias de $20 \mathrm{~cm}, 40 \mathrm{~cm}$ e $60 \mathrm{~cm}$ até a superfície do filtro, no plano mediano, como é apresentado na figura 13.

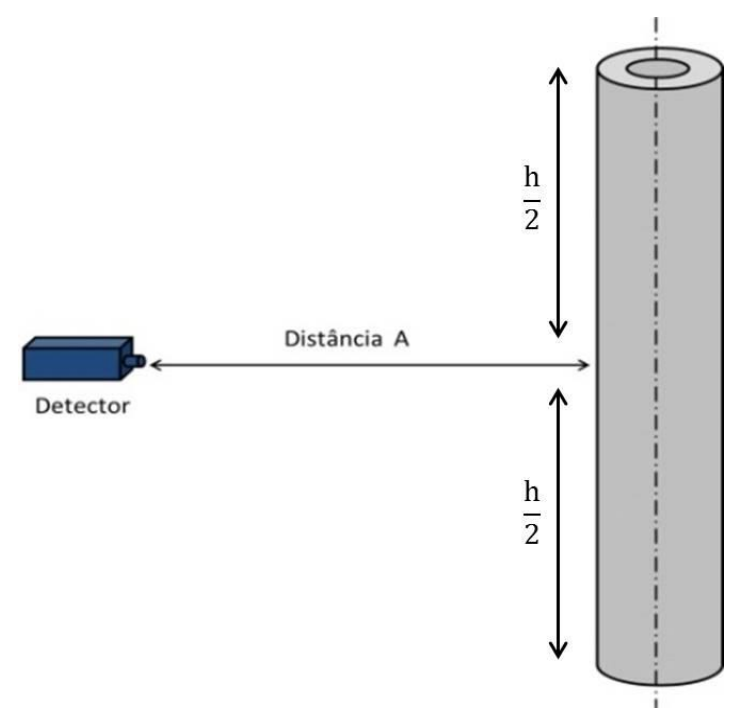

FIGURA 13- Arranjo experimental para a medição da taxa de dose 


\subsection{Espectrometria Gama}

Os filtros escolhidos foram submetidos à espectrometria gama com germânio hiperpuro (HPGe), modelo EPGC-15-190-R (FIG. 14). Este detector é coaxial tipo-P, com eficiência intrínseca de 15\% que utiliza um sistema de aquisição de dados gerenciado pelo software Genie-2000 ${ }^{\circledR}$ (Canberra, 2001). A eletrônica associada consiste de um módulo analisador multicanal Multiport II marca Canberra, uma fonte de alta tensão e um amplificador e os ajustes são feitos por software.

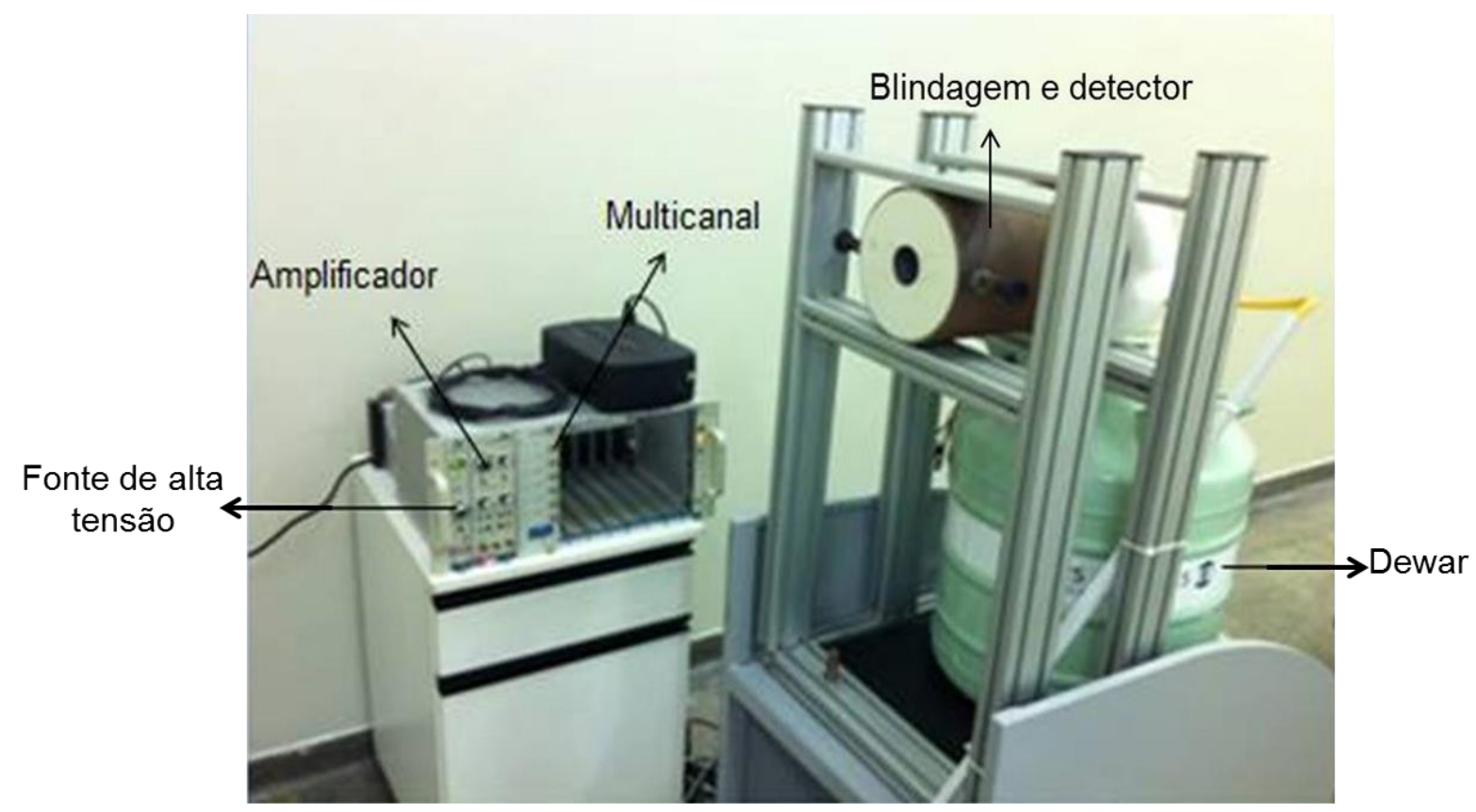

FIGURA 14- Detector EPGC-15-190-R

A curva de eficiência do equipamento é apresentada na figura 15, junto com a sua equação. 


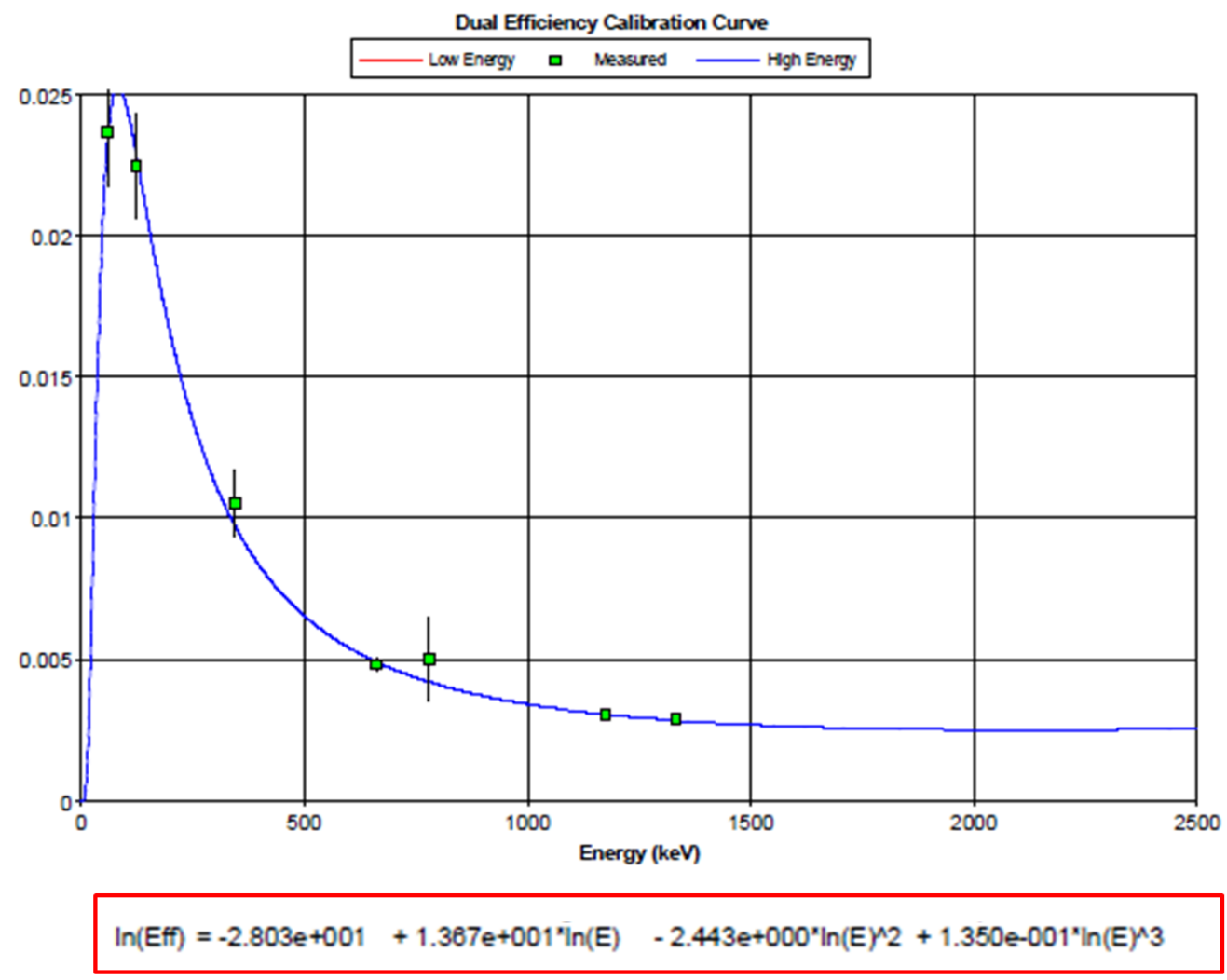

FIGURA 15- curva de eficiência do detector EPGC-15-190-R

Cada filtro foi medido por um período de 600 segundos, no arranjo experimental apresentado na figura 17. O posicionamento escolhido para o filtro com a distância de $43 \mathrm{~cm}$ permitiu a análise de todo o filtro. $O$ tempo de contagem escolhido garantiu um número de contagens suficientes para análise. Para a correção das áreas dos picos, fez-se a subtração da radiação de fundo (BG) da sala, onde o experimento foi realizado. Para tanto, utilizou-se o software Genie-2000 ${ }^{\circledR}$ (FIG. 16).

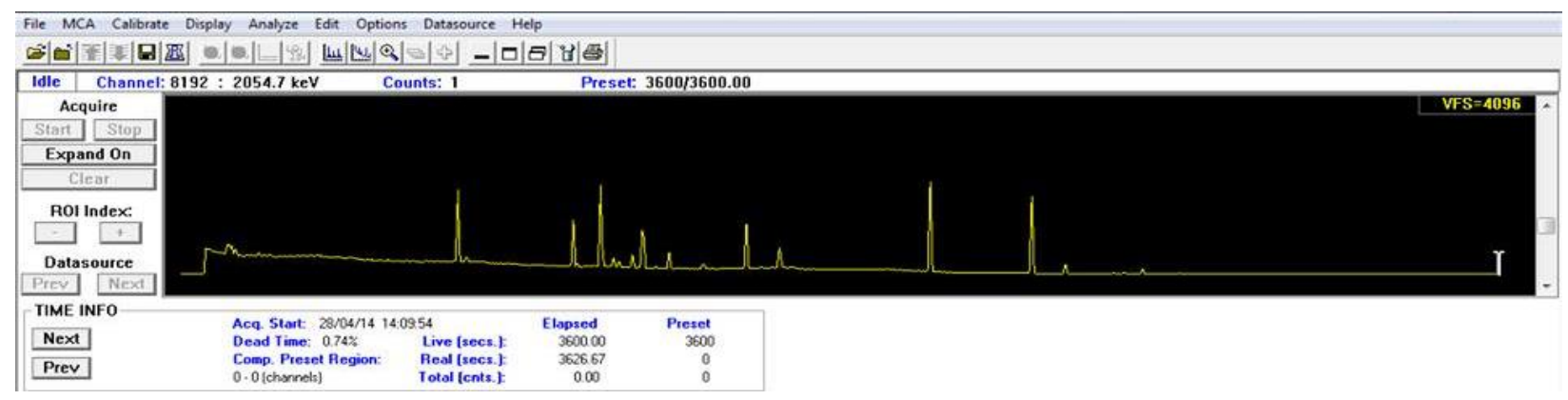

FIGURA 16- Espectro gerado pelo software Genie-2000 


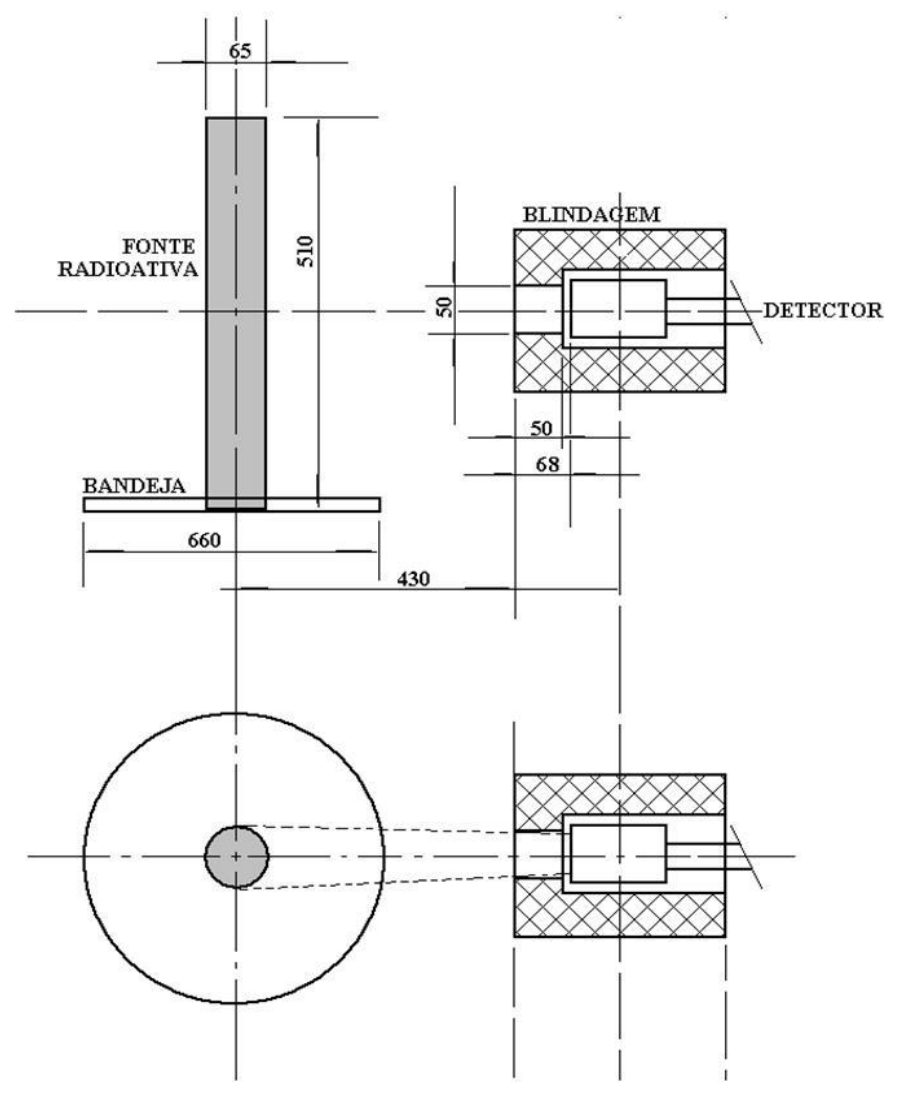

FIGURA 17- Arranjo experimental utilizado no HPGe (distâncias em mm)

Por meio dos resultados da espectrometria, foi possível identificar os emissores gama presentes nas unidades filtrantes contaminadas e calcular a estimativa de atividade que fornece o número de fótons. A estimativa de atividade é dada pela equação 1.

$$
A=\frac{A_{p}}{I_{\gamma \cdot \varepsilon \cdot T}}
$$

Onde:

$\mathrm{A}$ : atividade dada em $\mathrm{Bq}$

$A_{p}$ : representa a contagem da área de pico $\mathrm{I}_{\gamma}$ : a probabilidade de emissão do raio gama 
$\varepsilon$ : a eficiência

T: tempo de contagem

A estimativa do número de fótons emitidos por segundo é dada pela multiplicação da estimativa de atividade pelo valor da probabilidade de emissão do raio gama $\left(\mathrm{I}_{\gamma}\right)$.

\subsection{Relação Atividade- Taxa de Dose}

O método de Point Kernel descrito por Rockwell (ROCKWELL, 1956) foi utilizado para calcular as taxas de dose através da estimativa do número de fótons por segundo, obtidos anteriormente com cálculos baseados nos valores dados pela espectrometria gama.

Cada radionuclídeo contribui para o fluxo de fótons no ponto de medição, considerando-se o ponto no eixo mediano e em distâncias de $20 \mathrm{~cm}, 40 \mathrm{~cm}$ e $60 \mathrm{~cm}$ para todos os radionuclídeos identificados.

Utilizando a equação 2 é possível obter a taxa de dose no ponto $P$.

$$
\dot{D}=\sum_{i} \Phi_{i} \cdot G_{i}
$$

Onde:

$\dot{\mathrm{D}}$ : Taxa de dose no ponto $\mathrm{P}$, dado em Gy. $\mathrm{h}^{-1}$,

$\Phi_{\mathrm{i}}$ : Fluxo de fótons de energia i no ponto $\mathrm{P}$, dado $\mathrm{em} \mathrm{cm}^{-2} . \mathrm{s}^{-1}$

$\mathrm{G}_{\mathrm{i}: \text { : }}$ fator de dose por unidade de fluxo de fóton, dado em Gy. $\mathrm{h}^{-1} \cdot \mathrm{cm}^{2} . \mathrm{s}$

O fator de dose é dado pela interpolação do gráfico "Gamma Dose Rate Due To 1 photon/cm².sec" (pag. 19, ROCKWELL, 1956) para cada energia apresentada pelos radionuclídeos identificados e o fluxo de fótons foi obtido utilizando a equação 3 . 


$$
\Phi=\frac{B \cdot S_{V} \cdot R_{o}^{2}}{2(a+Z)} \cdot F(\theta, b)
$$

Onde:

B é o fator de build up

Sv é a concentração de atividade, dada em Bq.cm ${ }^{-3}$

$\mathrm{R}_{0}$ é o raio do filtro, dado em $\mathrm{cm}$;

a é a distância do ponto de medição até a superfície do filtro, dado em $\mathrm{cm}$;

$Z$ é chamada de distância de atenuação, dada em cm;

$F(\theta, b): b=\mu_{s} . Z$ em que $\mu$ é a seção de choque macroscópica na fonte, dada em $\mathrm{cm}^{-1}$. Sendo que: $\theta_{1}=\theta_{2}$, para ponto $P$ o plano médio.

Assim, a taxa de dose no ponto de medição $P$ (FIG. 18), foi calculada multiplicando-se o fluxo de fótons de cada energia $E$ pela constante Gama de energia $(G)$.

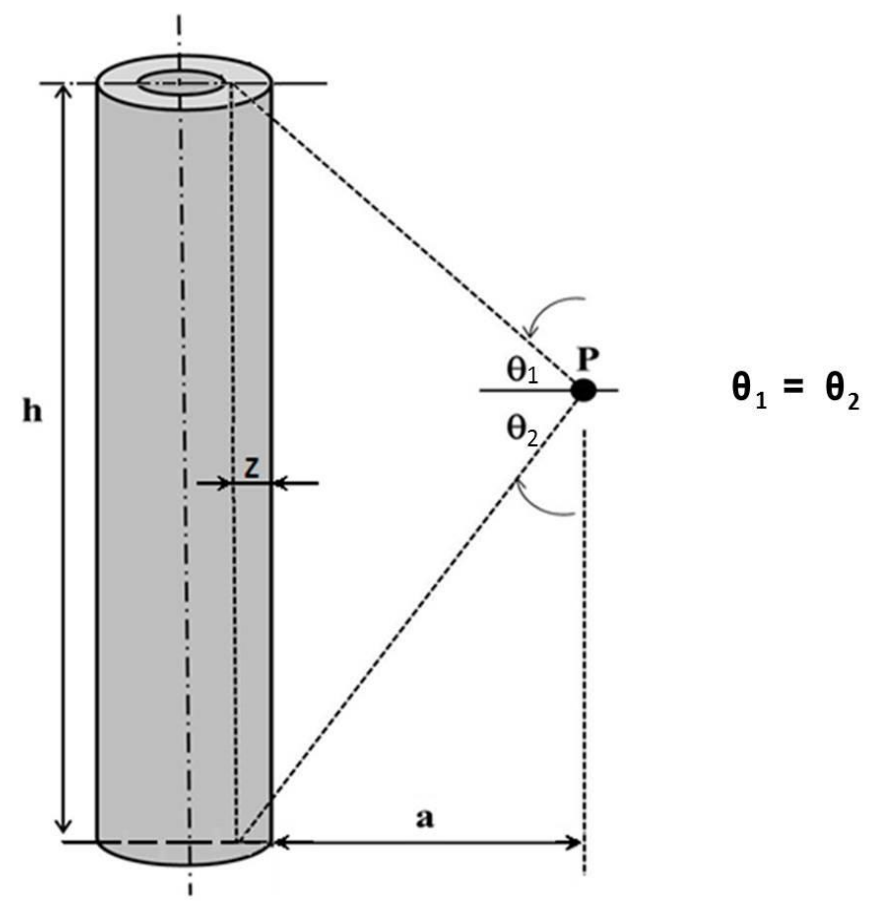

FIGURA 18- Geometria da fonte e localização do detector para determinação do fluxo de fótons 


\subsection{Características Físicas}

O filtro possuí geometria cilíndrica anular, como já citado anteriormente. No método de Point Kernel, descrito por Rockwell, essa geometria não é descrita, mas sim a geometria cilíndrica. Devido à alta complexidade para a aplicação do método em uma geometria cilíndrica anular, foi preferível aplicar o método já descrito. Para tanto, foi preciso calcular a densidade do filtro, que é composto de polipropileno termoexpandido e assumiu-se que o filtro é um cilindro completo.

Para tanto, foi necessário calcular o volume, que é dado pela equação 4.

$$
V=\left(\pi \cdot r^{2}\right) \cdot a
$$

Onde:

V é volume $\mathrm{cm}^{3}$

$\mathbf{r}^{2}$ é o raio dado em $\mathrm{cm}^{2}$

a é altura, dada em $\mathrm{cm}$

A equação 5 foi utilizada para calcular a densidade do material.

$$
d=\frac{m}{V}
$$

Onde:

d é densidade, dada em g.cm

m é a área da base dada em $\mathrm{g}$

$V$ é volume dado em $\mathrm{cm}^{3}$

A densidade calculada foi de $0,207 \mathrm{~g} / \mathrm{cm}^{3}$. 
Pela densidade calculada, entende-se que a auto absorção na unidade filtrante é baixa, ou seja, praticamente não interfere no valor do fluxo de fótons calculado através da modelagem cilíndrica.

\subsection{Taxas de dose calculadas com o MicroShield ${ }^{\circledR}$}

O MicroShield® 9.03 é um software que foi desenvolvido para a aplicação do método de Point Kernel de forma mais simplificada, já que o cálculo manual demanda de tempo, pois é composto de diversas etapas e interpolações gráficas.

Aplicando os valores obtidos com a espectrometria gama ao MicroShield® 9.03, foi possível calcular a taxa de dose para distâncias de $20 \mathrm{~cm}, 40 \mathrm{~cm}$ e $60 \mathrm{~cm}$, para cada um dos quinze filtros,

A inserção de dados no software se deu a partir da seleção da modelagem "Cylinder Volume- Side Shields" (FIG. 19), com as dimensões dos filtros, como altura da fonte $(50,8 \mathrm{~cm})$, o raio de $3,25 \mathrm{~cm}$, densidade calculada de $0,207 \mathrm{~g} / \mathrm{cm}^{3}$ e blindagem nula. Foram inseridas as energias e o número de fótons por segundo calculados para cada uma das energias, obtidos por meio da espectrometria gama.

Para corrigir o número de fótons e possibilitar estimar a atividade das unidades filtrantes, utilizou-se o cálculo de proporção entre os valores de taxa de dose medidos com os detectores manuais e aqueles obtidos pelo método de Point Kernel (descrito por Rockwell) e MicroShield ${ }^{\circledR}$.

A proporção foi feita para cada distância $(20,40$ e $60 \mathrm{~cm})$ e então, calculou-se a média aritmética dos três valores obtidos, obtendo como resultado o fator de correção para cada filtro.

Neste caso, a média aritmética foi escolhida, pois, a proporção entre os valores medidos e calculados não apresentam erros sistemáticos. 


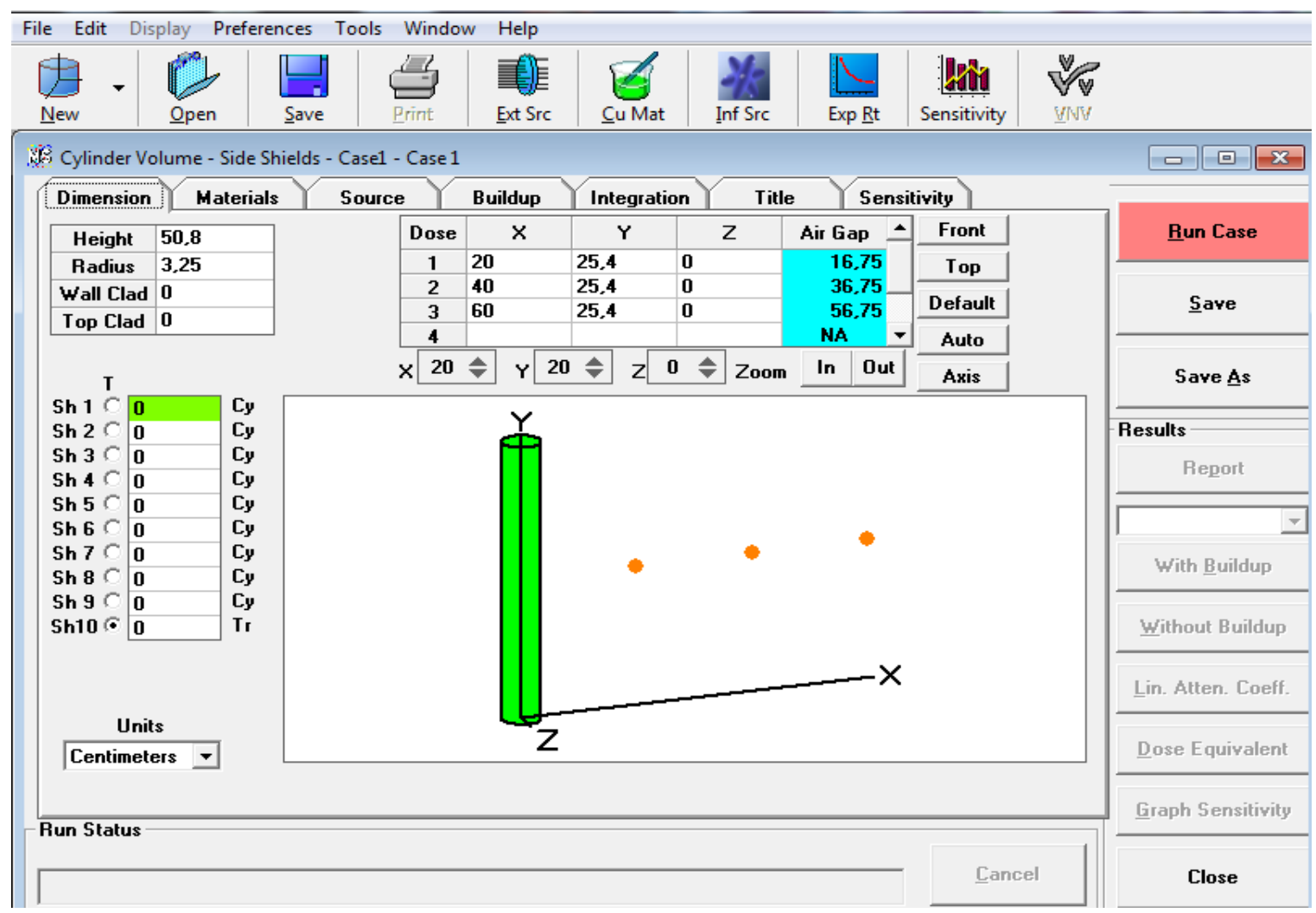

FIGURA 19- Interface do programa MicroShield ${ }^{\circledR} 9.03$

Os valores obtidos foram utilizados para corrigir o número de fótons de cada energia identificada e então os novos valores foram aplicados novamente ao MicroShield ${ }^{\boxplus}$, para a constatação de que o valor de correção foi assertivo. Desta forma, se a proporção entre as atividades dos emissores gama presentes no filtro é conhecida, também é possível estimar por meio de medições e cálculos da taxa de dose a atividade para cada um dos radionuclídeos.

A figura 20 apresenta, de forma simplificada, os passos que foram seguidos para a realização deste trabalho. 


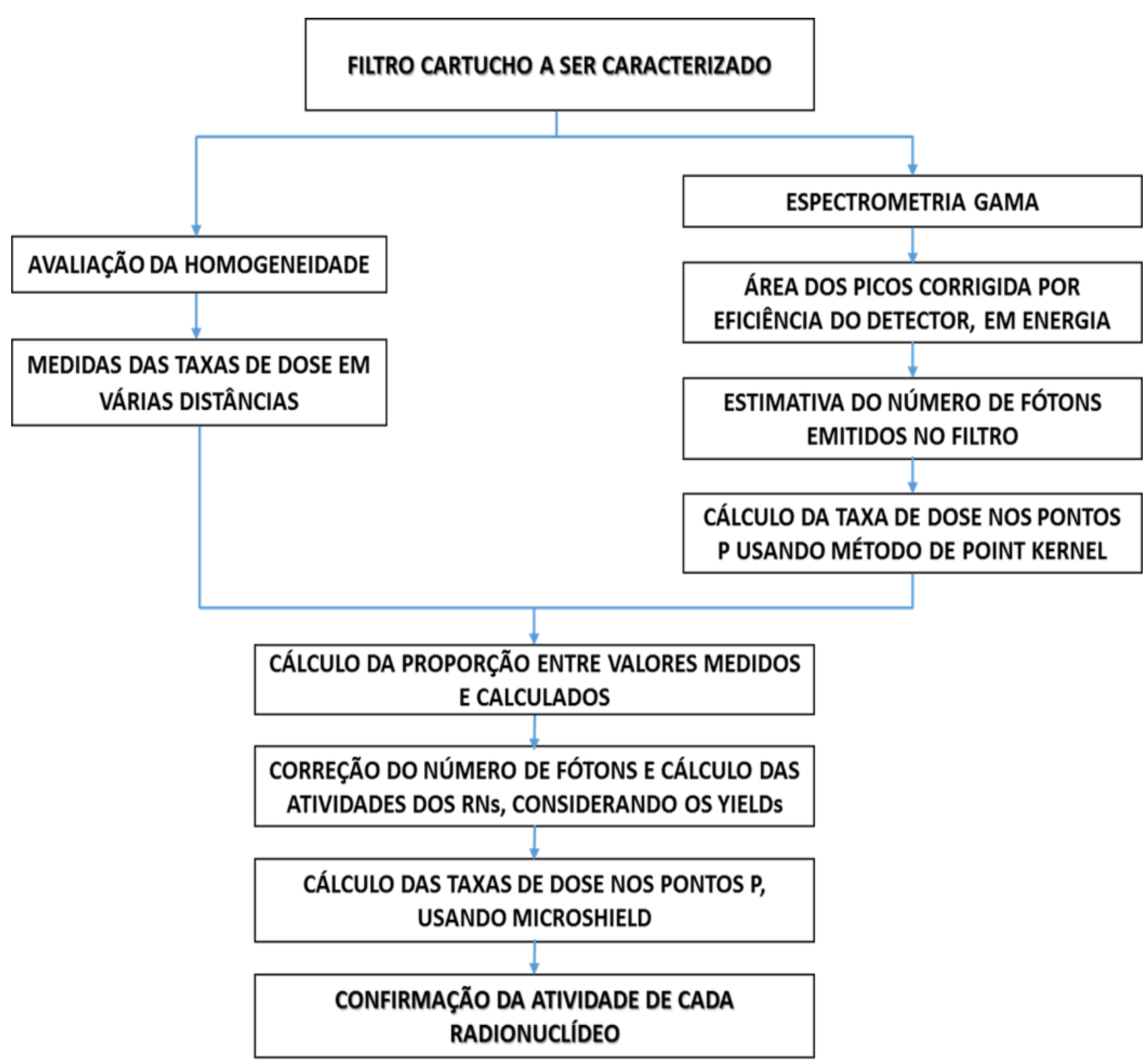

FIGURA 20: representação esquemática da metodologia utilizada na caracterização primária dos filtros 


\section{RESULTADOS E DISCUSSÃO}

\subsection{Homogeneidade}

Por meio do uso do detector Automess 6150AD (Canberra) associado ao uso da blindagem de chumbo (FIG. 12), foi possível medir a taxa de dose para cada fatia (de 3 $\mathrm{cm})$. Para avaliar se o rejeito radioativo é homogêneo, utilizou-se como limite a variação de até $30 \%$ nas medidas em torno da média, recomendado pela IAEA (IAEA, 2007).

Utilizou-se o método de desvio padrão das medidas obtidas para cada amostra, determinando assim as barras de erro. As medidas em todas as amostras forneceram resultados com variação máxima de $\pm 9,5 \%$. Deste modo, foi possível observar que apesar das flutuações nas medidas das amostras, considera-se que as unidades filtrantes são homogêneas, como pode ser visualizado nos gráficos a seguir (FIG. 2124):

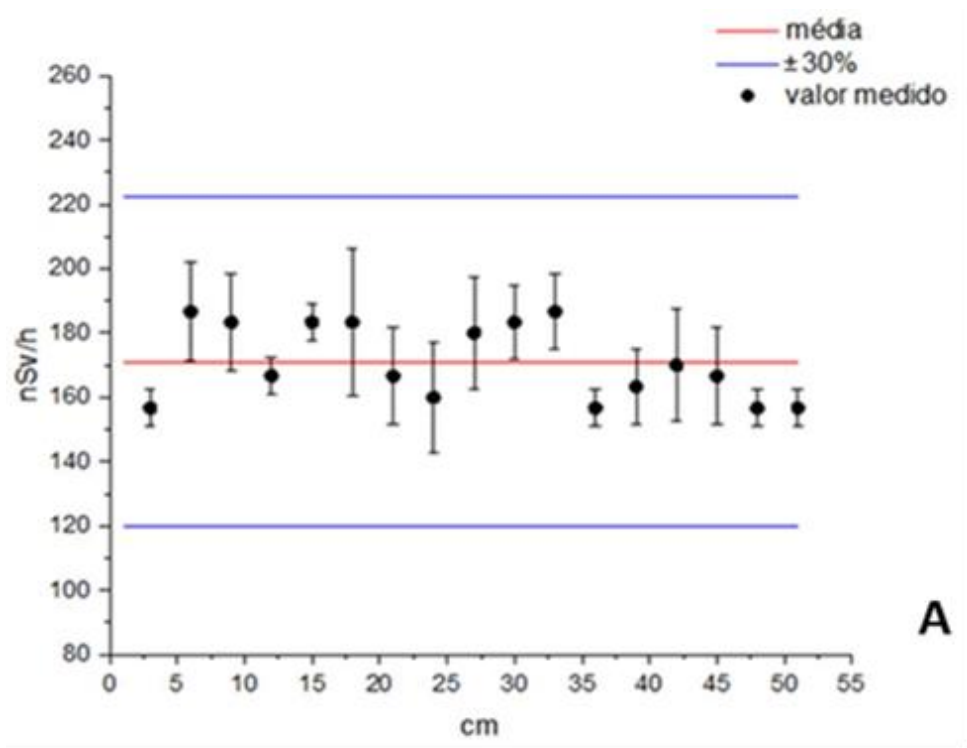

FIGURA 21- teste de homogeneidade amostra A 


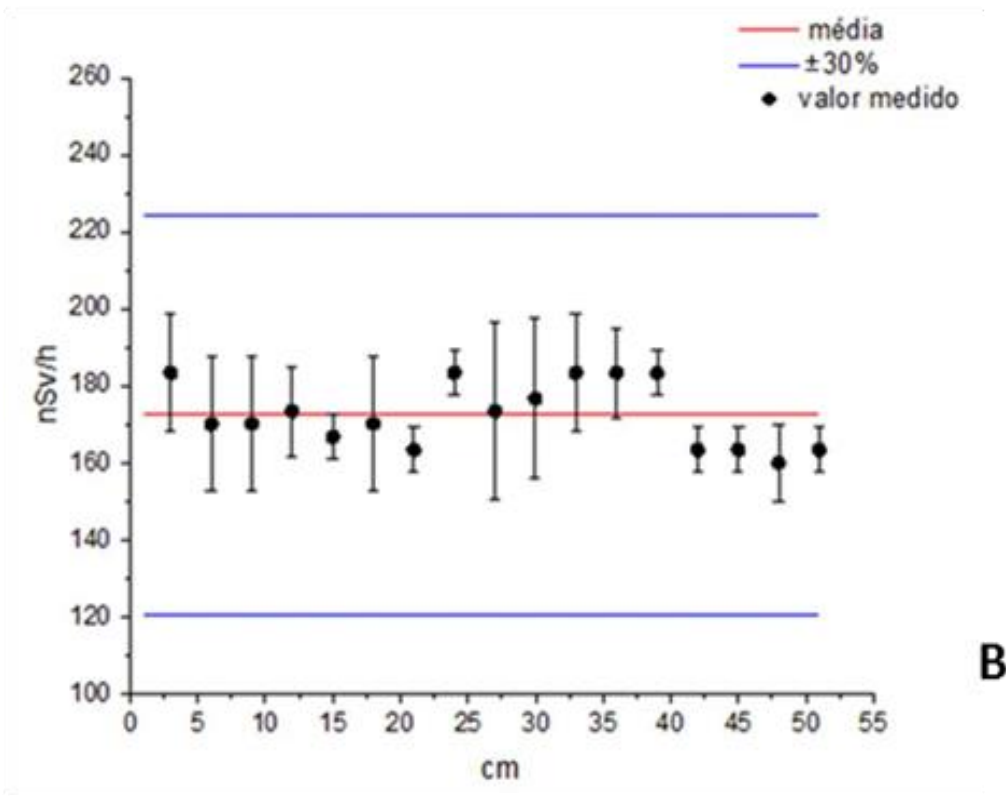

FIGURA 22- teste de homogeneidade amostra B

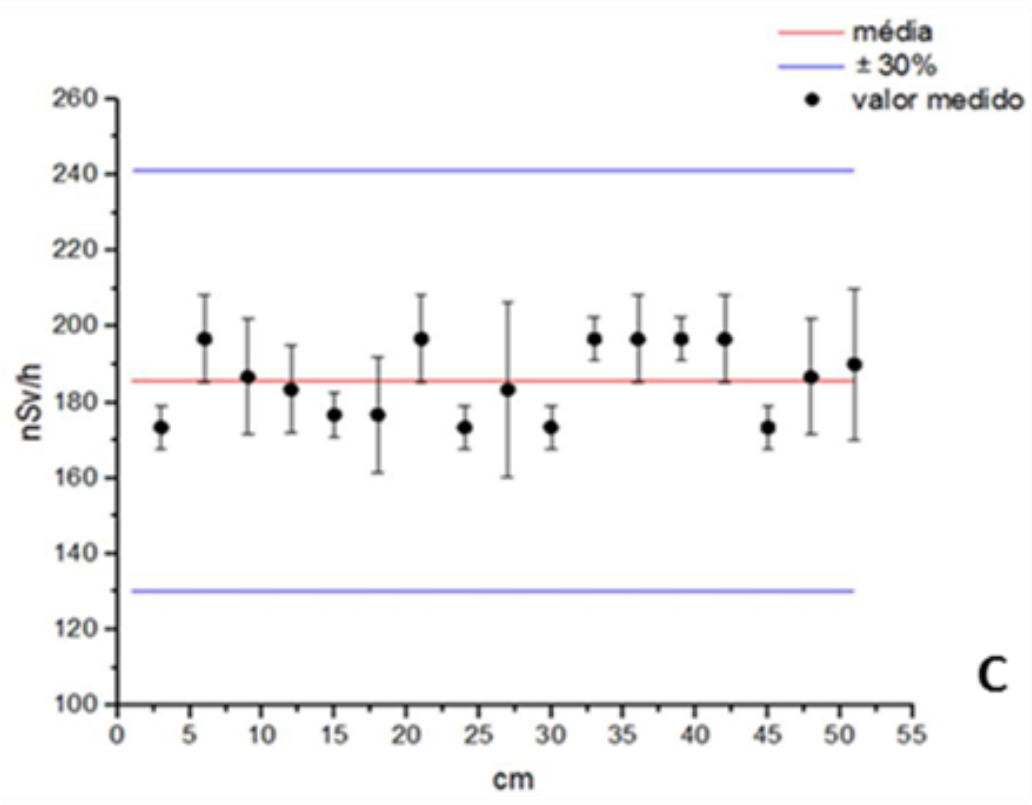

FIGURA 23- teste de homogeneidade amostra C 


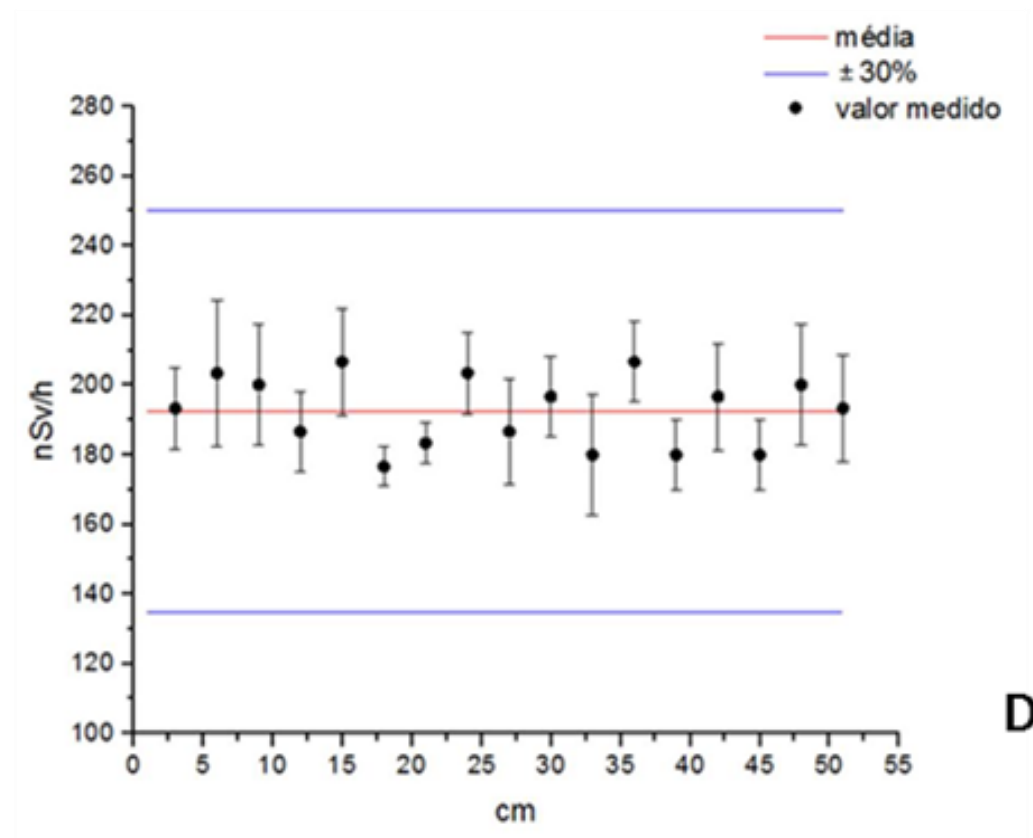

FIGURA 24- teste de homogeneidade amostra D

\subsection{Radionuclídeos identificados nos filtros}

A partir da varredura com espectrometria gama utilizando o equipamento EPGC15-190-R, foi possível identificar os mesmos emissores gama em todas as quinze unidades filtrantes avaliadas. Na tabela 6 são apresentados os radionuclídeos encontrados e suas respectivas características.

As ligas metálicas que estão ou já estiveram na piscina ou no cerne do reator IEA-R1 são:

> Aço inoxidável AISI 304 e Ni: Aço cromo-níquel, utilizado desde 1978 no revestimento interno da piscina e nos racks para armazenagem de combustíveis nucleares gastos; 
Liga de AI ASTM 1060, ASTM 6262 e ASTM 6061: utilizadas nos atuais racks para estocagem de combustíveis nucleares gastos, nas estruturas de suporte do cerne, no revestimento dos refletores de grafite e no revestimento dos combustíveis nucleares;

$>\quad$ Liga absorvedora de nêutrons: utilizada nas barras de controle. (TADDEl, 2013a)

Tabela 6- Radionuclídeos identificados nos filtros e suas características

\begin{tabular}{|c|c|c|c|c|c|}
\hline $\begin{array}{l}\text { Produto de } \\
\text { Ativação }\end{array}$ & $T_{1 / 2}$ & $\mathrm{E} \gamma(\mathrm{keV})$ & $l \gamma(\%)$ & $\begin{array}{l}\text { Reação de } \\
\text { Formação }\end{array}$ & Origem \\
\hline \multirow[t]{2}{*}{${ }^{60} \mathrm{Co}$} & \multirow[t]{2}{*}{$5,27 \mathrm{a}$} & 1173,2 & 99,9 & $\begin{array}{l}{ }^{60} \mathrm{Ni}(\mathrm{n}, \mathrm{p}){ }^{60} \mathrm{Co} \\
{ }^{61} \mathrm{Ni}(\mathrm{n}, \mathrm{np}){ }^{60} \mathrm{Co}\end{array}$ & $\begin{array}{c}\text { AISI } 304 \\
\mathrm{Ni} \\
\mathrm{AISI} 304 \\
\mathrm{Ni} \\
\end{array}$ \\
\hline & & 1332,5 & 100 & ${ }^{63} \mathrm{Cu}(\mathrm{n}, \mathrm{a}){ }^{60} \mathrm{Co}$ & $\begin{array}{l}\text { ASTM } 1060 \\
\text { ASTM } 6262 \\
\text { ASTM } 6061 \\
\end{array}$ \\
\hline${ }^{108 m} \mathrm{Ag}$ & $418 \mathrm{a}$ & $\begin{array}{l}722,9 \\
614,4 \\
433,9\end{array}$ & $\begin{array}{l}91,3 \\
91,2 \\
90,7\end{array}$ & $\begin{array}{c}{ }^{107} \mathrm{Ag}(\mathrm{n}, \mathrm{g})^{108 \mathrm{~m}} \mathrm{Ag} \\
{ }^{109} \mathrm{Ag}(\mathrm{g}, \mathrm{n}){ }^{108 \mathrm{~m}} \mathrm{Ag} \\
{ }^{109} \mathrm{Ag}(\mathrm{n}, 2 \mathrm{n}){ }^{108 \mathrm{~m}} \mathrm{Ag}\end{array}$ & $\begin{array}{l}\text { Liga } \\
\text { absorvedora } \\
\text { de nêutrons }\end{array}$ \\
\hline${ }^{110 \mathrm{~m}} \mathrm{Ag}$ & $249,9 d$ & $\begin{array}{c}657,7 \\
884,7 \\
937,5 \\
1384,3\end{array}$ & $\begin{array}{l}94,7 \\
72,9 \\
34,3 \\
24,3\end{array}$ & $\begin{array}{l}{ }^{109} \mathrm{Ag}(\mathrm{n}, \mathrm{g}){ }^{110 \mathrm{~m}} \mathrm{Ag} \\
{ }^{113} \mathrm{In}(\mathrm{n}, \mathrm{a})^{110 \mathrm{~m}} \mathrm{Ag} \\
{ }^{110} \mathrm{Cd}(\mathrm{n}, \mathrm{p}){ }^{110 \mathrm{~m}} \mathrm{Ag} \\
\left.{ }^{111} \mathrm{Cd}(\mathrm{n}, \mathrm{np})\right)^{110 \mathrm{~m}} \mathrm{Ag}\end{array}$ & $\begin{array}{l}\text { Liga } \\
\text { absorvedora } \\
\text { de nêutrons }\end{array}$ \\
\hline
\end{tabular}

O ${ }^{137} \mathrm{Cs}$ não foi observado em nenhum dos filtros analisados, embora seja um dos principais radionuclídeos encontrados nos rejeitos provenientes do reator IEA-R1. Isto indica que $0{ }^{137} \mathrm{Cs}$ é completamente dissolvido em água e não é detectado em qualquer precipitado, nem é absorvido pelo material particulado em suspensão na água. 


\subsection{Cálculo dos Fatores de Ajuste}

Para a situação simulada no MicroShield®, utilizou-se o método de entrada "Cylinder Volume- Side Shields". Essa modelagem foi escolhida por representar valores de taxa de dose que podem ser obtidos lateralmente a unidade filtrante.

Por meio dos valores apresentados nos gráficos a seguir (fig. 25-27), fez-se a proporção entre as taxas de dose obtidas nas três distâncias. As proporções foram feitas com os valores obtidos pelas estimativas de atividade (apêndices de 1 a 15) aplicadas ao software MicroShield ${ }^{\boxplus}$ e as medidas do detector Radiagem 2000. Essa proporção forneceu o fator de correção (TAB. 7) para cada unidade filtrante.

As figuras 25-27 mostram que existe congruência nos valores obtidos pelos métodos de Point Kernel, descrito por Rockwell e o software MicroShield $\Theta$, demonstrando que os métodos para cálculo da taxa de dose foram aplicados corretamente.
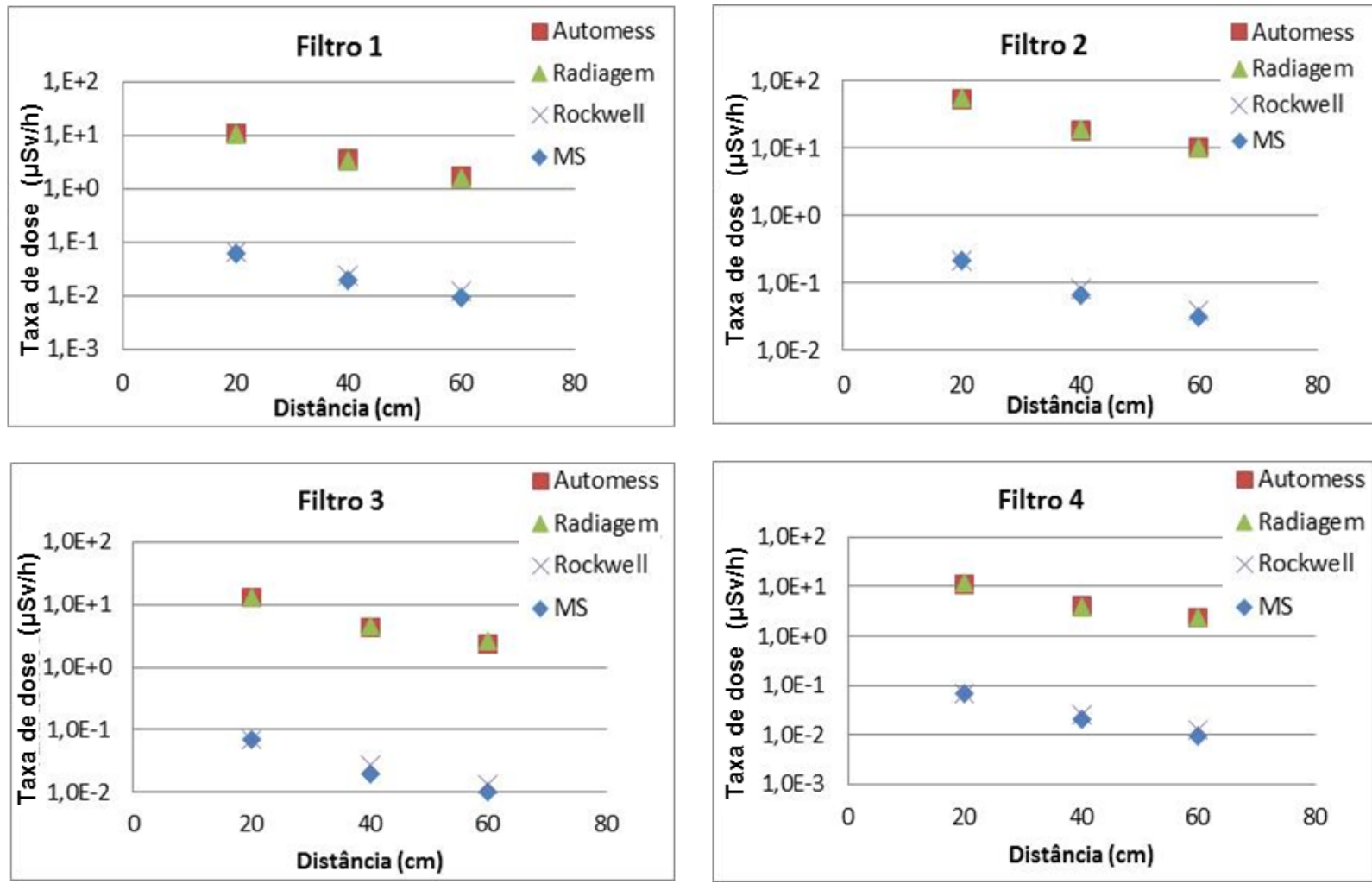

FIGURA 25: valores medidos e calculados utilizados para calcular o fator de correção, onde taxa de dose é dada em $\mu \mathrm{Sv} / \mathrm{h}$ para os filtros de 1-4. 

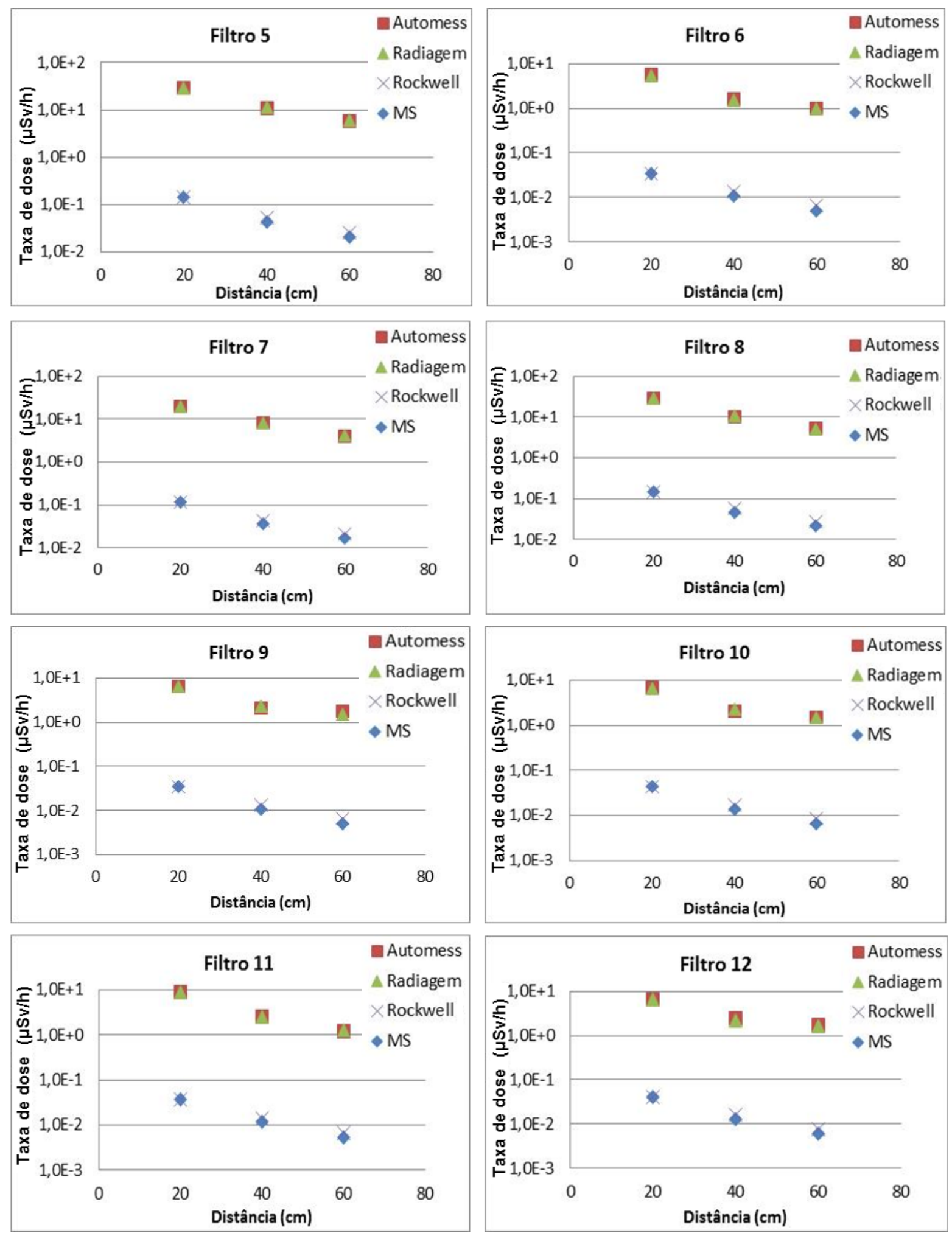

FIGURA 26: Valores medidos e calculados utilizados para calcular o fator de correção, onde taxa de dose é dada em $\mu \mathrm{Sv} / \mathrm{h}$ para os filtros de 5-12. 

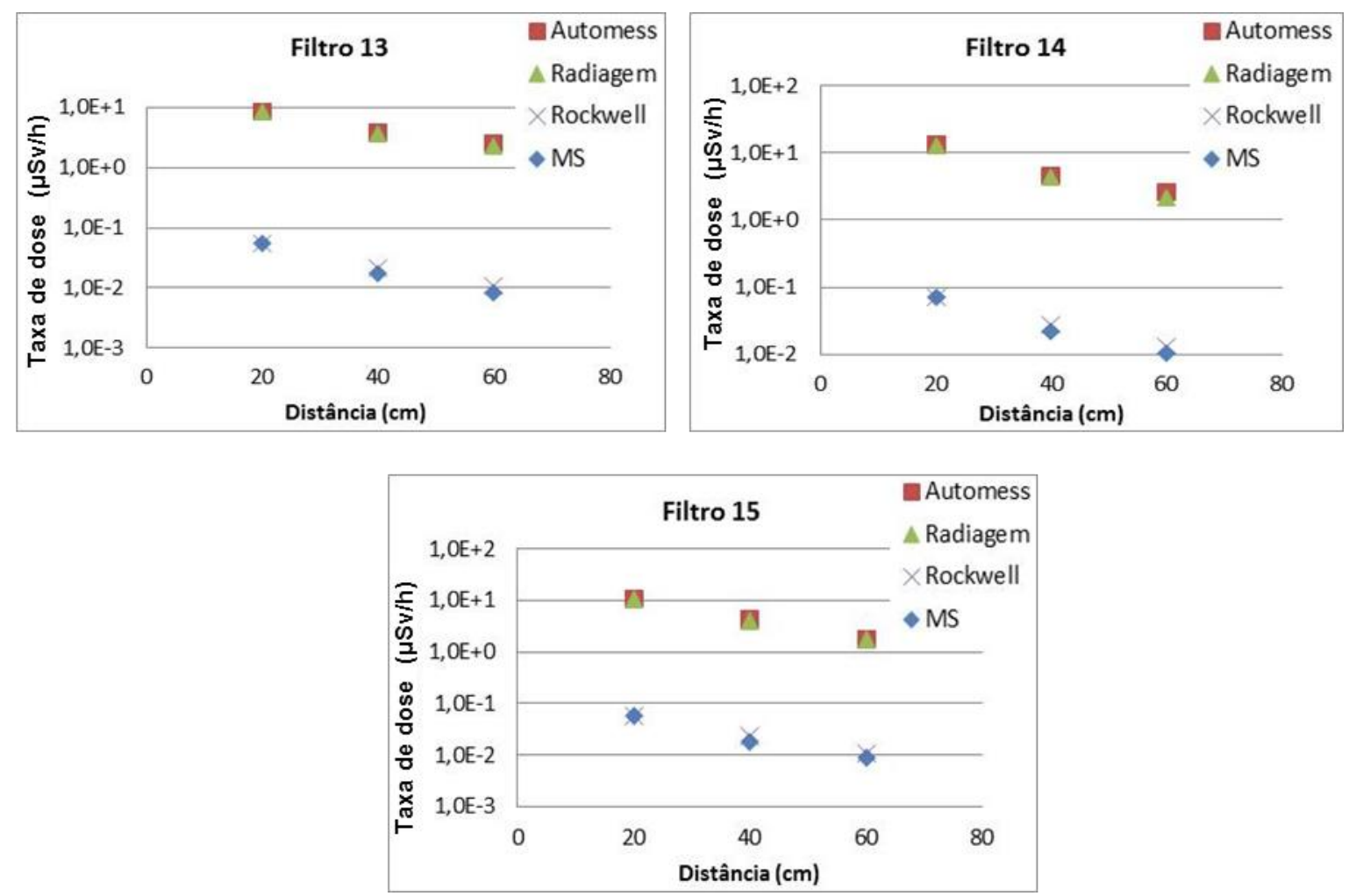

FIGURA 27- Valores medidos e calculados utilizados para calcular o fator de correção, onde taxa de dose é dada em $\mu \mathrm{Sv} / \mathrm{h}$ para os filtros de 13-15.

Tabela 7- Fatores de correção obtidos pela proporção entre os valores medidos e calculados

\begin{tabular}{cccc}
\hline Filtro & $\begin{array}{c}\text { Fator de } \\
\text { correção }\end{array}$ & Filtro & $\begin{array}{c}\text { Fator de } \\
\text { correção }\end{array}$ \\
\hline $\mathbf{1}$ & 173 & $\mathbf{9}$ & 239 \\
$\mathbf{2}$ & 291 & $\mathbf{1 0}$ & 183 \\
$\mathbf{3}$ & 223 & $\mathbf{1 1}$ & 232 \\
$\mathbf{4}$ & 201 & $\mathbf{1 2}$ & 206 \\
$\mathbf{5}$ & 251 & $\mathbf{1 3}$ & 215 \\
$\mathbf{6}$ & 169 & $\mathbf{1 4}$ & 196 \\
$\mathbf{7}$ & 212 & $\mathbf{1 5}$ & 199 \\
$\mathbf{8}$ & 218 & & \\
\hline
\end{tabular}


Nessa primeira etapa, foram utilizados dois detectores diferentes e dois métodos de cálculo de taxa de dose de modo que é possível reconhecer que não há necessidade da utilização de um detector específico ou ainda obrigatoriedade no uso do software, apesar de este otimizar o processo de cálculo de taxa de dose.

\subsection{Atividades corrigidas}

Após a correção dos valores dos fótons com os fatores obtidos anteriormente, foi possível calcular a atividade para cada unidade filtrante (tab. 8). A atividade total para todo os filtros estão na ordem de MBq.

Tabela 8- Valores de atividade total corrigidos dos filtros e a contribuição dos radionuclídeos identificados

\begin{tabular}{|c|c|c|c|c|}
\hline$n^{\circ}$ filtro & $\begin{array}{l}\text { Atividade } \\
{ }^{60} \mathrm{Co}(\mathrm{Bq})\end{array}$ & $\begin{array}{c}\text { Atividade }{ }^{108 m} \mathrm{Ag} \\
(\mathrm{Bq})\end{array}$ & $\begin{array}{c}\text { Atividade }{ }^{110 \mathrm{~m}} \mathrm{Ag} \\
(\mathrm{Bq})\end{array}$ & $\begin{array}{c}\text { Atividade Total } \\
(\mathrm{Bq})\end{array}$ \\
\hline 1 & $7,5 E+05$ & $1,8 E+05$ & $9,9 E+05$ & $1,9 \mathrm{E}+06$ \\
\hline 2 & $2,9 E+06$ & $2,1 E+05$ & $7,8 \mathrm{E}+06$ & $1,1 \mathrm{E}+07$ \\
\hline 3 & $1,1 E+06$ & $2,5 E+05$ & $1,4 \mathrm{E}+06$ & $2,8 E+06$ \\
\hline 4 & $9,0 \mathrm{E}+05$ & $2,2 \mathrm{E}+05$ & $1,2 \mathrm{E}+06$ & $2,3 E+06$ \\
\hline 6 & $6,1 E+05$ & $1,8 \mathrm{E}+05$ & $3,0 E+05$ & $1,1 \mathrm{E}+06$ \\
\hline 7 & $9,9 E+05$ & $1,0 \mathrm{E}+05$ & $3,0 E+06$ & $4,1 E+06$ \\
\hline 8 & $1,3 E+06$ & $1,3 E+05$ & $4,1 E+06$ & $5,5 E+06$ \\
\hline 9 & $8,7 E+05$ & $2,6 \mathrm{E}+05$ & $4,7 E+05$ & $1,6 \mathrm{E}+06$ \\
\hline 10 & $7,8 \mathrm{E}+05$ & $1,9 \mathrm{E}+05$ & $5,2 E+05$ & $1,5 E+06$ \\
\hline 11 & $8,8 E+05$ & $2,1 E+05$ & $6,4 \mathrm{E}+05$ & $1,7 E+06$ \\
\hline 12 & $7,9 E+05$ & $1,9 E+05$ & $5,3 E+05$ & $1,5 E+06$ \\
\hline 13 & $8,7 E+05$ & $2,4 \mathrm{E}+05$ & $1,0 \mathrm{E}+06$ & $2,2 E+06$ \\
\hline 14 & $9,5 \mathrm{E}+05$ & $2,7 E+05$ & $1,2 \mathrm{E}+06$ & $2,5 E+06$ \\
\hline 15 & $8,1 \mathrm{E}+05$ & $2,5 \mathrm{E}+05$ & $1,0 \mathrm{E}+06$ & $2,1 E+06$ \\
\hline
\end{tabular}


Em caráter confirmatório, utilizou-se o MicroShield® novamente, com a mesma modelagem, mas inserindo o valor médio de atividade em Becquerel (Bq) para os radionuclídeos identificados, sendo estes ${ }^{108 \mathrm{~m}} \mathrm{Ag},{ }^{110 \mathrm{~m}} \mathrm{Ag} \mathrm{e}{ }^{60} \mathrm{Co}$. Como resultado, obtivemos as taxas de dose que são apresentadas nas figuras 28-30. Ao observar tais gráficos, nota-se que as taxas de dose, medidas e calculadas, são congruentes entre si, mostrando que os fatores de correção utilizados e a atividade calculada estão corretos.
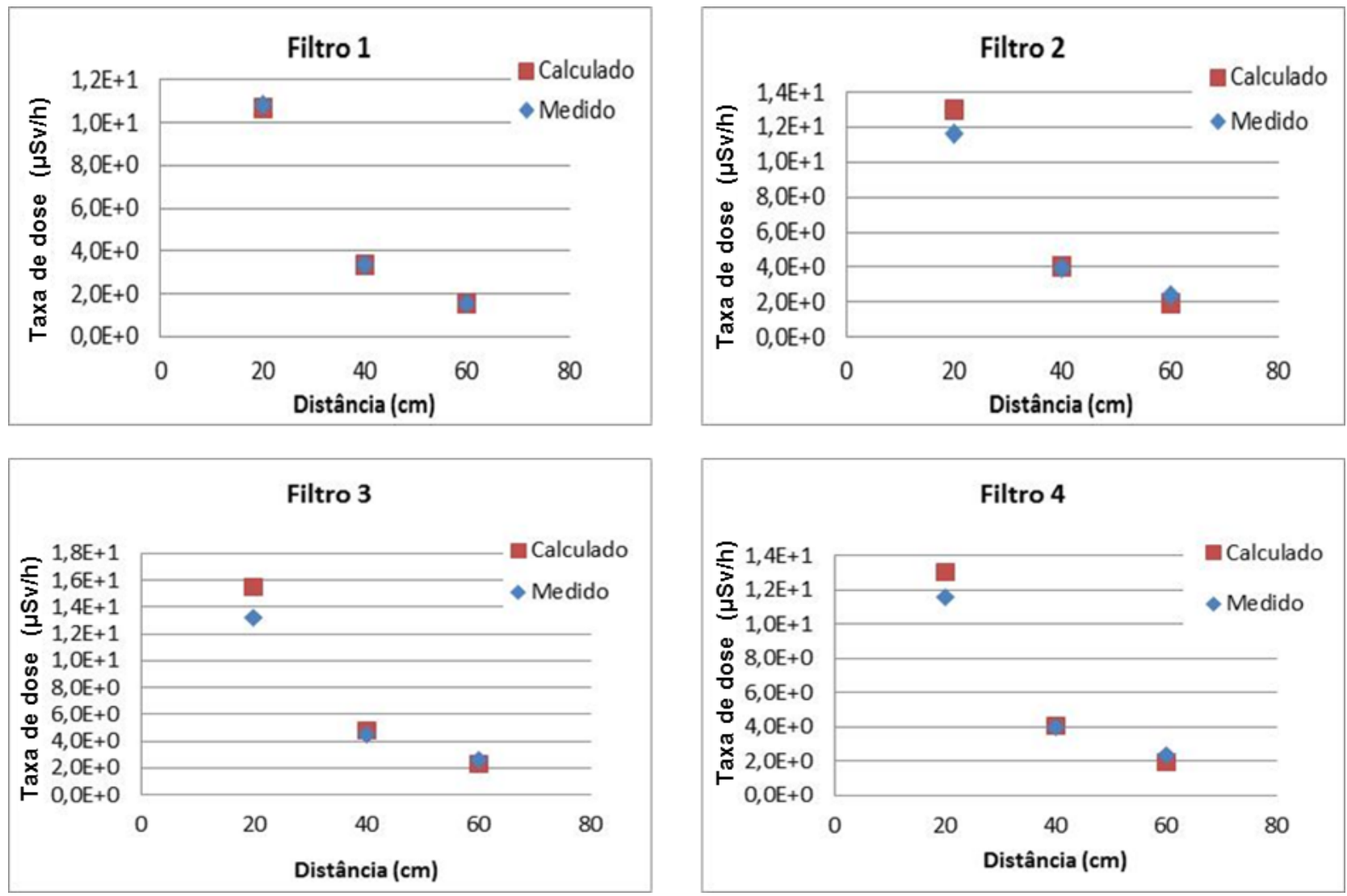

FIGURA 28: Taxas de dose medidas e taxas de dose calculadas, em $\mu \mathrm{Sv} / \mathrm{h}$ utilizando a atividade dos radionuclídeos após aplicar o fator de correção para os filtros de 1-4. 

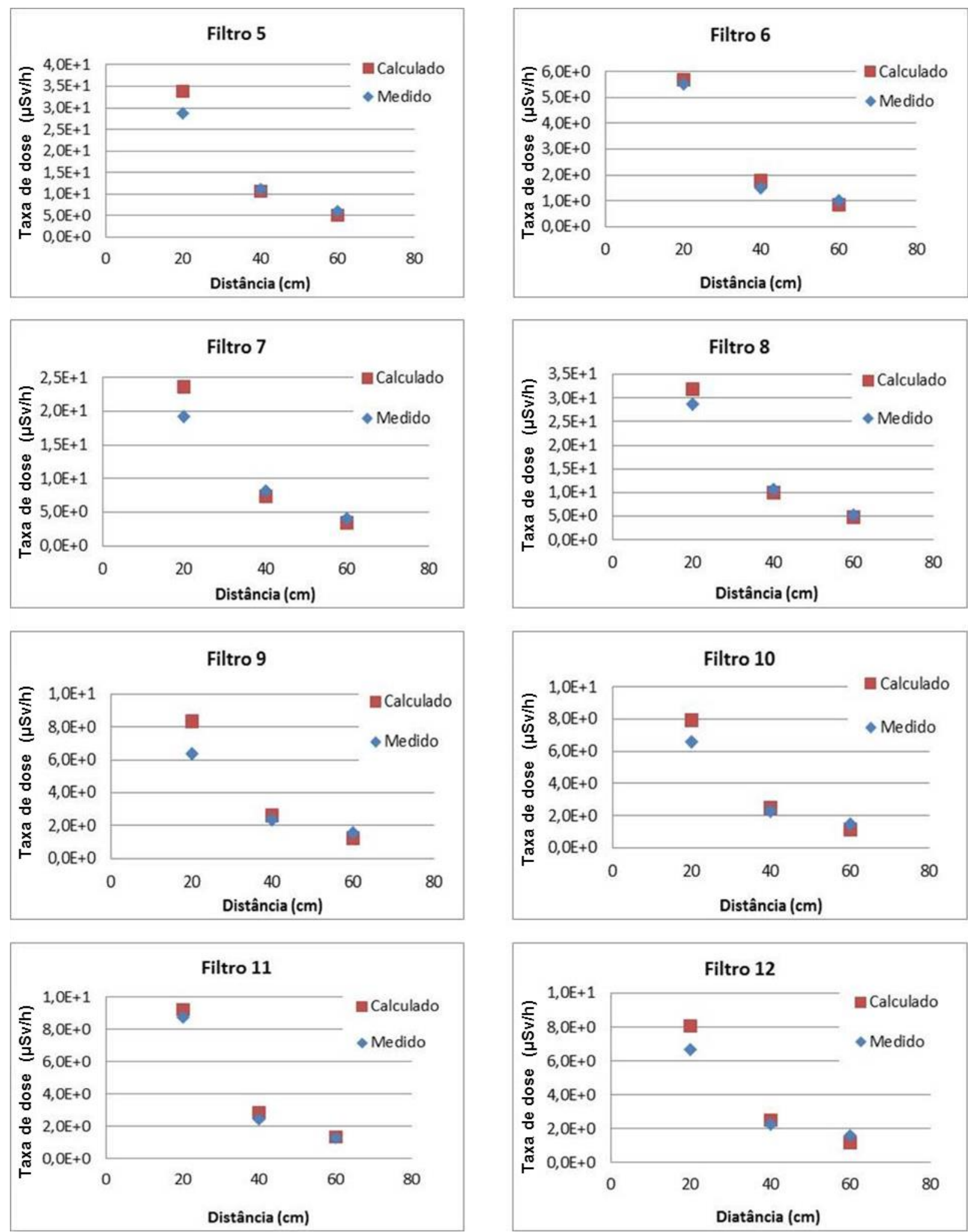

FIGURA 29: Taxas de dose medidas e taxas de dose calculadas, em $\mu \mathrm{Sv} / \mathrm{h}$ utilizando a atividade dos radionuclídeos após aplicar o fator de correção para os filtros de 5-12. 

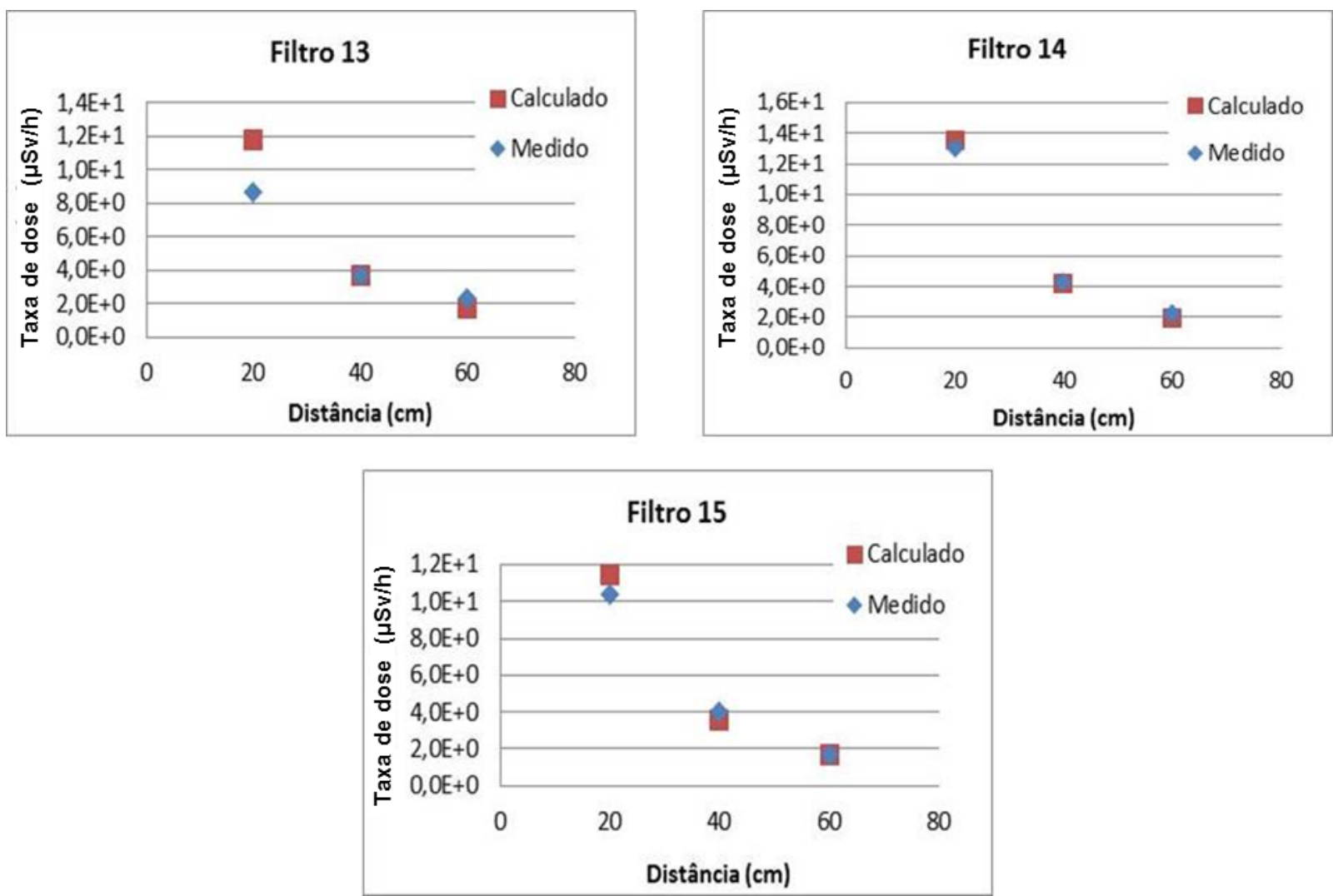

FIGURA 30: Taxas de dose medidas e taxas de dose calculadas, em $\mu \mathrm{Sv} / \mathrm{h}$ utilizando a atividade dos radionuclídeos após aplicar o fator de correção para os filtros de 13-15.

É possível notar que em alguns casos, na distância de $20 \mathrm{~cm}$, os valores medidos são ligeiramente menores que os valores calculados. Essa diferença pode ser dada por interferências no ambiente no qual os filtros foram submetidos à avaliação ou ainda pelo ângulo de leitura do detector.

Não foi possível estimar as incertezas nos resultados finais, visto que o processo para alcançar tais resultados passou por diversas etapas, como cálculos manuais e uso do software MicroShield ${ }^{\circledR}$, que não fornece dados de erro nos relatórios gerados. Entretanto, os resultados obtidos se mostraram satisfatórios quando submetidos à avaliação apresentada na figura 28-30. 


\subsection{Protocolo final}

\section{MÉTODOS RADIOMÉTRICOS PARA A CARACTERIZAÇÃO DE REJEITOS RADIOATIVOS}

O método aqui descrito pode ser empregado na determinação da atividade dos filtros cartucho originários do sistema de retratamento da água do reator IEA-R1.

\section{Equipamentos:}

Detector Geiger Müller

Espectrômetro gama

Balança

\section{Utensílios:}

Garra auxiliar

Saco plástico

Plástico filme

Luvas

Fita métrica

\section{Software:}

Microshield

Gennie 2000

Procedimento:

1. Separe sacos plásticos devidamente identificados por números e/ou letras, com data e anote o peso dos sacos plásticos;

2. Abra o tambor onde os filtros estão acondicionados em um local adequado, preferencialmente com baixo background $(\mathrm{BG})$, facilitando as etapas seguintes;

3. Caso necessite apoiar os filtros para que sejam ensacados, forre a bancada com plástico filme;

4. Retire cada filtro do tambor com auxílio da garra e acondicione um a um nos sacos plásticos devidamente identificados lacrando-os em seguida; 
5. Pese cada filtro e desconte o peso do saco plástico onde o filtro está acondicionado;

6. Meça a altura do filtro e o raio com a fita métrica;

7. Utilizando o detector Geiger Müller, faça medidas da taxa de dose em diferentes distâncias. Recomenda-se distâncias de $20 \mathrm{~cm}, 40 \mathrm{~cm}$ e $60 \mathrm{~cm}$;

8. Faça a espectrometria gama do filtro inteiro, lembrando-se de escolher uma distância que permita verificar o material todo. A espectrometria gama deve ser feita com o tempo de aproximadamente 600 segundos;

9. Após realizar as etapas citadas, mantenha os filtros ensacados individualmente e acondicione-os novamente no tambor;

10. Utilizando o software Genie 2000 abra o espectro gerado pela espectrometria gama e origine o relatório que fornecerá as áreas dos picos e suas respectivas energias;

11. Em uma planilha eletrônica armazene os dados obtidos no passo anterior;

12. Calcule a eficiência para cada energia utilizando a equação fornecida pelo equipamento;

13. Identifique a probabilidade (yield) de emissão de cada energia;

14. Calcule a estimativa de atividade utilizando a equação:

$$
A=\frac{A_{p}}{I_{y} \cdot \varepsilon \cdot T}
$$

15. Calcule o número de fótons multiplicando 0 valor da atividade pela probabilidade de emissão;

16. Siga as instruções do tópico "MicroShield" listadas no final do protocolo;

17. Após calcular os valores de taxa de dose, faça a proporção entre os valores medidos e calculados para as três distâncias escolhidas e então faça a média aritmética desses valores. Isso fornecerá um valor de ajuste;

18. Utilize os valores de ajuste para corrigir o número de fótons e os valores de atividade. Basta multiplicar esses valores pelo fator de ajuste obtido;

19. Após corrigir os valores de atividade, faça a média desses valores para cada radionuclídeo identificado no rejeito, de modo que será possível saber a 
contribuição de cada um deles individualmente. Para saber a atividade total, some a contribuição de cada um;

20. Confirme os valores de atividade calculados. Para isso utilize novamente o MicroShield e compare as novas taxas de dose com as taxas de dose obtidas com os detectores portáteis.

\section{MicroShield}

a) Selecione a geometria;

b) Insira as informações: altura e raio, distâncias do ponto de medição e altura dos pontos;

c) Na aba "materials" selecione "custom materials", "ordinary" pressione "ok" e na primeira coluna insira a densidade do material;

d) Na aba "source" insira os valores dos fótons manualmente para cada energia identificada ou ainda selecione os radionuclídeos de interesse no item "nuclides" e insira os valores da média da atividade em Bq de cada um;

e) Clique na aba "buildup" e pressione "run case";

f) Será gerado um relatório com informações sobre a fonte e as taxas de dose nas distâncias informadas no passo $b$. 


\section{CONCLUSÃO}

A finalidade deste trabalho foi contribuir para o processo de caracterização primária de unidades filtrantes provenientes do reator IEA-R1, por meio de medidas de taxa de dose com detectores manuais, espectrometria com HPGe, cálculos manuais e utilização do software MicroShield ${ }^{\circledR}$, possibilitando deste modo estimar a atividade desses rejeitos.

Detectores HPGe necessitam de calibração para serem utilizados. Porém, este trabalho demonstrou que para a caracterização dos filtros utilizando os valores de proporção entre os radionuclídeos encontrados, é possível que o método seja empregado sem que necessariamente o detector esteja calibrado para a geometria do rejeito estudado.

Por meio dos testes realizados foi constatada a distribuição homogênea de contaminação nos filtros cartucho.

Observou-se também que o ${ }^{137} \mathrm{Cs}$ não foi identificado nos filtros cartucho como era esperado inicialmente. Esse fato pode ser dado pela diluição total desse radionuclídeo na água da piscina do reator, de forma que o material particulado em suspensão na água que chega até o filtro cartucho não o retém.

Com os fatores de correção obtidos através do cálculo de proporção foi possível determinar as concentrações de atividade dos radionuclídeos presentes no rejeito.

Os resultados obtidos com o método de point kernel (cálculo manual e com o software MicroShield ${ }^{\circledR}$ ) foram considerados satisfatórios na primeira e segunda etapa. As taxas de dose calculadas por meio do software com o uso dos valores de atividade em $\mathrm{Bq}$ indicam grande congruência no resultado final, quando comparadas aos valores medidos por meio dos gráficos, indicando que é possível utilizar o método desenvolvido no presente trabalho para a caracterização de rejeitos de forma rápida na rotina operacional do programa de gerenciamento de rejeitos radioativos. 
APÊNDICES: PLANILHA DE CÁLCULO DA ATIVIDADE CORRIGIDA FILTROS DE 1 A 15 
FILTRO 1

\begin{tabular}{|c|c|c|c|c|c|c|c|c|c|}
\hline Energia & Radionuclídeos & $\begin{array}{c}\text { Área do } \\
\text { pico }\end{array}$ & Yield & $\begin{array}{l}\text { Parâmetro } \\
\text { de eficiência }\end{array}$ & Eficiência & $\begin{array}{c}\text { Estimativa } \\
\text { Atividade (Bq) }\end{array}$ & $\begin{array}{l}\text { Taxa de } \\
\text { emissão de } \\
\text { fótons }\left(\mathbf{s}^{-1}\right)\end{array}$ & $\begin{array}{l}\text { Correção } n^{\circ} \\
\text { fótons }\left(\mathrm{s}^{-1}\right)\end{array}$ & $\begin{array}{c}\text { Atividade } \\
\text { corrigida (Bq) }\end{array}$ \\
\hline 79,21 & $\mathrm{Ag} 108$ & $4,05 E+02$ & $6,90 \mathrm{E}-02$ & $-3,68 E+00$ & $2,52 \mathrm{E}-02$ & $3,88 \mathrm{E}+02$ & $2,67 E+01$ & $4,63 E+03$ & $6,72 E+04$ \\
\hline 433,87 & Ag108 & $5,07 E+03$ & 9,03E-01 & $-4,88 E+00$ & $7,63 \mathrm{E}-03$ & $1,23 E+03$ & $1,11 \mathrm{E}+03$ & $1,92 E+05$ & $2,13 E+05$ \\
\hline 446,7 & Ag110 & $9,76 E+02$ & $3,66 \mathrm{E}-02$ & $-4,91 E+00$ & $7,40 \mathrm{E}-03$ & $6,01 E+03$ & $2,20 \mathrm{E}+02$ & $3,80 E+04$ & $1,04 \mathrm{E}+06$ \\
\hline 614,03 & Ag108 & $3,65 E+03$ & $9,08 \mathrm{E}-01$ & $-5,24 E+00$ & $5,31 E-03$ & $1,26 E+03$ & $1,15 E+03$ & $1,98 E+05$ & $2,19 E+05$ \\
\hline 620,18 & Ag110 & $4,86 \mathrm{E}+02$ & $2,78 \mathrm{E}-02$ & $-5,25 E+00$ & $5,26 \mathrm{E}-03$ & $5,54 \mathrm{E}+03$ & $1,54 \mathrm{E}+02$ & $2,67 E+04$ & $9,61 E+05$ \\
\hline 657,50 & Ag110 & $1,67 E+04$ & $9,47 \mathrm{E}-01$ & $-5,31 E+00$ & $4,96 \mathrm{E}-03$ & $5,92 E+03$ & $5,61 E+03$ & $9,71 \mathrm{E}+05$ & $1,03 E+06$ \\
\hline 677,37 & Ag110 & $1,80 E+03$ & 1,07E-01 & $-5,34 E+00$ & $4,82 \mathrm{E}-03$ & $5,82 E+03$ & $6,22 E+02$ & $1,08 E+05$ & $1,01 E+06$ \\
\hline 686,73 & Ag110 & $1,13 E+03$ & $6,49 \mathrm{E}-02$ & $-5,35 E+00$ & $4,76 \mathrm{E}-03$ & $6,10 E+03$ & $3,96 E+02$ & $6,85 E+04$ & $1,06 E+06$ \\
\hline 706,40 & Ag110 & $2,67 E+03$ & 1,67E-01 & $-5,38 E+00$ & $4,63 \mathrm{E}-03$ & $5,76 E+03$ & $9,61 E+02$ & $1,66 \mathrm{E}+05$ & $9,98 \mathrm{E}+05$ \\
\hline 722,61 & Ag108 & $3,21 E+03$ & $9,09 \mathrm{E}-01$ & $-5,40 E+00$ & $4,53 \mathrm{E}-03$ & $1,30 \mathrm{E}+03$ & $1,18 \mathrm{E}+03$ & $2,04 \mathrm{E}+05$ & $2,25 E+05$ \\
\hline 743,90 & Ag110 & $7,34 \mathrm{E}+02$ & $4,66 \mathrm{E}-02$ & $-5,42 E+00$ & 4,41E-03 & $5,95 E+03$ & $2,77 E+02$ & $4,80 \mathrm{E}+04$ & $1,03 E+06$ \\
\hline 763,59 & Ag110 & $3,46 E+03$ & $2,24 \mathrm{E}-01$ & $-5,45 E+00$ & $4,30 \mathrm{E}-03$ & $5,98 E+03$ & $1,34 \mathrm{E}+03$ & $2,32 E+05$ & $1,04 E+06$ \\
\hline 817,65 & Ag110 & $1,08 E+03$ & $7,32 \mathrm{E}-02$ & $-5,51 E+00$ & $4,05 E-03$ & $6,08 E+03$ & $4,45 E+02$ & $7,70 E+04$ & $1,05 E+06$ \\
\hline 884,24 & Ag110 & $9,94 \mathrm{E}+03$ & $7,29 \mathrm{E}-01$ & $-5,58 E+00$ & $3,78 \mathrm{E}-03$ & $6,01 E+03$ & $4,38 E+03$ & $7,58 \mathrm{E}+05$ & $1,04 \mathrm{E}+06$ \\
\hline 937,01 & Ag110 & $4,47 E+03$ & $3,43 \mathrm{E}-01$ & $-5,62 E+00$ & $3,61 \mathrm{E}-03$ & $6,02 E+03$ & $2,07 E+03$ & $3,57 \mathrm{E}+05$ & $1,04 \mathrm{E}+06$ \\
\hline 1172,26 & Co60 & $8,07 E+03$ & 9,99E-01 & $-5,79 E+00$ & $3,07 E-03$ & $4,39 E+03$ & $4,38 E+03$ & $7,58 \mathrm{E}+05$ & $7,60 E+05$ \\
\hline 1331,41 & Co60 & $7,41 \mathrm{E}+03$ & $1,00 E+00$ & $-5,86 E+00$ & $2,85 \mathrm{E}-03$ & $4,33 E+03$ & $4,33 E+03$ & $7,49 E+05$ & $7,51 \mathrm{E}+05$ \\
\hline 1383,17 & Ag110 & $2,26 E+03$ & $2,43 \mathrm{E}-01$ & $-5,88 E+00$ & $2,80 \mathrm{E}-03$ & $5,54 \mathrm{E}+03$ & $1,35 E+03$ & $2,33 E+05$ & $9,61 E+05$ \\
\hline 1474,51 & Ag110 & $3,23 E+02$ & 3,99E-02 & $-5,91 E+00$ & $2,72 \mathrm{E}-03$ & $4,96 E+03$ & $1,98 \mathrm{E}+02$ & $3,43 E+04$ & $8,61 \mathrm{E}+05$ \\
\hline 1503,81 & Ag110 & $1,10 E+03$ & 1,31E-01 & $-5,92 \mathrm{E}+00$ & $2,70 \mathrm{E}-03$ & $5,19 E+03$ & $6,80 \mathrm{E}+02$ & $1,18 \mathrm{E}+05$ & $9,00 E+05$ \\
\hline 1560,89 & Ag110 & $9,73 E+01$ & $1,18 \mathrm{E}-02$ & $-5,93 E+00$ & $2,66 \mathrm{E}-03$ & $5,17 E+03$ & $6,10 E+01$ & $1,06 E+04$ & $8,96 \mathrm{E}+05$ \\
\hline
\end{tabular}


FILTRO 2

\begin{tabular}{|c|c|c|c|c|c|c|c|c|c|}
\hline Energia & Radionuclídeos & $\begin{array}{c}\text { Área do } \\
\text { pico }\end{array}$ & Yield & $\begin{array}{l}\text { Parâmetro } \\
\text { de eficiência }\end{array}$ & Eficiência & $\begin{array}{c}\text { Estimativa } \\
\text { Atividade (Bq) }\end{array}$ & $\begin{array}{c}\text { Taxa de } \\
\text { emissão de } \\
\text { fótons }\left(\mathrm{s}^{-1}\right)\end{array}$ & $\begin{array}{l}\text { Correção } n^{\circ} \\
\text { fótons }\left(s^{-1}\right)\end{array}$ & $\begin{array}{c}\text { Atividade } \\
\text { corrigida }(\mathrm{Bq})\end{array}$ \\
\hline 434,13 & Ag108 & $2,77 E+03$ & $9,03 E-01$ & $-4,88 \mathrm{E}+00$ & $7,63 \mathrm{E}-03$ & $6,70 \mathrm{E}+02$ & $6,05 E+02$ & $1,77 E+05$ & $1,96 \mathrm{E}+05$ \\
\hline 446,92 & Ag110 & $3,40 E+03$ & $3,66 \mathrm{E}-02$ & $-4,91 E+00$ & $7,39 E-03$ & $2,09 E+04$ & $7,66 \mathrm{E}+02$ & $2,24 \mathrm{E}+05$ & $6,11 E+06$ \\
\hline 614,31 & Ag108 & $2,08 E+03$ & $9,08 \mathrm{E}-01$ & $-5,24 \mathrm{E}+00$ & $5,31 E-03$ & $7,19 E+02$ & $6,53 \mathrm{E}+02$ & $1,91 \mathrm{E}+05$ & $2,10 E+05$ \\
\hline 620,47 & $\mathrm{Ag} 110$ & $1,72 E+03$ & $2,78 \mathrm{E}-02$ & $-5,25 E+00$ & $5,26 \mathrm{E}-03$ & $1,96 E+04$ & $5,45 E+02$ & $1,59 E+05$ & $5,73 E+06$ \\
\hline 657,77 & Ag110 & $6,84 \mathrm{E}+04$ & $9,47 \mathrm{E}-01$ & $-5,31 E+00$ & 4,96E-03 & $2,43 E+04$ & $2,30 E+04$ & $6,71 E+06$ & $7,08 E+06$ \\
\hline 677,76 & Ag110 & $1,98 \mathrm{E}+04$ & $1,07 E-01$ & $-5,34 \mathrm{E}+00$ & $4,82 \mathrm{E}-03$ & $6,40 E+04$ & $6,85 E+03$ & $2,00 E+06$ & $1,87 E+07$ \\
\hline 687,02 & Ag110 & $4,17 E+03$ & $6,49 E-02$ & $-5,35 E+00$ & $4,75 E-03$ & $2,25 E+04$ & $1,46 \mathrm{E}+03$ & $4,27 E+05$ & $6,57 E+06$ \\
\hline 706,68 & Ag110 & $1,07 E+04$ & $1,67 E-01$ & $-5,38 \mathrm{E}+00$ & 4,63E-03 & $2,31 E+04$ & $3,85 E+03$ & $1,12 E+06$ & $6,74 \mathrm{E}+06$ \\
\hline 722,89 & Ag108 & $1,95 \mathrm{E}+03$ & $9,09 \mathrm{E}-01$ & $-5,40 E+00$ & $4,53 E-03$ & $7,90 \mathrm{E}+02$ & $7,18 \mathrm{E}+02$ & $2,09 E+05$ & $2,30 E+05$ \\
\hline 744,23 & $\mathrm{Ag} 110$ & $2,88 \mathrm{E}+03$ & $4,70 \mathrm{E}-02$ & $-5,42 E+00$ & $4,41 \mathrm{E}-03$ & $2,32 E+04$ & $1,09 E+03$ & $3,18 E+05$ & $6,76 \mathrm{E}+06$ \\
\hline 763,89 & Ag110 & $1,42 E+04$ & $2,21 \mathrm{E}-01$ & $-5,45 E+00$ & $4,30 \mathrm{E}-03$ & $2,48 E+04$ & $5,50 \mathrm{E}+03$ & $1,61 E+06$ & $7,25 E+06$ \\
\hline 817,96 & Ag110 & $4,26 E+03$ & $7,29 E-02$ & $-5,51 E+00$ & $4,04 \mathrm{E}-03$ & $2,41 E+04$ & $1,76 \mathrm{E}+03$ & $5,12 E+05$ & $7,03 E+06$ \\
\hline 884,55 & Ag110 & $4,28 E+04$ & $7,22 \mathrm{E}-01$ & $-5,58 \mathrm{E}+00$ & $3,78 \mathrm{E}-03$ & $2,61 E+04$ & $1,89 E+04$ & $5,51 E+06$ & $7,62 E+06$ \\
\hline 937,34 & Ag110 & $1,92 \mathrm{E}+04$ & $3,41 \mathrm{E}-01$ & $-5,63 E+00$ & $3,61 \mathrm{E}-03$ & $2,60 \mathrm{E}+04$ & $8,87 E+03$ & $2,59 \mathrm{E}+06$ & $7,59 \mathrm{E}+06$ \\
\hline 1172,64 & Co60 & $1,86 \mathrm{E}+04$ & 9,99E-01 & $-5,79 E+00$ & $3,07 E-03$ & $1,01 E+04$ & $1,01 E+04$ & $2,95 E+06$ & $2,95 E+06$ \\
\hline 1331,81 & Co60 & $1,72 E+04$ & $1,00 E+00$ & $-5,86 E+00$ & $2,85 \mathrm{E}-03$ & $1,01 E+04$ & $1,01 E+04$ & $2,93 E+06$ & $2,93 E+06$ \\
\hline 1383,57 & Ag110 & $1,06 E+04$ & $2,43 \mathrm{E}-01$ & $-5,88 \mathrm{E}+00$ & $2,80 \mathrm{E}-03$ & $2,60 E+04$ & $6,31 E+03$ & $1,84 \mathrm{E}+06$ & $7,58 E+06$ \\
\hline 1475,03 & Ag110 & $1,69 E+03$ & $3,99 \mathrm{E}-02$ & $-5,91 E+00$ & $2,72 \mathrm{E}-03$ & $2,60 E+04$ & $1,04 E+03$ & $3,02 E+05$ & $7,58 \mathrm{E}+06$ \\
\hline 1504,2 & Ag110 & $5,45 E+03$ & 1,31E-01 & $-5,92 \mathrm{E}+00$ & $2,70 \mathrm{E}-03$ & $2,57 E+04$ & $3,37 E+03$ & $9,83 E+05$ & $7,50 E+06$ \\
\hline 1561,6 & Ag110 & $4,60 \mathrm{E}+02$ & $1,18 \mathrm{E}-02$ & $-5,93 E+00$ & $2,66 \mathrm{E}-03$ & $2,44 E+04$ & $2,88 \mathrm{E}+02$ & $8,42 E+04$ & $7,13 E+06$ \\
\hline
\end{tabular}


FILTRO 3

\begin{tabular}{|c|c|c|c|c|c|c|c|c|c|}
\hline Energia & Radionuclídeos & $\begin{array}{c}\text { Área do } \\
\text { pico }\end{array}$ & Yield & $\begin{array}{l}\text { Parâmetro } \\
\text { de eficiência }\end{array}$ & Eficiência & $\begin{array}{c}\text { Estimativa } \\
\text { Atividade (Bq) }\end{array}$ & $\begin{array}{c}\text { Taxa de } \\
\text { emissão de } \\
\text { fótons }\left(\mathrm{s}^{-1}\right)\end{array}$ & $\begin{array}{l}\text { Correção } n^{\circ} \\
\text { fótons }\left(s^{-1}\right)\end{array}$ & $\begin{array}{c}\text { Atividade } \\
\text { corrigida (Bq) }\end{array}$ \\
\hline 79,19 & Ag108 & $4,09 E+02$ & $6,90 \mathrm{E}-02$ & $-3,68 E+00$ & $2,52 \mathrm{E}-02$ & $3,91 E+02$ & $2,70 E+01$ & $6,03 E+03$ & $8,74 E+04$ \\
\hline 433,9 & Ag108 & $5,45 E+03$ & $9,03 \mathrm{E}-01$ & $-4,88 E+00$ & $7,63 \mathrm{E}-03$ & $1,32 E+03$ & $1,19 E+03$ & $2,66 \mathrm{E}+05$ & $2,94 \mathrm{E}+05$ \\
\hline 446,78 & Ag110 & $1,02 E+03$ & $3,66 \mathrm{E}-02$ & $-4,91 E+00$ & $7,40 \mathrm{E}-03$ & $6,28 E+03$ & $2,30 E+02$ & $5,13 E+04$ & $1,40 E+06$ \\
\hline 614,08 & Ag108 & $3,98 E+03$ & $9,08 \mathrm{E}-01$ & $-5,24 \mathrm{E}+00$ & $5,31 \mathrm{E}-03$ & $1,38 E+03$ & $1,25 E+03$ & $2,79 E+05$ & $3,07 E+05$ \\
\hline 620,13 & $\operatorname{Ag} 110$ & $6,05 E+02$ & $2,78 \mathrm{E}-02$ & $-5,25 E+00$ & $5,26 \mathrm{E}-03$ & $6,90 E+03$ & $1,92 E+02$ & $4,28 E+04$ & $1,54 \mathrm{E}+06$ \\
\hline 657,55 & Ag110 & $1,89 E+04$ & $9,47 E-01$ & $-5,31 E+00$ & $4,96 \mathrm{E}-03$ & $6,70 E+03$ & $6,35 E+03$ & $1,42 E+06$ & $1,50 E+06$ \\
\hline 677,38 & $\operatorname{Ag} 110$ & $1,96 E+03$ & $1,07 E-01$ & $-5,34 \mathrm{E}+00$ & $4,82 \mathrm{E}-03$ & $6,33 E+03$ & $6,78 E+02$ & $1,51 E+05$ & $1,41 E+06$ \\
\hline 686,75 & Ag110 & $1,15 E+03$ & $6,49 E-02$ & $-5,35 E+00$ & $4,76 \mathrm{E}-03$ & $6,21 E+03$ & $4,03 E+02$ & $9,00 E+04$ & $1,39 E+06$ \\
\hline 706,44 & Ag110 & $3,04 \mathrm{E}+03$ & $1,67 \mathrm{E}-01$ & $-5,38 \mathrm{E}+00$ & $4,63 \mathrm{E}-03$ & $6,56 \mathrm{E}+03$ & $1,09 E+03$ & $2,45 E+05$ & $1,46 \mathrm{E}+06$ \\
\hline 722,67 & Ag108 & $3,46 E+03$ & $9,09 \mathrm{E}-01$ & $-5,40 E+00$ & $4,53 \mathrm{E}-03$ & $1,40 E+03$ & $1,27 E+03$ & $2,84 \mathrm{E}+05$ & $3,13 E+05$ \\
\hline 743,97 & Ag110 & $8,30 E+02$ & $4,66 \mathrm{E}-02$ & $-5,42 E+00$ & 4,41E-03 & $6,73 E+03$ & $3,14 E+02$ & $7,01 E+04$ & $1,50 E+06$ \\
\hline 763,64 & $\operatorname{Ag} 110$ & $3,87 E+03$ & $2,24 \mathrm{E}-01$ & $-5,45 E+00$ & $4,30 \mathrm{E}-03$ & $6,69 E+03$ & $1,50 E+03$ & $3,35 E+05$ & $1,49 E+06$ \\
\hline 817,68 & Ag110 & $1,22 E+03$ & $7,32 \mathrm{E}-02$ & $-5,51 E+00$ & $4,05 E-03$ & $6,87 E+03$ & $5,03 E+02$ & $1,12 E+05$ & $1,53 E+06$ \\
\hline 884,29 & Ag110 & $1,11 E+04$ & $7,29 E-01$ & $-5,58 \mathrm{E}+00$ & $3,78 \mathrm{E}-03$ & $6,71 E+03$ & $4,89 \mathrm{E}+03$ & $1,09 E+06$ & $1,50 E+06$ \\
\hline 937,05 & Ag110 & $5,04 E+03$ & $3,43 E-01$ & $-5,62 E+00$ & $3,61 \mathrm{E}-03$ & $6,79 E+03$ & $2,33 E+03$ & $5,20 E+05$ & $1,52 E+06$ \\
\hline 1172,37 & Co60 & $9,12 E+03$ & 9,99E-01 & $-5,79 E+00$ & $3,07 E-03$ & $4,96 E+03$ & $4,95 E+03$ & $1,11 E+06$ & $1,11 E+06$ \\
\hline 1331,51 & Co60 & $8,47 E+03$ & $1,00 E+00$ & $-5,86 E+00$ & $2,85 \mathrm{E}-03$ & $4,95 E+03$ & $4,95 E+03$ & $1,11 E+06$ & $1,11 E+06$ \\
\hline 1383,27 & Ag110 & $2,71 E+03$ & $2,43 \mathrm{E}-01$ & $-5,88 \mathrm{E}+00$ & $2,80 \mathrm{E}-03$ & $6,64 \mathrm{E}+03$ & $1,61 \mathrm{E}+03$ & $3,61 E+05$ & $1,48 E+06$ \\
\hline 1474,66 & Ag110 & $4,08 E+02$ & $3,99 \mathrm{E}-02$ & $-5,91 E+00$ & $2,72 \mathrm{E}-03$ & $6,27 E+03$ & $2,50 E+02$ & $5,59 E+04$ & $1,40 E+06$ \\
\hline 1503,93 & Ag110 & $1,23 E+03$ & $1,31 \mathrm{E}-01$ & $-5,92 E+00$ & $2,70 \mathrm{E}-03$ & $5,80 E+03$ & $7,60 \mathrm{E}+02$ & $1,70 \mathrm{E}+05$ & $1,30 E+06$ \\
\hline 1561,34 & Ag110 & $1,04 \mathrm{E}+02$ & $1,18 \mathrm{E}-02$ & $-5,93 E+00$ & $2,66 \mathrm{E}-03$ & $5,52 E+03$ & $6,52 E+01$ & $1,46 \mathrm{E}+04$ & $1,23 E+06$ \\
\hline
\end{tabular}


FILTRO 4

\begin{tabular}{|c|c|c|c|c|c|c|c|c|c|}
\hline Energia & Radionuclídeos & $\begin{array}{l}\text { Área do } \\
\text { pico }\end{array}$ & Yield & $\begin{array}{l}\text { Parâmetro } \\
\text { de eficiência }\end{array}$ & Eficiência & $\begin{array}{c}\text { Estimativa } \\
\text { Atividade (Bq) }\end{array}$ & $\begin{array}{c}\text { Taxa de } \\
\text { emissão de } \\
\text { fótons }\left(\mathrm{s}^{-1}\right)\end{array}$ & $\begin{array}{l}\text { Correção } n^{\circ} \\
\text { fótons }\left(s^{-1}\right)\end{array}$ & $\begin{array}{c}\text { Atividade } \\
\text { corrigida (Bq) }\end{array}$ \\
\hline 79,21 & Ag108 & $4,37 E+02$ & $6,90 \mathrm{E}-02$ & $-3,68 \mathrm{E}+00$ & $2,52 \mathrm{E}-02$ & $4,18 \mathrm{E}+02$ & $2,89 \mathrm{E}+01$ & $5,83 E+03$ & $8,45 E+04$ \\
\hline 433,88 & Ag108 & $5,36 E+03$ & $9,03 E-01$ & $-4,88 E+00$ & $7,63 \mathrm{E}-03$ & $1,30 E+03$ & $1,17 E+03$ & $2,36 E+05$ & $2,62 E+05$ \\
\hline 446,75 & Ag110 & $9,79 E+02$ & $3,66 \mathrm{E}-02$ & $-4,91 E+00$ & $7,40 \mathrm{E}-03$ & $6,03 E+03$ & $2,21 E+02$ & $4,45 E+04$ & $1,22 E+06$ \\
\hline 614,06 & Ag108 & $3,83 E+03$ & $9,08 \mathrm{E}-01$ & $-5,24 \mathrm{E}+00$ & $5,31 \mathrm{E}-03$ & $1,32 E+03$ & $1,20 \mathrm{E}+03$ & $2,43 E+05$ & $2,67 E+05$ \\
\hline 620,24 & Ag110 & $4,96 \mathrm{E}+02$ & $2,78 \mathrm{E}-02$ & $-5,25 E+00$ & $5,26 \mathrm{E}-03$ & $5,66 \mathrm{E}+03$ & $1,57 E+02$ & $3,17 E+04$ & $1,14 \mathrm{E}+06$ \\
\hline 657,5 & $\operatorname{Ag} 110$ & $1,91 E+04$ & 9,47E-01 & $-5,31 E+00$ & $4,96 \mathrm{E}-03$ & $6,78 E+03$ & $6,42 E+03$ & $1,30 E+06$ & $1,37 E+06$ \\
\hline 677,36 & Ag110 & $1,93 E+03$ & $1,07 E-01$ & $-5,34 \mathrm{E}+00$ & $4,82 \mathrm{E}-03$ & $6,24 \mathrm{E}+03$ & $6,67 E+02$ & $1,35 E+05$ & $1,26 E+06$ \\
\hline 686,69 & Ag110 & $1,17 E+03$ & $6,49 E-02$ & $-5,35 E+00$ & $4,76 \mathrm{E}-03$ & $6,32 E+03$ & $4,10 E+02$ & $8,28 E+04$ & $1,28 \mathrm{E}+06$ \\
\hline 706,37 & $\operatorname{Ag} 110$ & $2,92 E+03$ & $1,67 \mathrm{E}-01$ & $-5,38 E+00$ & 4,63E-03 & $6,30 E+03$ & $1,05 E+03$ & $2,12 E+05$ & $1,27 E+06$ \\
\hline 722,6 & Ag108 & $3,30 E+03$ & $9,09 E-01$ & $-5,40 E+00$ & 4,53E-03 & $1,34 \mathrm{E}+03$ & $1,21 E+03$ & $2,45 E+05$ & $2,70 E+05$ \\
\hline 743,97 & Ag110 & $7,12 E+02$ & $4,66 \mathrm{E}-02$ & $-5,42 E+00$ & 4,41E-03 & $5,78 \mathrm{E}+03$ & $2,69 \mathrm{E}+02$ & $5,44 \mathrm{E}+04$ & $1,17 \mathrm{E}+06$ \\
\hline 763,59 & Ag110 & $3,58 E+03$ & $2,24 \mathrm{E}-01$ & $-5,45 E+00$ & $4,30 \mathrm{E}-03$ & $6,19 E+03$ & $1,39 \mathrm{E}+03$ & $2,80 E+05$ & $1,25 E+06$ \\
\hline 817,58 & Ag110 & $1,15 E+03$ & $7,32 \mathrm{E}-02$ & $-5,51 E+00$ & $4,05 E-03$ & $6,47 E+03$ & $4,74 \mathrm{E}+02$ & $9,56 E+04$ & $1,31 E+06$ \\
\hline 884,25 & Ag110 & $1,06 E+04$ & $7,29 E-01$ & $-5,58 \mathrm{E}+00$ & $3,78 \mathrm{E}-03$ & $6,41 \mathrm{E}+03$ & $4,67 E+03$ & $9,43 E+05$ & $1,29 E+06$ \\
\hline 936,99 & Ag110 & $4,81 E+03$ & $3,43 E-01$ & $-5,62 E+00$ & $3,61 E-03$ & $6,48 E+03$ & $2,22 E+03$ & $4,49 E+05$ & $1,31 E+06$ \\
\hline 1172,28 & Co60 & $8,22 E+03$ & 9,99E-01 & $-5,79 E+00$ & $3,07 E-03$ & $4,47 E+03$ & $4,46 E+03$ & $9,01 E+05$ & $9,02 E+05$ \\
\hline 1331,38 & Co60 & $7,69 E+03$ & $1,00 E+00$ & $-5,86 E+00$ & $2,85 \mathrm{E}-03$ & $4,49 E+03$ & $4,49 E+03$ & $9,07 E+05$ & $9,07 E+05$ \\
\hline 1383,14 & Ag110 & $2,49 E+03$ & $2,43 \mathrm{E}-01$ & $-5,88 \mathrm{E}+00$ & $2,80 \mathrm{E}-03$ & $6,10 E+03$ & $1,48 \mathrm{E}+03$ & $2,99 \mathrm{E}+05$ & $1,23 E+06$ \\
\hline 1474,57 & Ag110 & $4,02 E+02$ & 3,99E-02 & $-5,91 E+00$ & $2,72 \mathrm{E}-03$ & $6,18 \mathrm{E}+03$ & $2,46 \mathrm{E}+02$ & $4,98 \mathrm{E}+04$ & $1,25 E+06$ \\
\hline 1503,81 & $\operatorname{Ag} 110$ & $1,24 \mathrm{E}+03$ & 1,31E-01 & $-5,92 E+00$ & $2,70 \mathrm{E}-03$ & $5,85 E+03$ & $7,66 \mathrm{E}+02$ & $1,55 E+05$ & $1,18 \mathrm{E}+06$ \\
\hline 1560,99 & $\mathrm{Ag} 110$ & $9,16 \mathrm{E}+01$ & $1,18 \mathrm{E}-02$ & $-5,93 E+00$ & $2,66 \mathrm{E}-03$ & $4,87 E+03$ & $5,74 \mathrm{E}+01$ & $1,16 \mathrm{E}+04$ & $9,82 E+05$ \\
\hline
\end{tabular}


FILTRO 5

\begin{tabular}{|c|c|c|c|c|c|c|c|c|c|}
\hline Energia & Radionuclídeos & Área do pico & Yield & $\begin{array}{l}\text { Parâmetro } \\
\text { de eficiência }\end{array}$ & Eficiência & $\begin{array}{c}\text { Estimativa } \\
\text { Atividade (Bq) }\end{array}$ & $\begin{array}{c}\text { Taxa de } \\
\text { emissão de } \\
\text { fótons }\left(\mathrm{s}^{-1}\right)\end{array}$ & $\begin{array}{l}\text { Correção } n^{\circ} \\
\text { fótons }\left(s^{-1}\right)\end{array}$ & $\begin{array}{c}\text { Atividade } \\
\text { corrigida (Bq) }\end{array}$ \\
\hline 433,96 & Ag108 & $2,07 E+03$ & $9,03 \mathrm{E}-01$ & $-4,88 \mathrm{E}+00$ & $7,63 \mathrm{E}-03$ & $5,01 E+02$ & $4,52 E+02$ & $1,14 \mathrm{E}+05$ & $1,26 E+05$ \\
\hline 446,86 & Ag110 & $2,46 E+03$ & $3,66 \mathrm{E}-02$ & $-4,91 E+00$ & $7,39 \mathrm{E}-03$ & $1,51 E+04$ & $5,54 \mathrm{E}+02$ & $1,39 E+05$ & $3,81 E+06$ \\
\hline 614,15 & Ag108 & $4,88 \mathrm{E}+03$ & $9,08 \mathrm{E}-01$ & $-5,24 E+00$ & $5,31 E-03$ & $1,69 \mathrm{E}+03$ & $1,53 E+03$ & $3,85 E+05$ & $4,24 \mathrm{E}+05$ \\
\hline 620,23 & $\operatorname{Ag} 110$ & $1,31 E+03$ & $2,78 \mathrm{E}-02$ & $-5,25 E+00$ & $5,26 \mathrm{E}-03$ & $1,49 E+04$ & $4,15 E+02$ & $1,04 \mathrm{E}+05$ & $3,76 E+06$ \\
\hline 657,63 & Ag110 & $4,83 E+04$ & 9,47E-01 & $-5,31 E+00$ & $4,96 \mathrm{E}-03$ & $1,71 E+04$ & $1,62 E+04$ & $4,08 E+06$ & $4,31 E+06$ \\
\hline 677,46 & Ag110 & $5,09 E+03$ & 1,07E-01 & $-5,34 E+00$ & $4,82 \mathrm{E}-03$ & $1,65 E+04$ & $1,76 E+03$ & $4,43 E+05$ & $4,14 \mathrm{E}+06$ \\
\hline 686,86 & Ag110 & $3,16 E+03$ & $6,49 \mathrm{E}-02$ & $-5,35 E+00$ & $4,75 \mathrm{E}-03$ & $1,71 E+04$ & $1,11 E+03$ & $2,79 E+05$ & $4,29 E+06$ \\
\hline 706,52 & Ag110 & $7,73 E+03$ & 1,67E-01 & $-5,38 E+00$ & $4,63 \mathrm{E}-03$ & $1,67 E+04$ & $2,78 \mathrm{E}+03$ & $7,00 E+05$ & $4,19 E+06$ \\
\hline 722,78 & Ag108 & $1,33 E+03$ & $9,09 \mathrm{E}-01$ & $-5,40 E+00$ & $4,53 \mathrm{E}-03$ & $5,38 E+02$ & $4,89 \mathrm{E}+02$ & $1,23 E+05$ & $1,35 E+05$ \\
\hline 744,1 & Ag110 & $2,17 E+03$ & $4,66 \mathrm{E}-02$ & $-5,42 E+00$ & $4,41 E-03$ & $1,76 E+04$ & $8,21 E+02$ & $2,06 E+05$ & $4,43 E+06$ \\
\hline 763,73 & Ag110 & $1,02 E+04$ & $2,24 \mathrm{E}-01$ & $-5,45 E+00$ & $4,30 \mathrm{E}-03$ & $1,76 \mathrm{E}+04$ & $3,95 E+03$ & $9,94 \mathrm{E}+05$ & $4,44 \mathrm{E}+06$ \\
\hline 817,79 & Ag110 & $3,16 E+03$ & $7,32 \mathrm{E}-02$ & $-5,51 E+00$ & $4,05 E-03$ & $1,78 E+04$ & $1,30 E+03$ & $3,28 E+05$ & $4,47 E+06$ \\
\hline 884,4 & Ag110 & $2,94 \mathrm{E}+04$ & $7,29 \mathrm{E}-01$ & $-5,58 \mathrm{E}+00$ & $3,78 \mathrm{E}-03$ & $1,78 \mathrm{E}+04$ & $1,30 \mathrm{E}+04$ & $3,26 E+06$ & $4,47 E+06$ \\
\hline 937,17 & Ag110 & $1,33 E+04$ & $3,43 \mathrm{E}-01$ & $-5,62 E+00$ & $3,61 \mathrm{E}-03$ & $1,79 E+04$ & $6,15 E+03$ & $1,55 E+06$ & $4,51 E+06$ \\
\hline 1172,47 & Co60 & $1,12 E+04$ & 9,99E-01 & $-5,79 E+00$ & $3,07 E-03$ & $6,09 E+03$ & $6,08 E+03$ & $1,53 E+06$ & $1,53 E+06$ \\
\hline 1331,61 & Co60 & $1,02 E+04$ & $1,00 E+00$ & $-5,86 E+00$ & $2,85 \mathrm{E}-03$ & $5,96 \mathrm{E}+03$ & $5,96 E+03$ & $1,50 E+06$ & $1,50 E+06$ \\
\hline 1383,37 & Ag110 & $6,98 \mathrm{E}+03$ & $2,43 E-01$ & $-5,88 E+00$ & $2,80 \mathrm{E}-03$ & $1,71 E+04$ & $4,16 E+03$ & $1,05 E+06$ & $4,30 E+06$ \\
\hline 1474,8 & Ag110 & $1,10 E+03$ & $3,99 \mathrm{E}-02$ & $-5,91 E+00$ & $2,72 \mathrm{E}-03$ & $1,69 E+04$ & $6,74 \mathrm{E}+02$ & $1,70 \mathrm{E}+05$ & $4,25 E+06$ \\
\hline 1504,01 & Ag110 & $3,39 E+03$ & $1,31 \mathrm{E}-01$ & $-5,92 E+00$ & $2,70 \mathrm{E}-03$ & $1,60 \mathrm{E}+04$ & $2,09 E+03$ & $5,27 E+05$ & $4,02 E+06$ \\
\hline 1561,19 & Ag110 & $3,03 E+02$ & $1,18 \mathrm{E}-02$ & $-5,93 E+00$ & $2,66 \mathrm{E}-03$ & $1,61 \mathrm{E}+04$ & $1,90 E+02$ & $4,78 E+04$ & $4,05 E+06$ \\
\hline
\end{tabular}




\section{FILTRO 6}

\begin{tabular}{|c|c|c|c|c|c|c|c|c|c|}
\hline Energia & Radionuclídeos & $\begin{array}{l}\text { Área do } \\
\text { pico }\end{array}$ & Yield & $\begin{array}{l}\text { Parâmetro } \\
\text { de eficiência }\end{array}$ & Eficiência & $\begin{array}{c}\text { Estimativa } \\
\text { Atividade (Bq) }\end{array}$ & $\begin{array}{c}\text { Taxa de } \\
\text { emissão de } \\
\text { fótons }\left(\mathbf{s}^{-1}\right)\end{array}$ & $\begin{array}{l}\text { Correção } n^{\circ} \\
\text { fótons }\left(s^{-1}\right)\end{array}$ & $\begin{array}{c}\text { Atividade } \\
\text { corrigida (Bq) }\end{array}$ \\
\hline 79,4 & Ag108 & $1,19 \mathrm{E}+03$ & $6,90 \mathrm{E}-02$ & $-3,68 E+00$ & $2,52 \mathrm{E}-02$ & $1,14 \mathrm{E}+03$ & $7,86 \mathrm{E}+01$ & $1,34 \mathrm{E}+04$ & $1,93 E+05$ \\
\hline 433,86 & $\mathrm{Ag} 108$ & $4,47 E+03$ & $9,03 \mathrm{E}-01$ & $-4,88 \mathrm{E}+00$ & $7,63 \mathrm{E}-03$ & $1,08 \mathrm{E}+03$ & $9,76 \mathrm{E}+02$ & $1,66 \mathrm{E}+05$ & $1,84 \mathrm{E}+05$ \\
\hline 446,73 & Ag110 & $3,26 E+02$ & $3,66 \mathrm{E}-02$ & $-4,91 E+00$ & $7,40 \mathrm{E}-03$ & $2,01 E+03$ & $7,35 E+01$ & $1,25 E+04$ & $3,41 E+05$ \\
\hline 614,03 & Ag108 & $3,14 \mathrm{E}+03$ & $9,08 \mathrm{E}-01$ & $-5,24 \mathrm{E}+00$ & $5,31 \mathrm{E}-03$ & $1,09 \mathrm{E}+03$ & $9,85 E+02$ & $1,67 E+05$ & $1,84 \mathrm{E}+05$ \\
\hline 620,11 & $\mathrm{Ag} 110$ & $1,28 E+02$ & $2,78 \mathrm{E}-02$ & $-5,25 E+00$ & $5,26 \mathrm{E}-03$ & $1,46 \mathrm{E}+03$ & $4,06 E+01$ & $6,89 E+03$ & $2,48 E+05$ \\
\hline 657,5 & Ag110 & $5,20 \mathrm{E}+03$ & $9,47 \mathrm{E}-01$ & $-5,31 E+00$ & 4,96E-03 & $1,84 \mathrm{E}+03$ & $1,75 E+03$ & $2,97 E+05$ & $3,13 E+05$ \\
\hline 677,38 & Ag110 & $5,69 \mathrm{E}+02$ & $1,07 E-01$ & $-5,34 \mathrm{E}+00$ & $4,82 \mathrm{E}-03$ & $1,84 \mathrm{E}+03$ & $1,97 \mathrm{E}+02$ & $3,34 E+04$ & $3,12 E+05$ \\
\hline 686,76 & $\operatorname{Ag} 110$ & $3,25 E+02$ & $6,49 \mathrm{E}-02$ & $-5,35 E+00$ & $4,76 \mathrm{E}-03$ & $1,76 \mathrm{E}+03$ & $1,14 \mathrm{E}+02$ & $1,94 \mathrm{E}+04$ & $2,98 E+05$ \\
\hline 706,37 & Ag110 & $7,97 \mathrm{E}+02$ & 1,67E-01 & $-5,38 \mathrm{E}+00$ & 4,63E-03 & $1,72 E+03$ & $2,87 E+02$ & $4,88 \mathrm{E}+04$ & $2,92 E+05$ \\
\hline 722,62 & $\mathrm{Ag} 108$ & $2,78 E+03$ & $9,09 \mathrm{E}-01$ & $-5,40 E+00$ & $4,53 \mathrm{E}-03$ & $1,13 E+03$ & $1,02 E+03$ & $1,74 \mathrm{E}+05$ & $1,91 \mathrm{E}+05$ \\
\hline 743,86 & Ag110 & $2,08 \mathrm{E}+02$ & $4,66 \mathrm{E}-02$ & $-5,42 E+00$ & 4,41E-03 & $1,69 \mathrm{E}+03$ & $7,86 \mathrm{E}+01$ & $1,34 \mathrm{E}+04$ & $2,87 E+05$ \\
\hline 763,59 & Ag110 & $1,06 \mathrm{E}+03$ & $2,24 \mathrm{E}-01$ & $-5,45 E+00$ & $4,30 \mathrm{E}-03$ & $1,83 E+03$ & $4,11 E+02$ & $6,97 E+04$ & $3,11 E+05$ \\
\hline 817,64 & Ag110 & $3,49 \mathrm{E}+02$ & $7,32 \mathrm{E}-02$ & $-5,51 E+00$ & $4,05 E-03$ & $1,96 \mathrm{E}+03$ & $1,44 \mathrm{E}+02$ & $2,44 \mathrm{E}+04$ & $3,34 \mathrm{E}+05$ \\
\hline 884,28 & Ag110 & $3,11 E+03$ & $7,29 E-01$ & $-5,58 \mathrm{E}+00$ & $3,78 \mathrm{E}-03$ & $1,88 \mathrm{E}+03$ & 1,37E+03 & $2,33 E+05$ & $3,19 E+05$ \\
\hline 936,99 & Ag110 & $1,29 \mathrm{E}+03$ & $3,43 \mathrm{E}-01$ & $-5,62 E+00$ & $3,61 \mathrm{E}-03$ & $1,74 \mathrm{E}+03$ & $5,96 \mathrm{E}+02$ & $1,01 E+05$ & $2,95 E+05$ \\
\hline 1172,31 & Co60 & $6,75 E+03$ & 9,99E-01 & $-5,79 E+00$ & $3,07 E-03$ & $3,67 E+03$ & $3,66 E+03$ & $6,23 E+05$ & $6,23 E+05$ \\
\hline 1331,46 & Co60 & $6,06 E+03$ & $1,00 E+00$ & $-5,86 E+00$ & $2,85 \mathrm{E}-03$ & $3,54 \mathrm{E}+03$ & $3,54 \mathrm{E}+03$ & $6,02 E+05$ & $6,02 E+05$ \\
\hline 1383,22 & Ag110 & $7,31 E+02$ & $2,43 \mathrm{E}-01$ & $-5,88 \mathrm{E}+00$ & $2,80 \mathrm{E}-03$ & $1,79 E+03$ & $4,35 E+02$ & $7,40 \mathrm{E}+04$ & $3,04 \mathrm{E}+05$ \\
\hline 1474,67 & Ag110 & $1,16 \mathrm{E}+02$ & $3,99 \mathrm{E}-02$ & $-5,91 E+00$ & $2,72 \mathrm{E}-03$ & $1,78 E+03$ & $7,11 \mathrm{E}+01$ & $1,21 E+04$ & $3,03 E+05$ \\
\hline 1503,88 & Ag110 & $3,26 E+02$ & $1,31 \mathrm{E}-01$ & $-5,92 E+00$ & $2,70 \mathrm{E}-03$ & $1,54 \mathrm{E}+03$ & $2,01 E+02$ & $3,42 E+04$ & $2,61 \mathrm{E}+05$ \\
\hline
\end{tabular}


FILTRO 7

\begin{tabular}{|c|c|c|c|c|c|c|c|c|c|}
\hline Energia & Radionuclídeos & $\begin{array}{c}\text { Área do } \\
\text { pico }\end{array}$ & Yield & $\begin{array}{l}\text { Parâmetro } \\
\text { de eficiência }\end{array}$ & Eficiência & $\begin{array}{c}\text { Estimativa } \\
\text { Atividade (Bq) }\end{array}$ & $\begin{array}{c}\text { Taxa de } \\
\text { emissão de } \\
\text { fótons }\left(s^{-1}\right)\end{array}$ & $\begin{array}{l}\text { Correção } n^{\circ} \\
\text { fótons }\left(s^{-1}\right)\end{array}$ & $\begin{array}{c}\text { Atividade } \\
\text { corrigida (Bq) }\end{array}$ \\
\hline 433,97 & Ag108 & $1,88 \mathrm{E}+03$ & $9,03 \mathrm{E}-01$ & $-4,88 E+00$ & $7,63 \mathrm{E}-03$ & $4,55 E+02$ & $4,11 E+02$ & $8,75 E+04$ & $9,69 \mathrm{E}+04$ \\
\hline 446,97 & Ag110 & $2,22 \mathrm{E}+03$ & $3,66 \mathrm{E}-02$ & $-4,91 E+00$ & 7,39E-03 & $1,37 E+04$ & $5,00 E+02$ & $1,07 E+05$ & $2,91 E+06$ \\
\hline 614,11 & Ag108 & $1,36 \mathrm{E}+03$ & $9,08 \mathrm{E}-01$ & $-5,24 E+00$ & $5,31 \mathrm{E}-03$ & $4,70 E+02$ & $4,27 E+02$ & $9,09 E+04$ & $1,00 E+05$ \\
\hline 620,18 & Ag110 & $1,19 E+03$ & $2,78 \mathrm{E}-02$ & $-5,25 E+00$ & $5,26 \mathrm{E}-03$ & $1,36 \mathrm{E}+04$ & $3,77 E+02$ & $8,03 E+04$ & $2,89 E+06$ \\
\hline 657,57 & Ag110 & $4,14 \mathrm{E}+04$ & $9,47 \mathrm{E}-01$ & $-5,31 E+00$ & 4,96E-03 & $1,47 E+04$ & $1,39 \mathrm{E}+04$ & $2,96 \mathrm{E}+06$ & $3,13 E+06$ \\
\hline 677,42 & Ag110 & $4,39 E+03$ & 1,07E-01 & $-5,34 E+00$ & $4,82 \mathrm{E}-03$ & $1,42 E+04$ & $1,52 \mathrm{E}+03$ & $3,23 E+05$ & $3,02 E+06$ \\
\hline 686,82 & Ag110 & $2,65 E+03$ & $6,49 \mathrm{E}-02$ & $-5,35 E+00$ & $4,76 \mathrm{E}-03$ & $1,43 E+04$ & $9,29 \mathrm{E}+02$ & $1,98 \mathrm{E}+05$ & $3,05 E+06$ \\
\hline 706,45 & Ag110 & $6,56 \mathrm{E}+03$ & 1,67E-01 & $-5,38 \mathrm{E}+00$ & $4,63 \mathrm{E}-03$ & $1,41 E+04$ & $2,36 \mathrm{E}+03$ & $5,03 E+05$ & $3,01 E+06$ \\
\hline 722,69 & Ag108 & $1,31 E+03$ & $9,09 \mathrm{E}-01$ & $-5,40 E+00$ & 4,53E-03 & $5,30 \mathrm{E}+02$ & $4,82 \mathrm{E}+02$ & $1,03 E+05$ & $1,13 E+05$ \\
\hline 744,06 & Ag110 & $1,68 \mathrm{E}+03$ & $4,66 \mathrm{E}-02$ & $-5,42 E+00$ & 4,41E-03 & $1,36 \mathrm{E}+04$ & $6,35 E+02$ & $1,35 \mathrm{E}+05$ & $2,90 \mathrm{E}+06$ \\
\hline 763,67 & Ag110 & $8,56 E+03$ & $2,24 \mathrm{E}-01$ & $-5,45 E+00$ & $4,30 \mathrm{E}-03$ & $1,48 \mathrm{E}+04$ & $3,32 E+03$ & $7,06 \mathrm{E}+05$ & $3,15 E+06$ \\
\hline 817,71 & Ag110 & $2,64 E+03$ & $7,32 \mathrm{E}-02$ & $-5,51 E+00$ & 4,05E-03 & $1,49 E+04$ & $1,09 E+03$ & $2,32 E+05$ & $3,16 E+06$ \\
\hline 884,31 & Ag110 & $2,51 E+04$ & $7,29 \mathrm{E}-01$ & $-5,58 E+00$ & $3,78 \mathrm{E}-03$ & $1,52 E+04$ & $1,11 E+04$ & $2,36 E+06$ & $3,23 E+06$ \\
\hline 937,06 & Ag110 & $1,11 E+04$ & $3,43 \mathrm{E}-01$ & $-5,62 E+00$ & $3,61 \mathrm{E}-03$ & $1,50 \mathrm{E}+04$ & $5,13 E+03$ & $1,09 E+06$ & $3,18 \mathrm{E}+06$ \\
\hline 1172,35 & Co60 & $8,59 E+03$ & 9,99E-01 & $-5,79 E+00$ & $3,07 E-03$ & 4,67E+03 & $4,66 \mathrm{E}+03$ & $9,93 E+05$ & $9,94 \mathrm{E}+05$ \\
\hline 1331,5 & Co60 & $8,03 E+03$ & $1,00 E+00$ & $-5,86 E+00$ & $2,85 \mathrm{E}-03$ & $4,69 \mathrm{E}+03$ & $4,69 \mathrm{E}+03$ & $9,99 \mathrm{E}+05$ & $9,99 \mathrm{E}+05$ \\
\hline 1383,24 & Ag110 & $5,91 E+03$ & $2,43 E-01$ & $-5,88 E+00$ & $2,80 \mathrm{E}-03$ & $1,45 E+04$ & $3,52 E+03$ & $7,50 E+05$ & $3,08 E+06$ \\
\hline 1474,64 & Ag110 & $9,21 E+02$ & $3,99 \mathrm{E}-02$ & $-5,91 E+00$ & $2,72 \mathrm{E}-03$ & $1,42 E+04$ & $5,65 E+02$ & $1,20 E+05$ & $3,01 E+06$ \\
\hline 1503,87 & Ag110 & $2,89 E+03$ & $1,31 \mathrm{E}-01$ & $-5,92 E+00$ & $2,70 \mathrm{E}-03$ & $1,36 \mathrm{E}+04$ & $1,79 E+03$ & $3,80 E+05$ & $2,90 E+06$ \\
\hline 1561,04 & Ag110 & $2,56 \mathrm{E}+02$ & $1,18 \mathrm{E}-02$ & $-5,93 E+00$ & $2,66 \mathrm{E}-03$ & $1,36 \mathrm{E}+04$ & $1,60 \mathrm{E}+02$ & $3,42 E+04$ & $2,90 E+06$ \\
\hline
\end{tabular}




\section{FILTRO 8}

\begin{tabular}{|c|c|c|c|c|c|c|c|c|c|}
\hline Energia & Radionuclídeos & $\begin{array}{c}\text { Área do } \\
\text { pico }\end{array}$ & Yield & $\begin{array}{l}\text { Parâmetro } \\
\text { de eficiência }\end{array}$ & Eficiência & $\begin{array}{c}\text { Estimativa } \\
\text { Atividade } \\
\text { (Bq) }\end{array}$ & $\begin{array}{c}\text { Taxa de } \\
\text { emissão de } \\
\text { fótons }\left(s^{-1}\right)\end{array}$ & $\begin{array}{l}\text { Correção } n^{\circ} \\
\text { fótons }\left(s^{-1}\right)\end{array}$ & $\begin{array}{c}\text { Atividade } \\
\text { corrigida (Bq) }\end{array}$ \\
\hline 78,85 & Ag108 & $5,01 E+03$ & $6,90 \mathrm{E}-02$ & $-3,68 \mathrm{E}+00$ & $2,52 \mathrm{E}-02$ & $4,80 E+03$ & $3,31 \mathrm{E}+02$ & $7,24 \mathrm{E}+04$ & $1,05 E+06$ \\
\hline 434,01 & Ag108 & $2,48 E+03$ & $9,03 E-01$ & $-4,88 E+00$ & $7,63 \mathrm{E}-03$ & $6,00 E+02$ & $5,42 E+02$ & $1,19 E+05$ & $1,31 E+05$ \\
\hline 446,86 & Ag110 & $2,93 E+03$ & $3,66 \mathrm{E}-02$ & $-4,91 E+00$ & $7,39 \mathrm{E}-03$ & $1,80 E+04$ & $6,60 E+02$ & $1,44 E+05$ & $3,95 E+06$ \\
\hline 614,2 & $\mathrm{Ag} 108$ & $1,70 E+03$ & $9,08 \mathrm{E}-01$ & $-5,24 E+00$ & $5,31 \mathrm{E}-03$ & $5,88 \mathrm{E}+02$ & $5,34 \mathrm{E}+02$ & $1,17 E+05$ & $1,29 E+05$ \\
\hline 620,3 & Ag110 & $1,59 E+03$ & $2,78 \mathrm{E}-02$ & $-5,25 E+00$ & $5,26 \mathrm{E}-03$ & $1,81 E+04$ & $5,04 \mathrm{E}+02$ & $1,10 E+05$ & $3,97 E+06$ \\
\hline 657,65 & Ag110 & $5,35 E+04$ & $9,47 \mathrm{E}-01$ & $-5,31 E+00$ & $4,96 \mathrm{E}-03$ & $1,90 E+04$ & $1,80 E+04$ & $3,93 E+06$ & $4,15 E+06$ \\
\hline 677,5 & Ag110 & $5,74 \mathrm{E}+03$ & 1,07E-01 & $-5,34 \mathrm{E}+00$ & $4,82 \mathrm{E}-03$ & $1,86 E+04$ & $1,99 \mathrm{E}+03$ & $4,34 \mathrm{E}+05$ & $4,06 E+06$ \\
\hline 686,89 & Ag110 & $3,48 E+03$ & $6,49 E-02$ & $-5,35 E+00$ & $4,75 E-03$ & $1,88 \mathrm{E}+04$ & $1,22 E+03$ & $2,67 E+05$ & $4,11 E+06$ \\
\hline 706,56 & Ag110 & $8,69 \mathrm{E}+03$ & 1,67E-01 & $-5,38 E+00$ & 4,63E-03 & $1,87 \mathrm{E}+04$ & $3,13 E+03$ & $6,85 E+05$ & $4,10 E+06$ \\
\hline 722,77 & $\mathrm{Ag} 108$ & $1,48 E+03$ & $9,09 \mathrm{E}-01$ & $-5,40 E+00$ & $4,53 \mathrm{E}-03$ & $5,99 E+02$ & $5,45 E+02$ & $1,19 E+05$ & $1,31 E+05$ \\
\hline 744,16 & Ag110 & $2,30 E+03$ & $4,66 \mathrm{E}-02$ & $-5,42 E+00$ & 4,41E-03 & $1,87 E+04$ & $8,70 E+02$ & $1,90 E+05$ & $4,08 E+06$ \\
\hline 763,76 & Ag110 & $1,10 E+04$ & $2,24 \mathrm{E}-01$ & $-5,45 E+00$ & $4,30 \mathrm{E}-03$ & $1,90 E+04$ & $4,26 E+03$ & $9,32 E+05$ & $4,16 E+06$ \\
\hline 817,82 & Ag110 & $3,44 \mathrm{E}+03$ & $7,32 \mathrm{E}-02$ & $-5,51 E+00$ & $4,05 E-03$ & $1,94 \mathrm{E}+04$ & $1,42 E+03$ & $3,10 E+05$ & $4,23 E+06$ \\
\hline 884,42 & Ag110 & $3,22 E+04$ & $7,29 \mathrm{E}-01$ & $-5,58 E+00$ & $3,78 \mathrm{E}-03$ & $1,95 E+04$ & $1,42 E+04$ & $3,10 E+06$ & $4,26 E+06$ \\
\hline 937,19 & Ag110 & $1,45 E+04$ & $3,43 \mathrm{E}-01$ & $-5,62 E+00$ & $3,61 \mathrm{E}-03$ & $1,95 E+04$ & $6,70 E+03$ & $1,47 E+06$ & $4,27 E+06$ \\
\hline 1172,51 & Co60 & $1,17 \mathrm{E}+04$ & 9,99E-01 & $-5,79 E+00$ & $3,07 E-03$ & $6,36 E+03$ & $6,35 E+03$ & $1,39 E+06$ & $1,39 E+06$ \\
\hline 1331,67 & Co60 & $1,05 E+04$ & $1,00 \mathrm{E}+00$ & $-5,86 E+00$ & $2,85 \mathrm{E}-03$ & $6,14 \mathrm{E}+03$ & $6,14 \mathrm{E}+03$ & $1,34 \mathrm{E}+06$ & $1,34 \mathrm{E}+06$ \\
\hline 1383,42 & Ag110 & $7,52 E+03$ & $2,43 E-01$ & $-5,88 \mathrm{E}+00$ & $2,80 \mathrm{E}-03$ & $1,84 \mathrm{E}+04$ & $4,48 E+03$ & $9,80 E+05$ & $4,03 E+06$ \\
\hline 1474,89 & Ag110 & $1,20 \mathrm{E}+03$ & 3,99E-02 & $-5,91 E+00$ & $2,72 \mathrm{E}-03$ & $1,84 E+04$ & $7,36 \mathrm{E}+02$ & $1,61 E+05$ & $4,03 E+06$ \\
\hline 1504,06 & Ag110 & $3,87 E+03$ & 1,31E-01 & $-5,92 E+00$ & $2,70 \mathrm{E}-03$ & $1,83 E+04$ & $2,39 E+03$ & $5,23 E+05$ & $3,99 E+06$ \\
\hline 1561,41 & Ag110 & $3,23 E+02$ & $1,18 \mathrm{E}-02$ & $-5,93 E+00$ & $2,66 \mathrm{E}-03$ & $1,72 E+04$ & $2,02 E+02$ & $4,43 E+04$ & $3,75 E+06$ \\
\hline
\end{tabular}


FILTRO 9

\begin{tabular}{|c|c|c|c|c|c|c|c|c|c|}
\hline Energia & Radionuclídeos & $\begin{array}{l}\text { Área do } \\
\text { pico }\end{array}$ & Yield & $\begin{array}{l}\text { Parâmetro } \\
\text { de eficiência }\end{array}$ & Eficiência & $\begin{array}{c}\text { Estimativa } \\
\text { Atividade (Bq) }\end{array}$ & $\begin{array}{c}\text { Taxa de } \\
\text { emissão de } \\
\text { fótons }\left(\mathrm{s}^{-1}\right)\end{array}$ & $\begin{array}{l}\text { Correção } n^{0} \\
\text { fótons }\left(s^{-1}\right)\end{array}$ & $\begin{array}{c}\text { Atividade } \\
\text { corrigida }(\mathrm{Bq})\end{array}$ \\
\hline 79,13 & Ag108 & $3,70 E+02$ & $6,90 \mathrm{E}-02$ & $-3,68 E+00$ & $2,52 \mathrm{E}-02$ & $3,54 \mathrm{E}+02$ & $2,44 \mathrm{E}+01$ & $5,84 E+03$ & $8,47 E+04$ \\
\hline 433,85 & Ag108 & $4,40 E+03$ & $9,03 E-01$ & $-4,88 E+00$ & $7,63 \mathrm{E}-03$ & $1,06 E+03$ & $9,61 E+02$ & $2,30 E+05$ & $2,54 E+05$ \\
\hline 446,83 & Ag110 & $1,03 E+03$ & $3,66 \mathrm{E}-02$ & $-4,91 E+00$ & $7,40 \mathrm{E}-03$ & $6,34 E+03$ & $2,32 E+02$ & $5,55 E+04$ & $1,52 E+06$ \\
\hline 614,04 & Ag108 & $3,16 \mathrm{E}+03$ & $9,08 \mathrm{E}-01$ & $-5,24 E+00$ & $5,31 \mathrm{E}-03$ & $1,09 E+03$ & $9,92 E+02$ & $2,37 E+05$ & $2,61 E+05$ \\
\hline 620,04 & Ag110 & $1,33 E+02$ & $2,78 \mathrm{E}-02$ & $-5,25 E+00$ & $5,26 \mathrm{E}-03$ & $1,52 E+03$ & $4,22 E+01$ & $1,01 E+04$ & $3,62 E+05$ \\
\hline 657,48 & Ag110 & $5,14 \mathrm{E}+03$ & $9,47 \mathrm{E}-01$ & $-5,31 E+00$ & $4,96 \mathrm{E}-03$ & $1,82 E+03$ & $1,73 E+03$ & $4,13 E+05$ & $4,36 E+05$ \\
\hline 677,36 & Ag110 & $5,55 E+02$ & 1,07E-01 & $-5,34 E+00$ & $4,82 \mathrm{E}-03$ & $1,79 E+03$ & $1,92 E+02$ & $4,59 E+04$ & $4,29 E+05$ \\
\hline 686,72 & Ag110 & $3,26 E+02$ & $6,49 \mathrm{E}-02$ & $-5,35 E+00$ & $4,76 \mathrm{E}-03$ & $1,76 E+03$ & $1,14 E+02$ & $2,73 E+04$ & $4,21 E+05$ \\
\hline 706,37 & Ag110 & $8,67 E+02$ & $1,67 \mathrm{E}-01$ & $-5,38 E+00$ & $4,63 \mathrm{E}-03$ & $1,87 E+03$ & $3,12 E+02$ & $7,46 \mathrm{E}+04$ & $4,47 E+05$ \\
\hline 722,57 & Ag108 & $2,73 E+03$ & $9,09 E-01$ & $-5,40 E+00$ & $4,53 \mathrm{E}-03$ & $1,10 E+03$ & $1,00 E+03$ & $2,40 E+05$ & $2,64 E+05$ \\
\hline 743,9 & Ag110 & $2,12 E+02$ & $4,66 \mathrm{E}-02$ & $-5,42 E+00$ & 4,41E-03 & $1,72 E+03$ & $8,01 E+01$ & $1,92 E+04$ & $4,11 E+05$ \\
\hline 763,62 & Ag110 & $1,08 E+03$ & $2,24 \mathrm{E}-01$ & $-5,45 E+00$ & 4,30E-03 & $1,87 E+03$ & $4,18 E+02$ & $1,00 E+05$ & $4,46 E+05$ \\
\hline 817,55 & Ag110 & $2,81 E+02$ & $7,32 \mathrm{E}-02$ & $-5,51 E+00$ & $4,05 E-03$ & $1,58 E+03$ & $1,16 E+02$ & $2,77 E+04$ & $3,78 E+05$ \\
\hline 884,23 & Ag110 & $3,10 E+03$ & $7,29 \mathrm{E}-01$ & $-5,58 E+00$ & $3,78 \mathrm{E}-03$ & $1,87 E+03$ & $1,37 E+03$ & $3,27 E+05$ & $4,48 E+05$ \\
\hline 937,01 & Ag110 & $1,38 \mathrm{E}+03$ & $3,43 E-01$ & $-5,62 E+00$ & $3,61 \mathrm{E}-03$ & $1,86 \mathrm{E}+03$ & $6,38 \mathrm{E}+02$ & $1,52 E+05$ & $4,44 E+05$ \\
\hline 1172,29 & Co60 & $6,80 E+03$ & 9,99E-01 & $-5,79 E+00$ & $3,07 E-03$ & $3,70 E+03$ & $3,69 E+03$ & $8,83 E+05$ & $8,83 E+05$ \\
\hline 1331,44 & Co60 & $6,11 E+03$ & $1,00 E+00$ & $-5,86 E+00$ & $2,85 \mathrm{E}-03$ & $3,57 E+03$ & $3,57 E+03$ & $8,53 E+05$ & $8,53 E+05$ \\
\hline 1383,21 & Ag110 & $7,22 E+02$ & $2,43 E-01$ & $-5,88 E+00$ & $2,80 \mathrm{E}-03$ & $1,77 E+03$ & $4,30 E+02$ & $1,03 E+05$ & $4,23 E+05$ \\
\hline 1474,63 & Ag110 & $1,02 E+02$ & 3,99E-02 & $-5,91 E+00$ & $2,72 \mathrm{E}-03$ & $1,57 E+03$ & $6,25 E+01$ & $1,49 E+04$ & $3,75 E+05$ \\
\hline 1503,82 & Ag110 & $3,27 E+02$ & $1,31 \mathrm{E}-01$ & $-5,92 E+00$ & $2,70 \mathrm{E}-03$ & $1,54 \mathrm{E}+03$ & $2,02 E+02$ & $4,83 E+04$ & $3,69 E+05$ \\
\hline 1561,24 & $\mathrm{Ag} 110$ & $1,81 \mathrm{E}+01$ & $1,18 \mathrm{E}-02$ & $-5,93 E+00$ & $2,66 \mathrm{E}-03$ & $9,61 \mathrm{E}+02$ & $1,13 E+01$ & $2,71 E+03$ & $2,30 E+05$ \\
\hline
\end{tabular}




\section{FILTRO 10}

\begin{tabular}{|c|c|c|c|c|c|c|c|c|c|}
\hline Energia & Radionuclídeos & $\begin{array}{c}\text { Área do } \\
\text { pico }\end{array}$ & Yield & $\begin{array}{l}\text { Parâmetro } \\
\text { de eficiência }\end{array}$ & Eficiência & $\begin{array}{c}\text { Estimativa } \\
\text { Atividade (Bq) }\end{array}$ & $\begin{array}{c}\text { Taxa de } \\
\text { emissão de } \\
\text { fótons }\left(\mathrm{s}^{-1}\right)\end{array}$ & $\begin{array}{l}\text { Correção } n^{\circ} \\
\text { fótons }\left(s^{-1}\right)\end{array}$ & $\begin{array}{c}\text { Atividade } \\
\text { corrigida (Bq) }\end{array}$ \\
\hline 79,18 & Ag108 & $3,06 E+02$ & $6,90 \mathrm{E}-02$ & $-3,68 E+00$ & $2,52 \mathrm{E}-02$ & $2,93 E+02$ & $2,02 E+01$ & $3,70 E+03$ & $5,36 E+04$ \\
\hline 433,86 & Ag108 & $4,06 E+03$ & $9,03 E-01$ & $-4,88 \mathrm{E}+00$ & $7,63 \mathrm{E}-03$ & $9,82 \mathrm{E}+02$ & $8,87 \mathrm{E}+02$ & $1,62 E+05$ & $1,80 \mathrm{E}+05$ \\
\hline 446,74 & Ag110 & $4,73 E+02$ & $3,66 \mathrm{E}-02$ & $-4,91 E+00$ & $7,40 \mathrm{E}-03$ & $2,91 E+03$ & $1,07 E+02$ & $1,95 \mathrm{E}+04$ & $5,33 E+05$ \\
\hline 614,05 & Ag108 & $3,14 E+03$ & $9,08 \mathrm{E}-01$ & $-5,24 E+00$ & 5,31E-03 & $1,09 E+03$ & $9,85 E+02$ & $1,80 E+05$ & $1,99 E+05$ \\
\hline 620,1 & Ag110 & $2,48 E+02$ & $2,78 \mathrm{E}-02$ & $-5,25 E+00$ & $5,26 \mathrm{E}-03$ & $2,83 E+03$ & $7,86 E+01$ & $1,44 E+04$ & $5,18 \mathrm{E}+05$ \\
\hline 657,5 & Ag110 & $8,17 E+03$ & $9,47 \mathrm{E}-01$ & $-5,31 E+00$ & $4,96 \mathrm{E}-03$ & $2,90 E+03$ & $2,74 E+03$ & $5,03 E+05$ & $5,31 E+05$ \\
\hline 677,33 & Ag110 & $8,99 E+02$ & $1,07 E-01$ & $-5,34 E+00$ & $4,82 \mathrm{E}-03$ & $2,91 E+03$ & $3,11 E+02$ & $5,69 E+04$ & $5,32 E+05$ \\
\hline 686,75 & Ag110 & $5,88 \mathrm{E}+02$ & $6,49 \mathrm{E}-02$ & $-5,35 E+00$ & $4,76 \mathrm{E}-03$ & $3,18 E+03$ & $2,06 E+02$ & $3,77 E+04$ & $5,81 E+05$ \\
\hline 706,39 & Ag110 & $1,28 E+03$ & 1,67E-01 & $-5,38 E+00$ & $4,63 \mathrm{E}-03$ & $2,76 \mathrm{E}+03$ & $4,61 \mathrm{E}+02$ & $8,44 \mathrm{E}+04$ & $5,05 E+05$ \\
\hline 722,61 & Ag108 & $2,59 E+03$ & $9,09 E-01$ & $-5,40 E+00$ & $4,53 \mathrm{E}-03$ & $1,05 E+03$ & $9,53 E+02$ & $1,74 \mathrm{E}+05$ & $1,92 E+05$ \\
\hline 743,99 & Ag110 & $3,61 E+02$ & $4,66 \mathrm{E}-02$ & $-5,42 E+00$ & 4,41E-03 & $2,93 E+03$ & $1,36 \mathrm{E}+02$ & $2,50 E+04$ & $5,36 E+05$ \\
\hline 763,59 & Ag110 & $1,69 E+03$ & $2,24 \mathrm{E}-01$ & $-5,45 E+00$ & $4,30 \mathrm{E}-03$ & $2,92 E+03$ & $6,55 E+02$ & $1,20 E+05$ & $5,35 E+05$ \\
\hline 817,56 & Ag110 & $5,17 \mathrm{E}+02$ & $7,32 \mathrm{E}-02$ & $-5,51 E+00$ & $4,05 E-03$ & $2,91 E+03$ & $2,13 E+02$ & $3,90 \mathrm{E}+04$ & $5,33 E+05$ \\
\hline 884,26 & Ag110 & $5,02 E+03$ & $7,29 E-01$ & $-5,58 E+00$ & $3,78 \mathrm{E}-03$ & $3,03 E+03$ & $2,21 E+03$ & $4,05 E+05$ & $5,56 \mathrm{E}+05$ \\
\hline 936,99 & Ag110 & $2,24 E+03$ & $3,43 \mathrm{E}-01$ & $-5,62 E+00$ & $3,61 \mathrm{E}-03$ & $3,02 E+03$ & $1,03 E+03$ & $1,89 E+05$ & $5,52 E+05$ \\
\hline 1172,3 & Co60 & $7,98 \mathrm{E}+03$ & 9,99E-01 & $-5,79 E+00$ & $3,07 E-03$ & $4,34 \mathrm{E}+03$ & $4,33 E+03$ & $7,93 E+05$ & $7,94 \mathrm{E}+05$ \\
\hline 1331,43 & Co60 & $7,28 E+03$ & $1,00 E+00$ & $-5,86 E+00$ & $2,85 \mathrm{E}-03$ & $4,25 E+03$ & $4,25 E+03$ & $7,79 E+05$ & $7,79 E+05$ \\
\hline 1383,18 & Ag110 & $1,13 E+03$ & $2,43 E-01$ & $-5,88 E+00$ & $2,80 \mathrm{E}-03$ & $2,77 E+03$ & $6,73 E+02$ & $1,23 E+05$ & $5,07 E+05$ \\
\hline 1474,74 & Ag110 & $1,66 E+02$ & $3,99 \mathrm{E}-02$ & $-5,91 E+00$ & $2,72 \mathrm{E}-03$ & $2,55 E+03$ & $1,02 E+02$ & $1,86 E+04$ & $4,67 E+05$ \\
\hline 1503,9 & Ag110 & $5,54 \mathrm{E}+02$ & 1,31E-01 & $-5,92 E+00$ & $2,70 \mathrm{E}-03$ & $2,61 E+03$ & $3,42 E+02$ & $6,27 E+04$ & $4,79 E+05$ \\
\hline 1560,78 & Ag110 & $4,91 E+01$ & $1,18 \mathrm{E}-02$ & $-5,93 E+00$ & $2,66 \mathrm{E}-03$ & $2,61 E+03$ & $3,08 \mathrm{E}+01$ & $5,63 E+03$ & $4,78 E+05$ \\
\hline
\end{tabular}


FILTRO 11

\begin{tabular}{|c|c|c|c|c|c|c|c|c|c|}
\hline Energia & Radionuclídeos & $\begin{array}{l}\text { Área do } \\
\text { pico }\end{array}$ & Yield & $\begin{array}{l}\text { Parâmetro } \\
\text { de eficiência }\end{array}$ & Eficiência & $\begin{array}{c}\text { Estimativa } \\
\text { Atividade (Bq) }\end{array}$ & $\begin{array}{c}\text { Taxa de } \\
\text { emissão de } \\
\text { fótons }\left(\mathrm{s}^{-1}\right)\end{array}$ & $\begin{array}{l}\text { Correção } n^{\circ} \\
\text { fótons }\left(s^{-1}\right)\end{array}$ & $\begin{array}{c}\text { Atividade } \\
\text { corrigida }(\mathrm{Bq})\end{array}$ \\
\hline 79,15 & Ag108 & $3,09 E+02$ & $6,90 \mathrm{E}-02$ & $-3,68 E+00$ & $2,52 \mathrm{E}-02$ & $2,96 \mathrm{E}+02$ & $2,04 \mathrm{E}+01$ & $4,74 \mathrm{E}+03$ & $6,87 E+04$ \\
\hline 433,86 & Ag108 & $3,69 \mathrm{E}+03$ & $9,03 \mathrm{E}-01$ & $-4,88 \mathrm{E}+00$ & $7,63 \mathrm{E}-03$ & $8,92 \mathrm{E}+02$ & $8,06 E+02$ & $1,87 E+05$ & $2,07 E+05$ \\
\hline 446,8 & Ag110 & $1,33 E+03$ & $3,66 \mathrm{E}-02$ & $-4,91 E+00$ & $7,40 \mathrm{E}-03$ & $8,19 E+03$ & $3,00 E+02$ & $6,97 E+04$ & $1,90 E+06$ \\
\hline 614,03 & Ag108 & $2,66 E+03$ & $9,08 \mathrm{E}-01$ & $-5,24 \mathrm{E}+00$ & $5,31 \mathrm{E}-03$ & $9,19 E+02$ & $8,35 E+02$ & $1,94 \mathrm{E}+05$ & $2,14 E+05$ \\
\hline 620 & Ag110 & $2,35 E+02$ & $2,78 \mathrm{E}-02$ & $-5,25 E+00$ & $5,26 \mathrm{E}-03$ & $2,68 \mathrm{E}+03$ & $7,45 E+01$ & $1,73 E+04$ & $6,23 E+05$ \\
\hline 657,5 & $\mathrm{Ag} 110$ & $7,60 E+03$ & 9,47E-01 & $-5,31 E+00$ & 4,96E-03 & $2,70 E+03$ & $2,55 E+03$ & $5,93 E+05$ & $6,27 E+05$ \\
\hline 677,3 & Ag110 & $8,41 E+02$ & 1,07E-01 & $-5,34 \mathrm{E}+00$ & $4,82 \mathrm{E}-03$ & $2,72 E+03$ & $2,91 \mathrm{E}+02$ & $6,76 E+04$ & $6,32 E+05$ \\
\hline 686,69 & Ag110 & $4,55 E+02$ & $6,49 \mathrm{E}-02$ & $-5,35 E+00$ & $4,76 \mathrm{E}-03$ & $2,46 \mathrm{E}+03$ & $1,59 \mathrm{E}+02$ & $3,71 E+04$ & $5,71 E+05$ \\
\hline 706,39 & $\mathrm{Ag} 110$ & $1,21 E+03$ & 1,67E-01 & $-5,38 E+00$ & 4,63E-03 & $2,61 E+03$ & $4,36 E+02$ & $1,01 E+05$ & $6,06 E+05$ \\
\hline 722,59 & Ag108 & $2,34 \mathrm{E}+03$ & $9,09 \mathrm{E}-01$ & $-5,40 E+00$ & 4,53E-03 & $9,47 E+02$ & $8,61 E+02$ & $2,00 \mathrm{E}+05$ & $2,20 E+05$ \\
\hline 743,93 & Ag110 & $3,12 E+02$ & $4,66 \mathrm{E}-02$ & $-5,42 E+00$ & $4,41 \mathrm{E}-03$ & $2,53 E+03$ & $1,18 E+02$ & $2,74 E+04$ & $5,88 \mathrm{E}+05$ \\
\hline 763,59 & $\mathrm{Ag} 110$ & $1,60 E+03$ & $2,24 \mathrm{E}-01$ & $-5,45 E+00$ & 4,30E-03 & $2,77 E+03$ & $6,20 E+02$ & $1,44 \mathrm{E}+05$ & $6,43 E+05$ \\
\hline 817,75 & Ag110 & $4,38 \mathrm{E}+02$ & $7,32 \mathrm{E}-02$ & $-5,51 E+00$ & $4,05 E-03$ & $2,46 \mathrm{E}+03$ & $1,80 \mathrm{E}+02$ & $4,19 \mathrm{E}+04$ & $5,73 E+05$ \\
\hline 884,26 & $\mathrm{Ag} 110$ & $4,45 E+02$ & 7,29E-01 & $-5,58 E+00$ & $3,78 \mathrm{E}-03$ & $2,69 E+02$ & $1,96 E+02$ & $4,56 \mathrm{E}+04$ & $6,25 E+04$ \\
\hline 937,02 & Ag110 & $1,92 E+03$ & $3,43 \mathrm{E}-01$ & $-5,62 E+00$ & $3,61 \mathrm{E}-03$ & $2,59 E+03$ & $8,87 E+02$ & $2,06 \mathrm{E}+05$ & $6,01 E+05$ \\
\hline 1172,3 & Co60 & $6,93 E+03$ & 9,99E-01 & $-5,79 E+00$ & 3,07E-03 & $3,77 E+03$ & $3,76 E+03$ & $8,74 \mathrm{E}+05$ & $8,75 E+05$ \\
\hline 1331,45 & Co60 & $6,51 E+03$ & $1,00 E+00$ & $-5,86 E+00$ & $2,85 \mathrm{E}-03$ & $3,80 E+03$ & $3,80 E+03$ & $8,84 \mathrm{E}+05$ & $8,84 \mathrm{E}+05$ \\
\hline 1383,19 & Ag110 & $9,80 \mathrm{E}+02$ & $2,43 \mathrm{E}-01$ & $-5,88 \mathrm{E}+00$ & $2,80 \mathrm{E}-03$ & $2,40 E+03$ & $5,84 \mathrm{E}+02$ & $1,36 \mathrm{E}+05$ & $5,58 \mathrm{E}+05$ \\
\hline 1474,6 & Ag110 & $1,65 E+02$ & $3,99 \mathrm{E}-02$ & $-5,91 E+00$ & $2,72 \mathrm{E}-03$ & $2,54 \mathrm{E}+03$ & $1,01 E+02$ & $2,35 E+04$ & $5,89 \mathrm{E}+05$ \\
\hline 1503,86 & Ag110 & $5,11 E+02$ & 1,31E-01 & $-5,92 E+00$ & $2,70 \mathrm{E}-03$ & $2,41 E+03$ & $3,16 E+02$ & $7,34 \mathrm{E}+04$ & $5,60 \mathrm{E}+05$ \\
\hline 1561,03 & Ag110 & $3,72 E+01$ & $1,18 \mathrm{E}-02$ & $-5,93 E+00$ & $2,66 \mathrm{E}-03$ & $1,98 \mathrm{E}+03$ & $2,33 \mathrm{E}+01$ & $5,42 E+03$ & $4,59 \mathrm{E}+05$ \\
\hline
\end{tabular}


FILTRO 12

\begin{tabular}{|c|c|c|c|c|c|c|c|c|c|}
\hline Energia & Radionuclídeos & $\begin{array}{l}\text { Área do } \\
\text { pico }\end{array}$ & Yield & $\begin{array}{c}\text { Parâmetro } \\
\text { de eficiência }\end{array}$ & Eficiência & $\begin{array}{c}\text { Estimativa } \\
\text { Atividade (Bq) }\end{array}$ & $\begin{array}{c}\text { Taxa de } \\
\text { emissão de } \\
\text { fótons }\left(s^{-1}\right)\end{array}$ & $\begin{array}{l}\text { Correção } n^{\circ} \\
\text { fótons }\left(s^{-1}\right)\end{array}$ & $\begin{array}{c}\text { Atividade } \\
\text { corrigida }(\mathrm{Bq})\end{array}$ \\
\hline 79,17 & Ag108 & $3,17 E+02$ & $6,90 \mathrm{E}-02$ & $-3,68 E+00$ & $2,52 \mathrm{E}-02$ & $3,03 E+02$ & 2,09E+01 & $4,32 \mathrm{E}+03$ & $6,26 E+04$ \\
\hline 433,86 & $\mathrm{Ag} 108$ & $3,80 E+03$ & $9,03 E-01$ & $-4,88 E+00$ & $7,63 \mathrm{E}-03$ & $9,19 E+02$ & $8,30 E+02$ & $1,71 E+05$ & $1,90 E+05$ \\
\hline 446,77 & Ag110 & $4,34 \mathrm{E}+02$ & $3,66 \mathrm{E}-02$ & $-4,91 E+00$ & $7,40 \mathrm{E}-03$ & $2,67 E+03$ & $9,78 \mathrm{E}+01$ & $2,02 E+04$ & $5,51 E+05$ \\
\hline 614,08 & Ag108 & $2,78 \mathrm{E}+03$ & $9,08 \mathrm{E}-01$ & $-5,24 \mathrm{E}+00$ & $5,31 \mathrm{E}-03$ & $9,61 E+02$ & $8,73 E+02$ & $1,80 E+05$ & $1,98 \mathrm{E}+05$ \\
\hline 657,52 & Ag110 & $7,56 \mathrm{E}+03$ & $9,47 \mathrm{E}-01$ & $-5,31 E+00$ & 4,96E-03 & $2,68 \mathrm{E}+03$ & $2,54 \mathrm{E}+03$ & $5,24 \mathrm{E}+05$ & $5,53 E+05$ \\
\hline 677,39 & Ag110 & $7,89 E+02$ & 1,07E-01 & $-5,34 E+00$ & 4,82E-03 & $2,55 E+03$ & $2,73 E+02$ & $5,63 E+04$ & $5,26 E+05$ \\
\hline 686,77 & Ag110 & $4,71 E+02$ & $6,49 \mathrm{E}-02$ & $-5,35 E+00$ & $4,76 \mathrm{E}-03$ & $2,54 \mathrm{E}+03$ & $1,65 E+02$ & $3,41 E+04$ & $5,25 E+05$ \\
\hline 706,41 & Ag110 & $1,26 \mathrm{E}+03$ & 1,67E-01 & $-5,38 E+00$ & 4,63E-03 & $2,72 E+03$ & $4,54 \mathrm{E}+02$ & $9,36 \mathrm{E}+04$ & $5,61 E+05$ \\
\hline 722,67 & Ag108 & $2,41 E+03$ & $9,09 \mathrm{E}-01$ & $-5,40 E+00$ & $4,53 \mathrm{E}-03$ & $9,76 \mathrm{E}+02$ & $8,87 E+02$ & $1,83 E+05$ & $2,01 E+05$ \\
\hline 744,02 & Ag110 & $3,08 E+02$ & $4,66 \mathrm{E}-02$ & $-5,42 E+00$ & 4,41E-03 & $2,50 E+03$ & $1,16 \mathrm{E}+02$ & $2,40 E+04$ & $5,16 \mathrm{E}+05$ \\
\hline 817,62 & Ag110 & $4,55 E+02$ & $7,32 \mathrm{E}-02$ & $-5,51 E+00$ & $4,05 E-03$ & $2,56 \mathrm{E}+03$ & $1,87 E+02$ & $3,87 E+04$ & $5,28 \mathrm{E}+05$ \\
\hline 884,29 & Ag110 & $4,50 E+03$ & $7,29 E-01$ & $-5,58 E+00$ & $3,78 \mathrm{E}-03$ & $2,72 E+03$ & $1,98 \mathrm{E}+03$ & $4,09 E+05$ & $5,61 E+05$ \\
\hline 937,07 & Ag110 & $2,03 E+03$ & $3,43 E-01$ & $-5,62 E+00$ & $3,61 E-03$ & $2,73 E+03$ & $9,38 \mathrm{E}+02$ & $1,94 \mathrm{E}+05$ & $5,64 E+05$ \\
\hline 1172,36 & Co60 & $7,26 E+03$ & $9,99 E-01$ & $-5,79 E+00$ & $3,07 E-03$ & $3,95 E+03$ & $3,94 \mathrm{E}+03$ & $8,13 E+05$ & $8,14 \mathrm{E}+05$ \\
\hline 1331,49 & Co60 & $6,50 E+03$ & $1,00 E+00$ & $-5,86 E+00$ & $2,85 \mathrm{E}-03$ & $3,80 E+03$ & $3,80 E+03$ & $7,84 \mathrm{E}+05$ & $7,84 \mathrm{E}+05$ \\
\hline 1383,28 & Ag110 & $1,09 E+03$ & 2,43E-01 & $-5,88 E+00$ & $2,80 \mathrm{E}-03$ & $2,67 E+03$ & $6,49 E+02$ & $1,34 \mathrm{E}+05$ & $5,51 E+05$ \\
\hline 1474,67 & Ag110 & $1,50 E+02$ & 3,99E-02 & $-5,91 E+00$ & $2,72 \mathrm{E}-03$ & $2,30 \mathrm{E}+03$ & $9,20 \mathrm{E}+01$ & $1,90 E+04$ & $4,75 E+05$ \\
\hline 1503,91 & Ag110 & $5,99 \mathrm{E}+02$ & 1,31E-01 & $-5,92 E+00$ & $2,70 \mathrm{E}-03$ & $2,83 E+03$ & $3,70 E+02$ & $7,64 \mathrm{E}+04$ & $5,83 E+05$ \\
\hline 1561,15 & Ag110 & $4,46 E+01$ & $1,18 \mathrm{E}-02$ & $-5,93 E+00$ & $2,66 \mathrm{E}-03$ & $2,37 E+03$ & $2,80 E+01$ & $5,77 E+03$ & 4,89E+05 \\
\hline
\end{tabular}




\section{FILTRO 13}

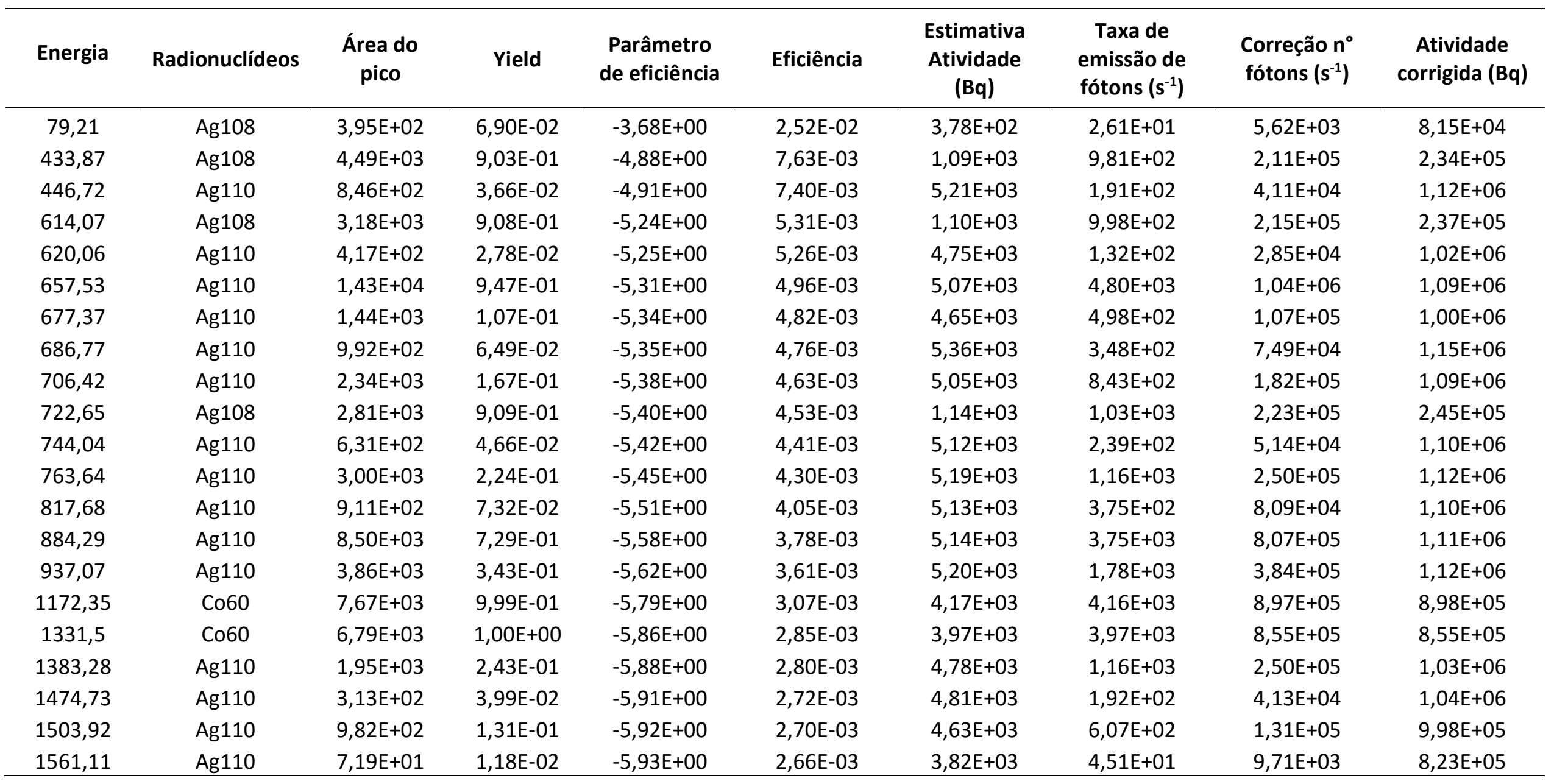


FILTRO 14

\begin{tabular}{|c|c|c|c|c|c|c|c|c|c|}
\hline Energia & Radionuclídeos & $\begin{array}{l}\text { Área do } \\
\text { pico }\end{array}$ & Yield & $\begin{array}{c}\text { Parâmetro } \\
\text { de eficiência }\end{array}$ & Eficiência & $\begin{array}{c}\text { Estimativa } \\
\text { Atividade (Bq) }\end{array}$ & $\begin{array}{c}\text { Taxa de } \\
\text { emissão de } \\
\text { fótons }\left(s^{-1}\right)\end{array}$ & $\begin{array}{l}\text { Correção } n^{\circ} \\
\text { fótons }\left(s^{-1}\right)\end{array}$ & $\begin{array}{c}\text { Atividade } \\
\text { corrigida (Bq) }\end{array}$ \\
\hline 79,19 & Ag108 & $3,94 \mathrm{E}+02$ & $6,90 \mathrm{E}-02$ & $-3,68 E+00$ & $2,52 \mathrm{E}-02$ & $3,77 E+02$ & $2,60 \mathrm{E}+01$ & $5,11 E+03$ & $7,40 \mathrm{E}+04$ \\
\hline 433,88 & Ag108 & $5,58 \mathrm{E}+03$ & $9,03 E-01$ & $-4,88 E+00$ & $7,63 \mathrm{E}-03$ & $1,35 E+03$ & $1,22 E+03$ & $2,39 E+05$ & $2,65 E+05$ \\
\hline 446,77 & Ag110 & $1,03 E+03$ & $3,66 \mathrm{E}-02$ & $-4,91 E+00$ & $7,40 \mathrm{E}-03$ & $6,34 \mathrm{E}+03$ & $2,32 \mathrm{E}+02$ & $4,55 E+04$ & $1,24 E+06$ \\
\hline 614,08 & Ag108 & $4,14 E+03$ & $9,08 \mathrm{E}-01$ & $-5,24 \mathrm{E}+00$ & $5,31 E-03$ & $1,43 E+03$ & $1,30 E+03$ & $2,55 E+05$ & $2,81 E+05$ \\
\hline 657,52 & Ag110 & $1,88 \mathrm{E}+04$ & $9,47 E-01$ & $-5,31 E+00$ & $4,96 \mathrm{E}-03$ & $6,67 E+03$ & $6,32 E+03$ & $1,24 \mathrm{E}+06$ & $1,31 E+06$ \\
\hline 677,35 & Ag110 & $2,04 E+03$ & 1,07E-01 & $-5,34 E+00$ & 4,82E-03 & $6,59 E+03$ & $7,05 E+02$ & $1,38 E+05$ & $1,29 E+06$ \\
\hline 686,77 & Ag110 & $1,19 E+03$ & $6,49 E-02$ & $-5,35 E+00$ & $4,76 \mathrm{E}-03$ & $6,43 E+03$ & $4,17 \mathrm{E}+02$ & $8,18 \mathrm{E}+04$ & $1,26 E+06$ \\
\hline 706,41 & $\mathrm{Ag} 110$ & $3,10 E+03$ & 1,67E-01 & $-5,38 E+00$ & 4,63E-03 & $6,68 E+03$ & $1,12 E+03$ & $2,19 E+05$ & $1,31 E+06$ \\
\hline 722,63 & Ag108 & $3,43 E+03$ & $9,09 \mathrm{E}-01$ & $-5,40 E+00$ & $4,53 \mathrm{E}-03$ & $1,39 E+03$ & $1,26 E+03$ & $2,48 E+05$ & $2,72 E+05$ \\
\hline 743,99 & Ag110 & $8,10 E+02$ & $4,66 \mathrm{E}-02$ & $-5,42 E+00$ & 4,41E-03 & $6,57 E+03$ & $3,06 \mathrm{E}+02$ & $6,01 E+04$ & $1,29 E+06$ \\
\hline 817,69 & Ag110 & $1,26 E+03$ & $7,32 \mathrm{E}-02$ & $-5,51 E+00$ & $4,05 E-03$ & $7,09 E+03$ & $5,19 E+02$ & $1,02 E+05$ & $1,39 E+06$ \\
\hline 884,27 & Ag110 & $1,13 E+04$ & $7,29 E-01$ & $-5,58 E+00$ & $3,78 \mathrm{E}-03$ & $6,83 E+03$ & $4,98 E+03$ & $9,77 \mathrm{E}+05$ & $1,34 \mathrm{E}+06$ \\
\hline 937,04 & Ag110 & $5,06 E+03$ & $3,43 \mathrm{E}-01$ & $-5,62 E+00$ & $3,61 E-03$ & $6,82 E+03$ & $2,34 \mathrm{E}+03$ & $4,59 E+05$ & $1,34 \mathrm{E}+06$ \\
\hline 1172,32 & Co60 & $9,10 E+03$ & 9,99E-01 & $-5,79 E+00$ & 3,07E-03 & $4,95 E+03$ & $4,94 E+03$ & $9,69 E+05$ & $9,70 E+05$ \\
\hline 1331,46 & Co60 & $8,18 \mathrm{E}+03$ & $1,00 E+00$ & $-5,86 E+00$ & $2,85 \mathrm{E}-03$ & $4,78 \mathrm{E}+03$ & $4,78 \mathrm{E}+03$ & $9,38 \mathrm{E}+05$ & $9,38 \mathrm{E}+05$ \\
\hline 1383,22 & Ag110 & $2,64 E+03$ & 2,43E-01 & $-5,88 E+00$ & $2,80 \mathrm{E}-03$ & $6,47 E+03$ & $1,57 E+03$ & $3,09 E+05$ & $1,27 E+06$ \\
\hline 1474,63 & Ag110 & $3,75 E+02$ & 3,99E-02 & $-5,91 E+00$ & $2,72 \mathrm{E}-03$ & $5,76 \mathrm{E}+03$ & $2,30 \mathrm{E}+02$ & $4,51 E+04$ & $1,13 E+06$ \\
\hline 1503,88 & $\mathrm{Ag} 110$ & $1,33 E+03$ & $1,31 \mathrm{E}-01$ & $-5,92 E+00$ & $2,70 \mathrm{E}-03$ & $6,27 E+03$ & $8,22 \mathrm{E}+02$ & $1,61 E+05$ & $1,23 E+06$ \\
\hline 1561,17 & Ag110 & $9,03 E+01$ & $1,18 \mathrm{E}-02$ & $-5,93 E+00$ & $2,66 \mathrm{E}-03$ & $4,80 E+03$ & $5,66 \mathrm{E}+01$ & $1,11 E+04$ & $9,41 E+05$ \\
\hline
\end{tabular}


FILTRO 15

\begin{tabular}{|c|c|c|c|c|c|c|c|c|c|}
\hline Energia & Radionuclídeos & $\begin{array}{l}\text { Área do } \\
\text { pico }\end{array}$ & Yield & $\begin{array}{l}\text { Parâmetro } \\
\text { de eficiência }\end{array}$ & Eficiência & $\begin{array}{c}\text { Estimativa } \\
\text { Atividade (Bq) }\end{array}$ & $\begin{array}{c}\text { Taxa de } \\
\text { emissão de } \\
\text { fótons }\left(\mathrm{s}^{-1}\right)\end{array}$ & $\begin{array}{l}\text { Correção } n^{\circ} \\
\text { fótons }\left(s^{-1}\right)\end{array}$ & $\begin{array}{c}\text { Atividade } \\
\text { corrigida (Bq) }\end{array}$ \\
\hline 79,13 & $\mathrm{Ag} 108$ & $3,95 \mathrm{E}+02$ & $6,90 \mathrm{E}-02$ & $-3,68 E+00$ & $2,52 \mathrm{E}-02$ & $3,78 E+02$ & $2,61 \mathrm{E}+01$ & $5,21 E+03$ & $7,56 E+04$ \\
\hline 433,86 & Ag108 & $5,98 E+03$ & $9,03 \mathrm{E}-01$ & $-4,88 E+00$ & $7,63 \mathrm{E}-03$ & $1,45 E+03$ & $1,31 E+03$ & $2,61 E+05$ & $2,89 E+05$ \\
\hline 446,76 & $\mathrm{Ag} 110$ & $8,93 E+02$ & $3,66 \mathrm{E}-02$ & $-4,91 E+00$ & $7,40 \mathrm{E}-03$ & $5,50 E+03$ & $2,01 E+02$ & $4,02 E+04$ & $1,10 E+06$ \\
\hline 614,06 & $\mathrm{Ag} 108$ & $3,28 E+03$ & $9,08 \mathrm{E}-01$ & $-5,24 E+00$ & $5,31 \mathrm{E}-03$ & $1,13 E+03$ & $1,03 E+03$ & $2,06 \mathrm{E}+05$ & $2,27 E+05$ \\
\hline 620,15 & $\mathrm{Ag} 110$ & $4,89 E+02$ & $2,78 \mathrm{E}-02$ & $-5,25 E+00$ & $5,26 \mathrm{E}-03$ & $5,58 \mathrm{E}+03$ & $1,55 E+02$ & $3,10 E+04$ & $1,11 E+06$ \\
\hline 657,51 & $\mathrm{Ag} 110$ & $1,53 \mathrm{E}+04$ & 9,47E-01 & $-5,31 E+00$ & 4,96E-03 & $5,43 E+03$ & $5,14 \mathrm{E}+03$ & $1,03 E+06$ & $1,08 E+06$ \\
\hline 677,35 & Ag110 & $1,64 \mathrm{E}+03$ & 1,07E-01 & $-5,34 \mathrm{E}+00$ & $4,82 \mathrm{E}-03$ & $5,30 \mathrm{E}+03$ & $5,67 E+02$ & $1,13 E+05$ & $1,06 E+06$ \\
\hline 686,72 & Ag110 & $1,00 E+03$ & $6,49 \mathrm{E}-02$ & $-5,35 E+00$ & $4,76 \mathrm{E}-03$ & $5,40 E+03$ & $3,50 E+02$ & $7,00 E+04$ & $1,08 E+06$ \\
\hline 706,4 & Ag110 & $2,49 E+03$ & 1,67E-01 & $-5,38 E+00$ & $4,63 \mathrm{E}-03$ & $5,37 E+03$ & $8,97 E+02$ & $1,79 E+05$ & $1,07 E+06$ \\
\hline 722,61 & Ag108 & $2,91 \mathrm{E}+03$ & $9,09 \mathrm{E}-01$ & $-5,40 E+00$ & $4,53 \mathrm{E}-03$ & $1,18 \mathrm{E}+03$ & $1,07 E+03$ & $2,14 \mathrm{E}+05$ & $2,35 E+05$ \\
\hline 743,97 & Ag110 & $6,47 E+02$ & $4,66 \mathrm{E}-02$ & $-5,42 E+00$ & 4,41E-03 & $5,25 E+03$ & $2,45 E+02$ & $4,89 E+04$ & $1,05 E+06$ \\
\hline 763,6 & Ag110 & $3,24 \mathrm{E}+03$ & $2,24 \mathrm{E}-01$ & $-5,45 E+00$ & 4,30E-03 & $5,60 \mathrm{E}+03$ & $1,25 E+03$ & $2,51 E+05$ & $1,12 \mathrm{E}+06$ \\
\hline 817,64 & Ag110 & $9,52 \mathrm{E}+02$ & $7,32 \mathrm{E}-02$ & $-5,51 E+00$ & $4,05 \mathrm{E}-03$ & $5,36 E+03$ & $3,92 E+02$ & $7,84 \mathrm{E}+04$ & $1,07 E+06$ \\
\hline 884,26 & Ag110 & $9,36 E+03$ & $7,29 E-01$ & $-5,58 \mathrm{E}+00$ & $3,78 \mathrm{E}-03$ & $5,66 \mathrm{E}+03$ & $4,12 E+03$ & $8,24 \mathrm{E}+05$ & $1,13 E+06$ \\
\hline 937,03 & Ag110 & $4,02 E+03$ & $3,43 \mathrm{E}-01$ & $-5,62 E+00$ & $3,61 \mathrm{E}-03$ & $5,41 E+03$ & $1,86 \mathrm{E}+03$ & $3,71 E+05$ & $1,08 E+06$ \\
\hline 1172,31 & Co60 & $7,66 E+03$ & 9,99E-01 & $-5,79 E+00$ & $3,07 E-03$ & $4,16 E+03$ & $4,16 E+03$ & $8,31 E+05$ & $8,32 E+05$ \\
\hline 1331,44 & Co60 & $6,79 E+03$ & $1,00 E+00$ & $-5,86 E+00$ & $2,85 \mathrm{E}-03$ & $3,97 E+03$ & $3,97 E+03$ & $7,93 E+05$ & $7,93 E+05$ \\
\hline 1383,2 & Ag110 & $2,10 E+03$ & $2,43 \mathrm{E}-01$ & $-5,88 \mathrm{E}+00$ & $2,80 \mathrm{E}-03$ & $5,15 E+03$ & $1,25 E+03$ & $2,50 \mathrm{E}+05$ & $1,03 E+06$ \\
\hline 1474,63 & Ag110 & $3,04 \mathrm{E}+02$ & 3,99E-02 & $-5,91 E+00$ & $2,72 \mathrm{E}-03$ & $4,67 E+03$ & $1,86 \mathrm{E}+02$ & $3,72 E+04$ & $9,34 \mathrm{E}+05$ \\
\hline 1503,84 & $\mathrm{Ag} 110$ & $1,02 E+03$ & 1,31E-01 & $-5,92 E+00$ & $2,70 \mathrm{E}-03$ & $4,81 E+03$ & $6,30 E+02$ & $1,26 E+05$ & $9,62 E+05$ \\
\hline 1560,98 & $\mathrm{Ag} 110$ & $8,09 \mathrm{E}+01$ & $1,18 \mathrm{E}-02$ & $-5,93 E+00$ & $2,66 \mathrm{E}-03$ & $4,30 \mathrm{E}+03$ & $5,07 \mathrm{E}+01$ & $1,01 \mathrm{E}+04$ & $8,59 \mathrm{E}+05$ \\
\hline
\end{tabular}




\section{REFERÊNCIAS}

AGARWAL, C.; CHAUDHURY, S.; GOSWAMI, A.; GATHIBANDHE, M. Full energy peak efficiency calibration of HPGe detector for point and extend sources using Monte Carlo code. J Radioanal Nucl Chem, v. 287, p. 701-708, 2011

AHN, Min Ho; LEE, Sang Chul; LEE, Kun Jai. Disposal concept for LILW in Korea: Characterization methodology and the disposal priority. Progress In Nuclear Energy. Coreia, p. 327-333. dez. 2009.

AMERICAN SOCIETY FOR TESTING AND MATERIALS - ASTM. Annual Book of ASTM Standards - Section 2: Nonferrous Metals Products, Volume 02.04. 1983.

AMPHLETT, C. B. Treatment and disposal of radioactive wastes. International series of monographs on nuclear energy. Division V, v. 2, Pergamon Press, London, 1961.

ANTILLA. M. Gamma and neutron dose rates on the outer surface of the nuclear waste disposal canisters. VTT Energy. Dezembro. 1996 (ISSN 12393096).

BRASIL. Lei № 10.308. Brasília , Disponível em: <http://www.camara.leg.br>. Acesso em: 14 ago. 2015

BARROS, Daniel Figueira de. Estudo Comparativo da Evolução da Legislação Internacional e Brasileira Sobre Repositórios Geológicos de Rejeitos Radioativos. 2012. 241 f. Tese (Doutorado) - Curso de Geociências e Ciências Exatas, Universidade Estadual Paulista, Rio Claro, 2012.

BENTO, Juliana; PEDROSO, Gelta M. J.. Avaliação econômica e ambiental da energia atômica no Brasil. Acta Scientiarum. Technology. Maringá, p. 159-165. 2009. 
BICKEL, M.; HOLMES, L.; JANSON, C.; KOULOURIS, G.; PILVIO, R.; SLOWISKOWSKI B.; HILL, C. Radiochemistry: inconvenient but indispensable. Applied Radiation Isotopes, v. 53, p. 5-11, 2000.

BEKEN, Tom Vander; DORN, Nicholas; VAN DAELE, Stijn. Security risks in nuclear waste management: Exceptionalism, opaqueness and vulnerability. Journal Of Environmental Management. p. 940-948. dez. 2009.

CANBERRA INDUSTRIES INC. GENIE 2000 Spectroscopy Software Customization Tools Manual. Meriden CT, 2001.

CARNEIRO, Paula Frassinetti Pereira. Avaliação Radiométrica em Parte do Estuário do Porto de Suape no Estado de Pernambuco. 2011. 49 f. Dissertação (Mestrado) - Curso de Ciências, Universidade Federal de Pernambuco, Recife, 2011.

COMISSÃO NACIONAL DE ENERGIA NUCLEAR - CNEN. Gerência de Rejeitos Radioativos de Baixo e Médio Níveis de Radiação. CNEN NN 8.01, Rio de Janeiro, 2014 a.

COMISSÃO NACIONAL DE ENERGIA NUCLEAR - CNEN. Licenciamento de Depósitos de Rejeitos Radioativos de Baixo e Médio Níveis de Radiação. CNEN NN 8.02, Rio de Janeiro, 2014 b.

COMISSÃO NACIONAL DE ENERGIA NUCLEAR - CNEN. Diretrizes Básicas de Proteção Radiológica. CNEN NN 3.01, Rio de Janeiro, 2014 c

COMISSÃO NACIONAL DE ENERGIA NUCLEAR - CNEN. Critérios de Aceitação para Deposição de Rejeitos Radioativos de Baixo e Médio Níveis de Radiação. CNEN-NN-6.09. Rio de Janeiro, 2002.

COSTA, Priscila. Desenvolvimento de uma Metodologia para Caracterização do Filtro Cuno do Reator IEA-R1 Utilizando o Método de Monte Carlo. 2014. 52 f. Dissertação (Mestrado) - Curso de Tecnologia Nuclear, Universidade de São Paulo, São Paulo, 2014.

CRISTIANO, Bárbara Fernandes Gonçalves. Caracterização de Pastilhas de $\mathrm{UO}_{2}$ por Método Semiautomático de Titulação Potenciométrica para Fins de 
Salvaguardas Nucleares. 2014. 110 f. Tese (Doutorado) - Curso de Engenharia Nuclear, Universidade Federal do Rio de Janeiro, Rio de Janeiro, 2014.

CUMO, Maurizio. Decommissioning of Nuclear Plants. In: CACUCI, Dan Gabriel. Handbook of Nuclear Engineering. Alemanha: Springer, 2010. Cap. 27. p. 3005-3245.

ELETROBRÁS TERMONUCLEAR. Sistema de desmineralização de água para o Reator IEA-R1: Unidade de Retratamento. Databook. São Paulo. Brasil. 2003.

GERALDO. B. Utilização de métodos radioanalíticos sequenciais para determinação de isótopos de urânio. Plutônio, amerício, cúrio e netúnio em rejeitos radioativos. 2012. Dissertação (Mestrado) - Instituto de Pesquisas Energéticas e Nucleares. São Paulo.

GRATE, Jay W.; O'HARA, Matthew J.; EGOROV, Oleg B.. Automated Radichemical Separation, Analisys, and Sensing. In: L'ANNUNZIATA, Michael F. (Ed.). Handbook of Radioactivity Analysis. 3. ed. San Diego: Elsevier, 2012. Cap. 18. p. 1179-1202.

HORWLTZ, E. Ph.; DIETZ, M. L.; CHIARIZIA, R.. The Application of Novel Extraction Chromatographic Materials to the Characterization of Radioactive Waste Solutions. Journal Of Radioanalytical And Nuclear Chemistry., p. 575583. 1992.

INTERNATIONAL ATOMIC ENERGY AGENCY. Conditioning of low-and intermediate-level radioactive wastes. Vienna, 1983a (TECDOC, 222).

INTERNATIONAL ATOMIC ENERGY AGENCY. Handling and storage of conditioned high-level wastes. Vienna, 1983b (TECDOC, 229).

INTERNATIONAL ATOMIC ENERGY AGENCY. Treatment of low-and intermediate-level liquid radioactive wastes. Vienna, 1984 (TECDOC, 236).

INTERNATIONAL ATOMIC ENERGY AGENCY. Radioactive waste management glossary. 2a ed. Vienna, 1988 (TECDOC, 447). 
INTERNATIONAL ATOMIC ENERGY AGENCY. Radioactive waste management - An IAEA source book. Vienna, 1992.

INTERNATIONAL ATOMIC ENERGY AGENCY - IAEA. The Principles of Radioactive Waste Management. IAEA Nuclear Safety Series No. 111-F. Vienna, 1995.

INTERNATIONAL ATOMIC ENERGY AGENCY - IAEA. Radioactive waste management glossary, Vienna, 2003.

INTERNATIONAL ATOMIC ENERGY AGENCY- IAEA. Predisposal Management of Low and Intermediate Level Radioactive Waste - Safety Guide. Vienna, 2003 (Safety Standards Series No. WS-G-2).

INTERNATIONAL ATOMIC ENERGY AGENCY - IAEA. Fundamental Safety Principles. Safety Standards Series No. SF-1, Vienna, 2006.

INTERNATIONAL ATOMIC ENERGY AGENCY - IAEA strategy and methodology for radioactive waste characterization, Vienna: 2007 (tecdoc15237)

INTERNATIONAL ATOMIC ENERGY AGENCY - IAEA. Determination and use of scaling factors for waste characterization in nuclear power plants. IAEA Nuclear Energy Series No. NW-T-1.18. Vienna, 2009.

INTERNATIONAL ATOMIC ENERGY AGENCY- IAEA. Disposal of Radioactive Waste - Specific Safety Requirements. Vienna, 2011 (Safety Standards Series No. SSR-5).

IAEA, International Atomic Energy Agency-. IAEA. Disponível em: $<$ https://www.iaea.org/>. Acesso em: 20 jun. 2015.

IAEA, International Atomic Energy Agency-. IAEA. Disponível em: <https://www.iaea.org/pris/>. Acesso em: 19 jun. 2015. 
INTERNATIONAL ORGANIZATION FOR STANDARDIZATION. Nuclear Fuel Technology - The Scaling Factor method to determine the radioactivity of low and intermediate level radioactive waste packages generated at nuclear power plants. ISO 21238:2007.

KEKKI, T.; TIITTA, A. Evaluation of the radioactive waste characterization at the Olkiluoto nuclear power plant. STUK-YTO-TR 162. Helsinki, 2000.

KLOOSTERMAN. J. L.; HOOGENBOOM. J. E. Marme.A flexible point-kernel shielding code.Interfaculty Reactor Institute. Delft University of Technology. Disponível em: http://www.janleenkloosterman.nl/papers/klooster8801.pdf. Acesso 03 fev. 2015.

KNOLL G. F., Radiation Detection and Measurement. 3 ed. JOHN WILEY \& SONS, 2002.

KOCHER, D. C.. Calculation of External Dose from Distributed Source. Health and Safety Research Division. Pensilvania, p. 1-29. 1986.

LEOPOLD, Ines Günther.; KIVEL, Niko; WALDIS, Judith Kobler; WERNLI, Beat. Characterization of nuclear fuels by ICP mass-spectrometric techniques. Anal Bioanal Chem, Suiça, p.503-510, 09 out. 2007.

LIERSE, C.; GOEBEL, H.; KACINIEL, E.; BUECHERL, T.; KREBS, K.. Application of digital radiography for the non-destructive characterization of radioactive waste packages. American Society Of Mechanical Engineers, Nova lorque, $31 \mathrm{dez}$. 1995.

MARCELLINO. S.; C. A. OLIVEIRA.; MATTAR NETO. M. Ageing assessment of the Brazilian Research Reactor IEA-R1 Core Support Structures. Technical Meeting on Assessment of Core Structural Materials and Surveillance Programme Of Research Reactor - Viena. Aústria - 14-18 Junho. 2010.

MAIORINO, J.R.. The Utilization and Operational Experience of IEA-R1 Brazilian Research Reactor. IAEA-SM. São Paulo, 1999. 
MARUMO, J.T. Avaliação da contaminação provocada por pára-raios radioativos de Amerício-241 descartados em lixões. Tese (Doutorado), Instituto de Pesquisas Energéticas e Nucleares, São Paulo, 2006.

MONTANHEIRO, M. N. S.; V. F. NASCIMENTO FILHO e F. A. PINTO, Introdução à espectrometria gama. Boletim Didático $n^{\circ} 021$, Piracicaba, 37 p., 1977.

NATIONAL REPORT OF BRAZIL 2014: for the 5th review meeting of the joint convention on the safety of spent fuel management and on the safety of radioactive waste management. Rio de Janeiro, 2014. 153 p.

NATIONAL RESEARCH COUNCIL- NRC. Committee on the Characterization Of Remote-Handled Transuranic Waste For The Waste Isolation Pilot Plant Board on Radioactive Waste Management. Division on Earth and Life Studies. 2002. Disponível

em:

http://www.nap.edu/openbook.php?record_id=10492\&page=105. Acesso em 14 de junho de 2015.

OKOSHI, M.; SAKAI, A.; ABE, M. ; TANAKA, M. Radiological Characterization of LLW arising from JAERI Tokai Research Establishment, JAERI, Tokaimura, Naka-gun, Ibaraki-ken, Japan, , 2001.

PASCHOA, A. S.; TRANJAN FILHO, A. Radioactive Waste Management in Developing and Newly Industrialized Countries. Applied Radiation And Isotopes. Grã-bretanha, p. 707-715.1995.

PERROTTA, J.A., TERREMOTO, L.A.A., ZEITUNI, C.A. Experience on wet storage spent fuel sipping at IEA-R1 Brazilian research reactor. Annals of Nuclear Energy, v. 25, p. 237-258, 1998.

PERROTA, José Augusto. Introdução à Engenharia do Núcleo de Reatores. São Paulo, 1999.

PROKHORETS. I. M.; PROKHORETS. S. I.; KHAZHMURADOV. M. A.; RUDYCHEV. E.V.; FEDORCHENKO. D.V. Point-Kernel Method For Radiation Fields Simulation. Problems Of Atomic Science And Technology. 2007. No 5. Series: Nuclear Physics Investigations (48). p.106-109. National Science Center "Kharkov Institute of Physics and Technology". 61108. Kharkov. Ucrânia. 2007. 
POTIENS JÚNIOR. A. J.; HIROMOTO. Goro. Desenvolvimento de uma metodologia para caracterização isotópica de tambores de rejeito radioativo utilizando-se técnicas de simulação matemática. Revista Brasileira de Pesquisa e Desenvolvimento. São Paulo. n. 3. p. 1348-1350. v. 4. 2002.

RAJ, K.; PRASAD, K.K.; BANSAL, N.k.. Radioactive waste management practices in India. Nuclear Engineering And Design. India, p. 914-930. 2006.

RAMANA, M.V.. Shifting strategies and precarious progress: Nuclear waste management in Canada. Energy Policy. Princeton, p. 196-206. jul. 2013.

REMEIKIS, V.; A. Plukis, L. Juodis, A. Gudelis, D. Lukauskas, , R. Druteikienè, G. Lujanienè, B. Lukšienè, R. Plukienè, G. Duškesas. Study of the nuclide inventory of operational radioactive waste for the RBMK-1500 reactor. Nuclear Engineering And Design, Vilnius, v. 239, n. 4, p.813-818, abr. 2009.

ROCKWELL, T. Reactor shielding design manual. Princeton: van Nostrand, 1956.

SARTORI, Enrico. Nuclear data for radioactive waste management. Annals Of Nuclear Energy. Paris, p. 579-589. mar. 2013.

SAUER, Maria Eugênia Lago Jacques. Análise dos Procedimentos de Partida do Reator lea-R1 - Uma Aplicação da Técnica Hazop-. 2000. 129 f. Dissertação (Mestrado) -IPEN, Universidade de São Paulo, São Paulo, 2000.

SINGLEDECKER, Steven J. et al. Radioactive Waste Characterization Strategies; Comparisons Between AK/PK, Dose to Curie Modeling, Gamma Spectroscopy, and Laboratory Analysis Methods. Wm2012 Conference. Phoenix, fev.2012.

SOUZA, Daiane Cristini Barbosa de. Desenvolvimento de método para a caracterização de embalados de rejeitos radioativos. 2013. 87 f. Dissertação (Mestrado) - Curso de Tecnologia Nuclear, Universidade de São Paulo, São Paulo, 2013. 
TADDEI, M. H. T., MARUMO J. T., TERREMOTO L. A., VICENTE R.. Characterization of Radioactive Spent lon-Exchange Resins. WM2011 Conference, February 27 - March 3, 2011, Phoenix, AZ.

TADDEI, M. H. T. Determinação de fatores de escala para estimativa do inventário de radionuclídeos em rejeitos de média e baixa atividade do reator IEA-R1. 2013a. Dissertação (Doutoramento) - Instituto de Pesquisas Energéticas e Nucleares - IPEN-CNEN/SP, São Paulo

TADEI, M. H. T; VICENTE, R.; MARUMO, J. T.; SAKATA, S. K.; TERREMOTO, L. A. A. Determination of long-lived radionuclides in radioactive wastes from the IEAR1 nuclear research reactor. $\boldsymbol{J}$ Radioanl Nucl Chem, v. 295, n. 2, p. 951-957, 2013b.

TOMA, M.; SIMA, O.; OLTEANU, C. Experimental and simulated studies for the calibration of a radioactive waste assay system. Nuclear Instruments and Methods in Physics Research A, v. 580, p. 391-395, 2007.

TZICA, F.; KONTOGEORGAKOS, D.; VASILOPOULOU, T.; STAMATELATOS, I. E. Application of the Monte Carlo method for the calibration of an in situ gamma spectrometer. Applied Radiation and Isotopes, v. 68, p. 1441-1444, 2010.

VARGAS, M. J.; TIMÓN, A. F.; DÍAZ, N. C.; SÁNCHEZ, D. P. Influence of the geometrical characteristics of an HPGe detector on its efficiency. $\boldsymbol{J}$ Radional Nucl Chem, v. 253, p. 439-443, 2002. 